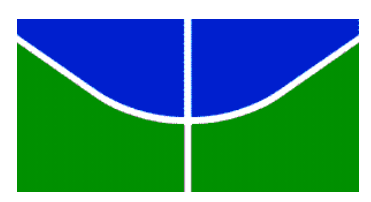

UNIVERSIDADE DE BRASÍLIA - UNB

PROGRAMA DE PÓS-GRADUAÇÃO EM NANOCIÊNCIA E NANOBIOTECNOLOGIA PPGNANO

DISSERTAÇÃO DE MESTRADO

SÍNTESE E CARACTERIZAÇÃO DE NANOCOMPÓSITOS MAGNETO-POLIMÉRICOS À BASE DE POLÍMEROS EXTRAÍDOS DE ÓLEOS NATURAIS

LAFFERT GOMES FERREIRA DA SILVA 


\section{LAFFERT GOMES FERREIRA DA SILVA}

SÍNTESE E CARACTERIZAÇÃO DE NANOCOMPÓSITOS MAGNETO-

POLIMÉRICOS À BASE DE POLÍMEROS EXTRAÍDOS DE ÓLEOS NATURAIS

ORIENTADORA:

Profa. Dra. LUCIENE BATISTA DA SILVEIRA

Dissertação apresentada ao curso de PósGraduação em Nanociência de Nanobiotecnologia da Universidade de Brasília como requisito parcial para obtenção de título de Mestre em Nanociência e Nanobiotecnologia

BRASÍLIA, DF 


\title{
SÍNTESE E CARACTERIZAÇÃo DE NANOCOMPÓSITOS MAGNeTO-POLIMÉRICOS À BASE de POLÍMERos EXTRAÍDOS DE Óleos NATƯRAIS
}

\author{
POR \\ Laffert Gomes Ferreira da Silva
}

Dissertação de Mestrado Apresentada ao Instituto de Ciências Biológicas da Universidade de Brasília como parte dos requisitos para a obtenção ao graus de Mestre em Nanociência e Nanobiotecnologia

Aprovada Por:

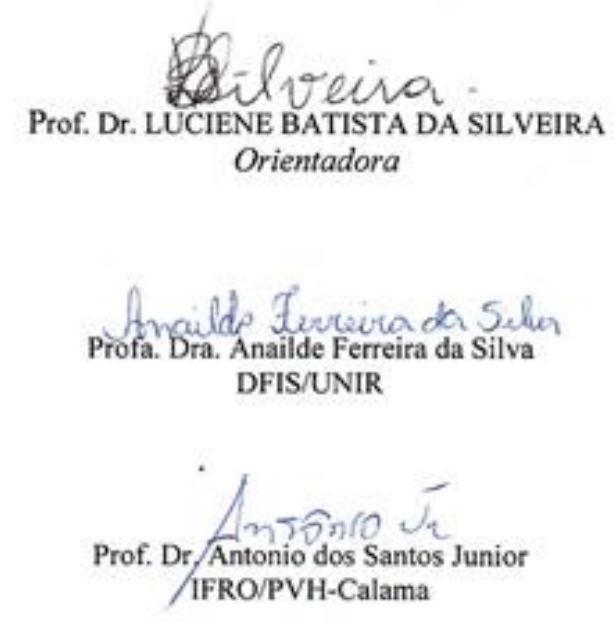

Brasília, 10 de julho de 2015. 
À minha esposa e companheira Claudia e a minha filha Cecília, pelo amor incondicional $e$ pela paciência durante esta longa caminhada a que me propus. 


\section{AGRADECIMENTOS}

Agradeço primeiramente a Deus, pois sem sua ajuda jamais conseguiria vencer essa etapa.

À professora Luciene Batista da Silveira pela orientação, incentivo e amizade, que me proporcionaram um maior crescimento como profissional.

Ao professor Judes Gonçalves dos Santos que é mais que um professor, é um exemplo de ser humano e profissional.

Ao Programa de Pós-graduação em Nanociência e Nanobiotecnologia da Universidade de Brasília e ao INCT Centro-Oeste e Norte de Nanobiotecnologia, por fornecerem os recursos acadêmicos e financeiros necessários para o desenvolvimento deste trabalho.

À Fundação Universidade Federal de Rondônia pela apoio no desenvolvimento deste trabalho.

À professora Emília Celma de Oliveira Lima do Instituto de Química da Universidade Federal de Goiás pelas medidas de Difratometria de Raios X. 
Ao professor Aderbal Carlos de Oliveira do Instituto de Física da Universidade de Brasília, pelas medidas de Espectroscopia por Fotoacústica.

Ao Tiago Aparício Beleza, pela amizade, discussões e ajuda nas medidas de Espectroscopia no Infravermelho com Transformada de Fourier realizadas no Departamento de Química da Fundação Universidade Federal de Rondônia.

À professora Sônia Nair Báo do Instituto de Biologia da Universidade de Brasília pelo apoio no uso do Microscópio Eletrônico de Transmissão e o Microscópio Eletrônico de Varredura.

Ao meu amigo Wágner Moreira Pinheiro que viabilizou as medidas de Microscopia Eletrônica de Transmissão e Microscopia Eletrônica de Varredura feitas na Universidade de Brasília.

Aos discentes do PPGNANO aqui de Rondônia, Juliana Bessa de Almeida, Ernani Marco Rodrigues dos Reis, Mauro Guilherme Ferreira Bezerra e Paulo Roberto dos Santos pela ajuda, ensinamentos, companhia, amizade e discussões.

À Banca, por participarem da defesa. 
"Se eu vi mais longe, foi por estar de pé sobre ombros de gigantes."

- Sir Isaac Newton 


\section{RESUMO}

O campo da Nanociência e Nanobiotecnologia desenvolve diversas pesquisas utilizando nanoestruturas com propriedades magnéticas, que podem apresentar diferentes propriedades físicas dependendo de seus compostos. Por isso podem apresentar diversas aplicações como: marcadores de fármacos, entrega de fármacos e microeletrônica. Este trabalho tem por objetivo sintetizar e caracterizar nanocompósito magneto-polimérico baseado em nanopartículas, com características superparamagnéticas, recobertas por polímero extraídos do óleo da semente de Carapa guianensis Aubl. Foram sintetizadas nanopartículas de óxidos de Ferro. O polímero é sintetizado utilizando o método de policondensação. O nanocompósito é preparado então pela dispersão das nanopartículas na matriz polimérica. Para caracterização das amostras são usadas diferentes técnicas como: Difração de Raios X, Microscopia Eletrônica de Transmissão, Microscopia Eletrônica de Varredura, Espectroscopia no UV-Vis, Espectroscopia no Infravermelho por Transformada de Fourier, Espectroscopia de Energia Dispersiva e Espectroscopia Fotoacústica. Os resultados indicam que a estrutura do nanocompósito magneto-poliméricos é do tipo core/shell onde o núcleo é formado por várias nanopartículas de $\gamma-\mathrm{Fe}_{2} \mathrm{O}_{3}$ recobertas pela matriz polimérica, que apresentou características do óleo natural utilizado em sua síntese.

Palavras-chave: Nanoestruturas Híbridas, Polímeros Naturais, Nanocompósitos Magnéticos. 


\section{ABSTRACT}

Nanoscience and Nanobiotechnology field develops several researches using nanostructures with magnetic properties, which may have different physical properties depending on their compounds. Therefore can be used in various applications as: drug markers, drug delivery and microelectronics. This study aims to synthesize and to characterize Magnetic- Polymeric Nanocomposites based on nanoparticles with superparamagnetic characteristics, coated with polymer oils extracted from seeds Carapa guianensis Aubl. Iron oxide nanoparticles were synthesized using the coprecipitation method. The polymer was synthesized using polycondensation method. Nanocomposite was prepared by dispersion of the nanoparticles in the polymer matrix. For characterization of the samples are used different techniques: X-ray Diffraction, Transmission Electron Microscopy, Scanning Electron Microscopy, UV-vis Spectroscopy, Fourier Transform Infrared Spectroscopy, Energy-dispersive X-Ray Spectroscopy and Photoacoustic Spectroscopy. The results indicate that magnetic-polymeric nanocomposites structure formed was type core/shell, wherein the core was formed by several nanoparticles of $\gamma-\mathrm{Fe}_{2} \mathrm{O}_{3}$, coated by the polymer matrix, which presents some characteristics of the natural oil used in their synthesis

Keywords: Hybrid Nanostructures, Natural Polymers, Magnetic Nanocomposites. 


\section{SUMÁRIO}

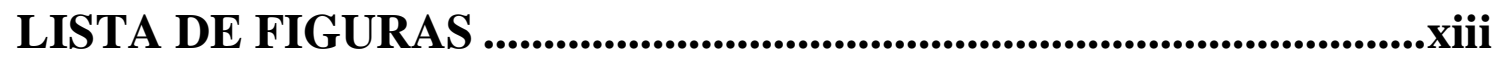

LISTA DE TABELAS ............................................................................

LISTA DE SÍMBOLOS E ACRÔNIMOS.................................................xix

CAPÍTULO 1 - INTRODUÇÃO...............................................................23

1.1 ÓLEOS EXTRAIDOS DA REGIÃO AMAZÔNICA ……...........................25

1.1.1 - Óleo Vegetal de Carapa guianensis........................................... 28

1.1.2 - Polímeros à base de Óleos Vegetais: Interesse Mercadológico..... 30

1.2 - NANOPARTÍCULAS MAGNÉTICAS DE ÓXIDO DE FERRO ................31

1.2.1 - Propriedades Magnéticas dos Materiais ......................................... 31

1.2.2 - Estrutura Cristalina..................................................................... 37

1.3 - NANOCOMPÓSITOS MAGNETO POLIMÉRICOS.......................................38

1.3.1 - Classificação dos Nanocompósitos Magneto-Poliméricos ............ 38 
2.1 - PREPARAÇÃO DO NANOCOMPÓSITO MAGNETO-POLIMÉRICO..45

2.1.1 - Polimerização do Óleo "in natura” 46

2.1.2 - Síntese das Nanopartículas de Óxido de Ferro 47

2.1.3 - Síntese do Nanocompósito Híbrido 49

2.2 - TÉCNICAS DE CARACTERIZAÇÃO .50

2.2.1 - Difratometria de Raios X (DRX) 51

2.2.2 - Microscopia Eletrônica de Transmissão (MET) 53

2.2.3 - Microscopia Eletrônica de Varredura (MEV) .56

2.2.4 - Espectroscopias 56

2.2.4.1 - Espectroscopia de Absorção (UV-VIS) 58

2.2.4.2 - Espectroscopia no Infravermelho por Transformada de Fourier (FTIR). 60

2.2.4.3 - Espectroscopia Fotoacústica (EF) 61

2.2.4.4 - Espectroscopia por Energia Dispersiva de Raios X (EDX) 63

\section{CAPÍTULO 3 - RESULTADOS E DISCUSSÕES} 65

3.1 - CARACTERIZAÇÃO DAS NANOPARTÍCULAS DE $\gamma$-Fe를 .65

3.1.1 - Medidas de Difratometria de Raios X. 66

3.1.2 - Medidas de Microscopia Eletrônica de Transmissão

3.1.3 - Medidas de Microscopia Eletrônica de Varredura 69 
3.2.1 - Medidas de Espectroscopia no Infravermelho por Transformada de Fourier 70

3.2.2 - Medidas de Espectroscopia no UV- VIS. 71

3.2.3 - Medidas de Espectroscopia por Energia Dispersiva de Raios X .. 76

3.2.4 - Medidas de Espectroscopia Fotoacústica 77

3.2.5 - Medidas de Microscopia Eletrônica de Transmissão (MET). 79

3.2.6 - Medidas de Microscopia Eletrônica de Varredura 80

CAPÍTULO 4 - CONSIDERAÇÕES FINAIS. 81

PERSPECTIVAS FUTURAS 84 REFERÊNCIAS BIBLIOGRÁFICAS 85 


\section{LISTA DE FIGURAS}

Figura 1.1 - Esquema com o grupo de glicerídeos. (a) monoglicerídeos (b) diglicerídeos

e (c) triglicerídeos.

Figura 1.2 - Representação da fórmula estrutural dos principais ácidos graxos encontrados nos óleos essenciais, extraídos de plantas (VILELA, 2012).

Figura 1.3 - Imagens do fruto (esquerda) e a semente (direita) da planta Carapa guianensis.

Figura 1.4 - Classificação das substâncias magnéticas de acordo com o arranjo dos dipolos magnéticos.

Figura 1.5 - Gráfico relacionando diâmetro dos materiais magnéticos com campo Coercivo(CULLITY, 1972 Adaptado). 
Figura 1.6 - Representação da estrutura cristalina das nanopartículas de magnetita $\left(\mathrm{Fe}_{3} \mathrm{O}_{4}\right)$. (a) Sítios Tetraédrico (b) Sítios Octaédricos. (NAMANGA et al, 2013) ....

Figura 1.7 - Classificação dos nanocompósitos magneto-poliméricos. (a) Pó ou Suspensão. (b) Fibras (c) Filmes-finos e (d) Sólidos Tridimensionais (MAI; YU, 2006 adaptado).

Figura 1.8 - Rota de síntese dos NCM por polimerização “in-situ”. (MAI; YU, 2006 adaptado).

Figura 1.9 - Rota de síntese dos NCMs por polimerização e precipitação “in situ” (direita) e precipitação “in situ” (esquerda). (MAI; YU, 2006 adaptado).

Figura 1.10 - Rota de síntese dos NCM por polimerização e precipitação seguida de uma mistura. (MAI; YU, 2006 adaptado).

Figura 2.1 - Transesterificação dos triglicerídeos em solução alcoólica (SILVA, 2005). .. 46

Figura 2.2 - Esquema de polimerização de ácidos graxos livres transesterificados a partir de triglicerídeos de óleos vegetais.

Figura 2.3 - Esquema simplificado da síntese das nanopartículas magnéticas 48

Figura 2.4 - Esquema simplificado da síntese do nanocompósito magneto-polimérico.... 50

Figura 2.5 - Lei de Braag que descreve que a amplitude máxima do raio difratado irá ocorrer quando a diferença de trajeto é um múltiplo do comprimento de onda incidente.

Figura 2.6 - Esquema de funcionamento de um Microscópio Eletrônico de Transmissão 
Figura 2.7 - Representação esquemática dos tipos de interação do feixe eletrônico com a amostra no microscópio de transmissão.

Figura 2.8 - - Esquema de funcionamento de Espectrômetro no UV-Vis.

Figura 2.9 - Esquema de construção de um Espectrômetro no infravermelho por transformada de Fourier.

Figura 2.10 - Esquema com o arranjo experimental da técnica de espectroscopia por Fotoacústica.

Figura 2.11 - Diagrama esquematizado da Espectroscopia por Energia Dispersiva no Raios X.

Figura 3.1 - Difratometria de Raios X das nanopartículas de $\gamma-\mathrm{Fe}_{2} \mathrm{O}_{3}$, sintetizadas 66

Figura 3.2 - Microscopia Eletrônica de Transmissão das nanopartículas de $\gamma$ - $\mathrm{Fe}_{2} \mathrm{O}_{3}$ sintetizadas

Figura 3.3 - Histograma da contagem das nanopartículas de $\gamma-\mathrm{Fe}_{2} \mathrm{O}_{3}$ sintetizadas obtidos pela Microscopia Eletrônica de Transmissão.

Figura 3.4 - Micrografia de Microscopia Eletrônica de Varredura das nanopartículas de $\gamma-\mathrm{Fe}_{2} \mathrm{O}_{3}$, sintetizadas, com um aumento de 40.000x.

Figura 3.5 - Micrografia de Microscopia Eletrônica de Varredura das nanopartículas de $\gamma-\mathrm{Fe}_{2} \mathrm{O}_{3}$ sintetizadas, com um aumento de $70.000 x$

Figura 3.6 - Espectro FTIR, que relaciona a transmitância em função do Número de Onda, do polímero (PCA) e do óleo extraído da semente da Carapa guianensis (OCA). 
Figura 3.7 - Espectro de Absorção no UV-VIS que relaciona os picos de Absorbância (u.a) em função do Comprimento de Onda (nm), do polímero (PCA) e do óleo extraído da semente da Carapa guianensis (OCA)

Figura 3.8 - Espectro de Absorção no UV-VIS das nanopartículas (NPs) e do nanocompósito magneto-polimérico (NMC) à base do óleo de Carapa guianensis

Figura 3.9 - Gráfico apresentando a população nos Níveis Eletrônicos em função da Energia para as nanopartículas (NPs) e do nanocompósito magneto-polimérico (NMC) à base do óleo de Carapa guianensis diluídos a 5\%

Figura 3.10 - Espectro de Energia no UV-VIS, do óleo de Carapa guianensis, do polímero sintetizado (OCA), das nanopartículas (NPs) e do nanocompósito magnetopolimérico (NMC)

Figura 3.11 - Ilustração da estrutura molecular do polímero sintetizado a partir o óleo "in natura" da Carapa guianensis.

Figura 3.12 - Espectro EDX do polímero (PCA), do óleo de Carapa guianensis. (OCA) e do nanocompósito magneto-polimérico (NMC)

Figura 3.13 - Espectro Fotoacústico do polímero (PCA), das nanopartículas de $\gamma$ - $\mathrm{Fe}_{2} \mathrm{O}_{3}$ (NPs) e do nanocompósito magneto-polimérico à base do óleo de Carapa guianensis (NMC).

Figura 3.14 - Espectro de Fotoacústica do ampliado do polímero (PCA), das nanopartículas de $\gamma-\mathrm{Fe}_{2} \mathrm{O}_{3}$ (NPs) e do nanocompósito magneto-polimérico à base do óleo de Carapa guianensis (NMC). 
Figura 3.15 - Microscopia Eletrônica de Transmissão do nanocompósito magnetopolimérico à base do óleo extraído da semente da Carapa guianensis. (A) aumento de $\mathrm{x} 80.000$ vezes e (B) aumento de $\mathrm{x} 300.000$ vezes.

Figura 3.16 - Microscopia Eletrônica de Varredura do nanocompósito magnetopolimérico à base do óleo extraído da semente da Carapa guianensis, com um aumento de 45.000x 


\section{LISTA DE TABELAS}

Tabela 1.1 - Composição química obtida a partir da cromatografia gasosa do óleo da Carapa guianensis.

Tabela 1.2 - Classificação dos materiais na presença de um Campo Magnético Externo (HAYT JR; BUCK, 2008).

Tabela 2.1 - Amostras investigadas com suas respectivas nomenclaturas. 50

Tabela 2.2 - Relação de amostras sintetizadas com as técnicas utilizadas para sua investigação.

Tabela 3.1 - Comparativo dos picos experimentais obtidos pela Difração de Raio-X, das nanopartículas de $\gamma$-Fe2O3 sintetizadas, com os picos tabelados pela ASTM 66 


\section{LISTA DE SÍMBOLOS E ACRÔNIMOS}

及 - Largura na Meia Altura do Pico de Maior Intensidade.

$\lambda$ - Comprimento de Onda

$\boldsymbol{\theta}$ - ângulo de difração

$-\mathrm{Fe}_{2} \mathrm{O}_{3}-$ Maguemita

$\boldsymbol{\mu}$ - Momento Magnético Total

$\boldsymbol{\mu}_{\text {orb }}$ - Momento Magnético do Orbital

$\boldsymbol{\mu}_{\boldsymbol{B}}$ - Magnéton de Bohr

$\boldsymbol{\mu}_{\boldsymbol{s}}$ - Momento Magnético do Spin

$\boldsymbol{\sigma}$ - desvio padrão

$\boldsymbol{\varepsilon}$ - Absorvidade Molecular ou Coeficiente de Extinção

$\boldsymbol{A}$ - Absorbância

ASTM - American Society for Testing and Materials

$\boldsymbol{B}_{\text {int }}$ - Campo Magnético Interno 
$\boldsymbol{B}_{\text {ext }}$ - Campo Magnético Externo

$c$ - Concentração do Material Absorvedor

CFC - Rede Cúbica de Face Centrada

D - Diâmetro Médio

$\boldsymbol{d}$ - Espaço entre os Planos Atômicos

Dc - Diâmetro Crítico

$\boldsymbol{D}_{\boldsymbol{h} \boldsymbol{k l}}$ - Diâmetro Médio no Plano $h k l$

DRX - Difratometria de Raios X

EDX - Espectroscopia por Energia Dispersiva de Raios-X

$\boldsymbol{E}_{\boldsymbol{f}}-$ Energia do Fóton

EF - Espectroscopia por Fotoacústica

$\mathrm{Fe}_{3} \mathrm{O}_{4}-$ Magnetita

FTIR - Espectroscopia no Infravermelho por transformada de Fourier

GMR - Magnetorresistência Gigante

$\boldsymbol{h}$ - Constante de Planck

$\boldsymbol{H c}$ - Campo Coercivo

IR - Infravermelho

K - Constante Dependente da Forma da Partícula

$\boldsymbol{L}$ - Momento Angular do Orbital de Elétrons 
$\boldsymbol{l}$ - Espessura da Amostra

$\boldsymbol{m}_{\boldsymbol{l}}$ - Número Quântico do Orbital Magnético

MEMS - Sistemas microeletrônicos

MET - Microscopia Eletrônica de Transmissão

MEV - Microscopia Eletrônica de Varredura

MHT - Magneto-hipertermia

N\&N\&Nb - Nanociência, Nanotecnologia e Nanobiotecnologia

NEMS - Sistemas Nanoeletrônicos

NMC - Nanocompósito magneto-polimérico à base do óleo da Carapa guianensis

NPs - Nanopartículas baseadas e óxidos de ferro

NCM - Nanocompósito magneto-polimérico

OCA - Óleo da Carapa guianensis "in natura"

PVA - Acetato de polivinila

PEG - Polietilenoglicol

PCA - Polímero do óleo da Carapa guianensis

$\boldsymbol{P}(\mathbf{D})$ - distribuição log-normal

RMI - Ressonância Magnética por Imagem

$\boldsymbol{S}$ - Momento Angular Intrínseco dos Elétrons

T - Transmitância 
TMR - Magnetorresistências de Tunelamento

UV-VIS - Espectroscopia no UV-Visível

Z - Número Atômico 


\section{CAPÍTULO 1 - INTRODUÇão}

Neste capítulo faremos uma breve introdução sobre polímeros sintetizados a partir de óleos vegetais, as características das nanopartículas magnéticas e dos nanocompósitos magnetopoliméricos. Citaremos algumas propriedades baseadas na sínteses desses materiais e possíveis aplicações.

A Nanociência, Nanotecnologia e Nanobiotecnologia (N\&N\&Nb) são responsáveis por designar, sintetizar, caracterizar e aplicar diversos tipos materiais em escala nanométrica (1 a $100 \mathrm{~nm}$ ). Por se tratar de uma abordagem multidisciplinar, os conhecimentos necessários para compreender os fenômenos associados derivam de diversas áreas do conhecimento (Física, Química e Biologia) e suas aplicações alcançam várias outras (Engenharias, Computação, Medicina) (EROKHIN; RAM; YAVUZ, 2008). Nanomateriais com cerca de um (01) nanômetro de diâmetro possuem como principal característica: o alinhamento de todos os átomos em sua superfície, enquanto em estruturas com diâmetros maiores que 100 nm não existem átomos na sua superfície (CAO, 2004). Em consequência a este efeito, as forças de 
interações que eram irrelevantes em macroescalas passam a ser fundamentais tornando as propriedades mecânicas, químicas, ópticas, elétricas e magnéticas das nanoestruturas dependentes de suas dimensões (GUO; TAN, 2009).

Na vanguarda das pesquisas em Nanociência é possível destacar a síntese e caracterização de nanoestruturas híbridas que possuem o objetivo de integrar dois ou mais compostos (orgânico/inorgânico) a fim de que a resultante deste processo possa adquirir as propriedades individuais das matérias-primas associadas ou obter diferentes propriedades resultantes dessa interação. Por exemplo, MACKAY e colaboradores (2011) relataram a síntese de uma nanoestrutura hibrida que pode ser utilizada como um sensor para aplicações de ressonância por imagem em alvos biológicos com diferentes tipos de doenças. MARDARE et al (2014) descreveram a síntese de um fotocatalizador baseado na deposição de filmes-finos de $\mathrm{TiO}_{2}$ com características hidrofílicas.

Para a construção dessas nanoestruturas, variados tipos de compostos podem ser empregados. Dentre eles, podemos destacar aqueles constituídos por materiais poliméricos e nanopartículas com propriedades magnéticas. Esses materiais possuem a alta capacidade de interação com os mais variados meios, incluindo aplicações como agentes Biológicos (PYUN, 2007). Na busca por possíveis materiais poliméricos biocompatíveis observa-se que, a região Norte do país possui uma vasta biodiversidade e sua matéria-prima, ainda pouco explorada, pode apresentar propriedades importantes, que poderão ser aplicadas nas indústrias ligadas à N\&N\&Nb (SANTOS et al., 2012).

Os objetivos desse estudo foram: sintetizar e descrever as características de um nanocompósito magneto-polimérico (NCM) biocompatível utilizando como matéria-prima óleos de origem vegetal encontrados na Região Sul da Amazônia Brasileira. O nanocompósito foi sintetizado e caracterizado por diversas técnicas a fim de elencar suas características e 
propriedades físico-químicas. Esse estudo pode ser de grande importância para demonstrar o desenvolvimento de novos nanomateriais utilizando matéria-prima natural encontrada em abundância na Região Sul da Amazônia Brasileira (RODRIGUEZ, A F R; JACOBSON; et al., 2013).

A seguir será abordada uma breve revisão literária sobre os óleos vegetais, incluindo aquelas oriundas da Carapa guianensis Aubl., que será utilizado nesta pesquisa. Também, serão abordados conceitos sobre polímeros de origem natural, nanopartículas à base de óxidos de ferro como a maguemita e a magnetita e nanocompósitos magneto-poliméricos híbridos.

\section{1 ÓLEOS EXTRAIDOS DA REGIÃO AMAZÔNICA}

A bacia Amazônica ocupa uma área de cerca de 7 milhões de quilômetros quadrados e está localizada entre os estados brasileiros do: Amazonas, Roraima, Rondônia, Mato Grosso, Pará e Amapá, além de países vizinhos como: Peru, Colômbia, Equador, Venezuela, Guiana e Bolívia. Diversos estudos tem sido realizados nessa região com resultados promissores em diversos campos de pesquisa. Dentre esses estudos pode-se destacar, aqueles enfocados na descrição de óleos de origem vegetal e suas aplicações nanotecnologicas (OSHTRAKH et al., 2010; RODRIGUEZ, A F R; COAQUIRA; et al., 2013; SANTOS et al., 2012).

Os óleos de origem vegetal são um dos principais produtos extraídos de plantas na atualidade. Normalmente esses óleos são extraídos do fruto ou da semente de plantas oleaginosas e seu uso varia de acordo com suas características. Sua extração pode ser feita por diversos métodos físico-químicos, sendo que os mais comuns envolvem a utilização de solventes e prensagem (RAMALHO; SUAREZ, 2013). 
Os óleos vegetais são compostos predominantemente por cadeias de triglicerídeos, todavia existem em pequenas concentrações, mono e diglicerídeos e ácidos graxos livres (REDA; CARNEIRO, 2007). É possível dividir as substâncias encontradas nesses óleos em dois grupos distintos:

Glicerídeos: que podem ser mono, di e tri e são o resultado da esterificação dos ácidos graxos de cadeia longa com o glicerol, esses compostos são responsáveis por algumas características dos óleos como viscosidade e grau de insaturação entre outros. A Figura 1.1 mostra, de forma simplificada, o grupo de glicerídeos onde R é a cadeia longa dos ácidos graxos livre.

Não-glicerídeos: que estão presentes em menor quantidade no óleo "in natura", porém são responsáveis por diversas características atribuídas a esses compostos como: odor, sabor, coloração e fator antioxidativo. Podem-se destacar neste grupo os fosfatídeos, esteróis, hidrocarbonetos insolúveis, ácidos graxos livres e etc.

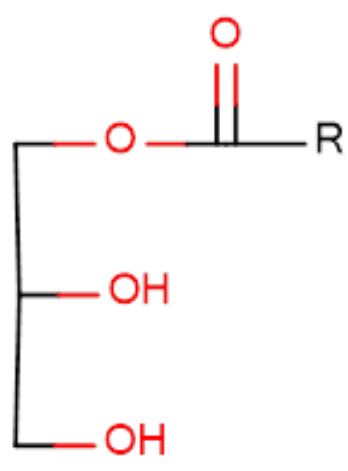

(a)

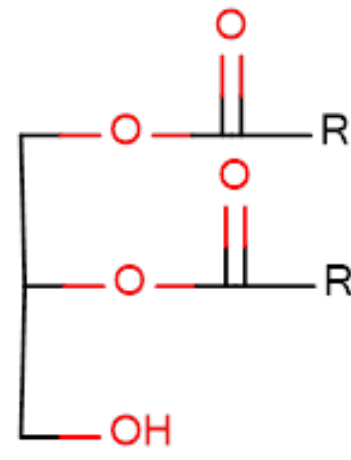

(b)

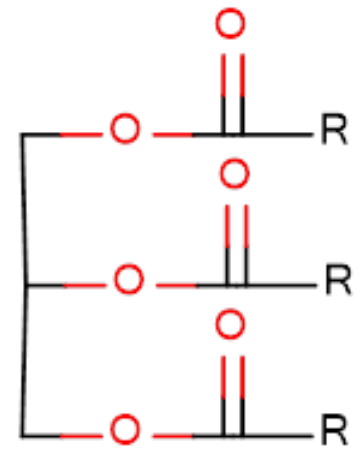

(C)

Figura 1.1 - Esquema com o grupo de glicerídeos. (a) monoglicerídeos (b) diglicerídeos e (c) triglicerídeos. 
Os ácidos graxos, compostos abundantemente encontrados nos óleos vegetais, são formados por grupos carboxílicos ligados a longas cadeias. A diferença entre os tipos ácidos graxos está no tamanho da cadeia de carbônica, que vai de 14 à 22 carbonos e se o composto é saturado ou insaturado. Ácidos saturados não possuem duplas ligações entre seus átomos de carbono, já os insaturados podem possuir uma ou mais duplas ligações em sua cadeia (REDA;

CARNEIRO, 2007).
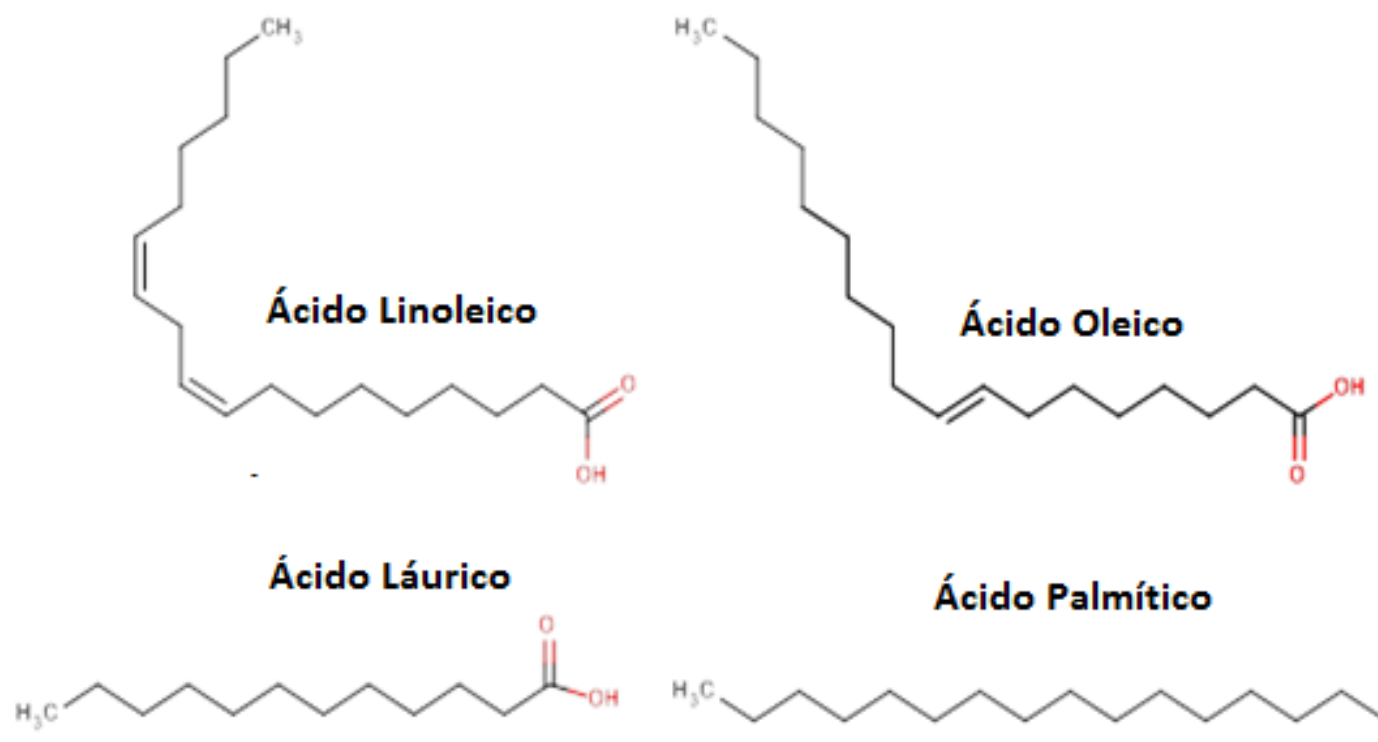

Ácido Palmítico

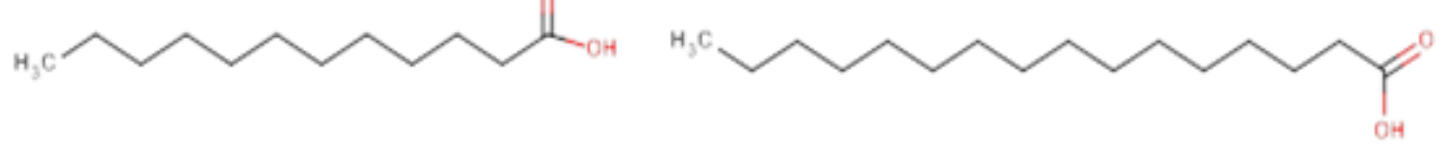

Ácido Cáprico

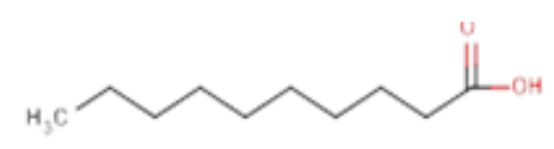

Ácido Mirístico

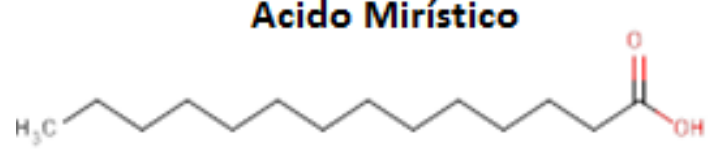

Ácido Esteárico

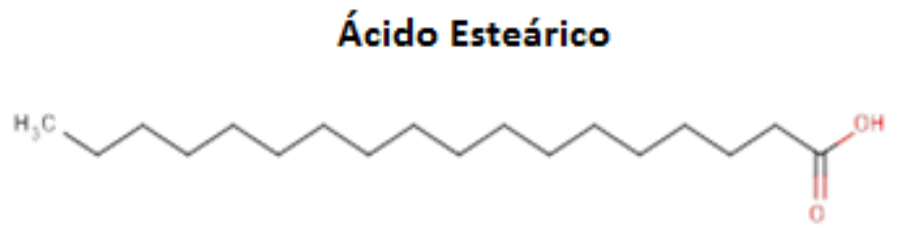

Ácido Palmitoleico

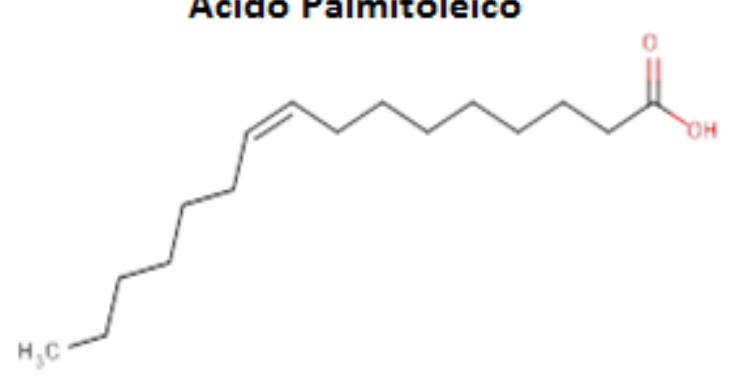

Figura 1.2 - Representação da fórmula estrutural dos principais ácidos graxos encontrados nos óleos essenciais, extraídos de plantas (VILELA, 2012). 
Os tipos de ácidos graxos e a concentração dos mesmos variam de acordo com o tipo de planta e o método de extração, fazendo com que cada óleo vegetal apresente propriedades peculiares (VILELA, 2012). Os ácidos mais comuns são: Linoleico, Oleico, Láurico, Palmítico, Cáprico, Esteárico, Mirístico e Palmitoleico, suas representações estruturais podem ser observadas na Figura 1.2.

Devido a sua origem abundante, barata e renovável, os óleos vegetais são utilizados largamente como matéria-prima, sendo que alguns de seus derivados já são comercializados como biocombustíveis, lubrificantes, fluídos de corte, surfactantes e produtos cosméticos. Um dos derivados desse material que vem ganhando muito atenção nos últimos anos são os polímeros, devido a sua biodegradabilidade, baixa toxicidade, aplicabilidade e biocompatibilidade em diferentes meios (ALAM et al., 2014; BELGACEM; GANDINI, 2008; SENIHA GÜNER; YAĞCI; TUNCER ERCIYES, 2006).

\subsection{1 - Óleo Vegetal de Carapa guianensis}

Carapa guianensis Aubl., da família da Meliaceae, é uma árvore nativa da região Amazônica, onde é popularmente conhecida como Andiroba. Cresce até 30 metros de altura, suas folhas são compridas e seus frutos, do tipo capsula, possuem diversas sementes (Figura 1.3). No Brasil, ocorre na bacia Amazônica, principalmente nas proximidades dos leitos de rios e faixas alagáveis, sendo encontrada também em terra firme (PEREIRA; TONINI, 2012). O óleo que é extraído das sementes, apresenta uma coloração amarelada, sabor amargo e se solidifica em temperaturas abaixo de $25^{\circ} \mathrm{C}$.

Um dos métodos para extração do óleo é praticamente artesanal e consiste no cozimento das sementes por cerca de 3h. Em seguida, a solução é colocada em descanso. Após 
algumas semanas, o composto obtido é colocado sob o sol em uma base levemente inclinada para que o óleo escoe gradativamente (SILVA, 2005).
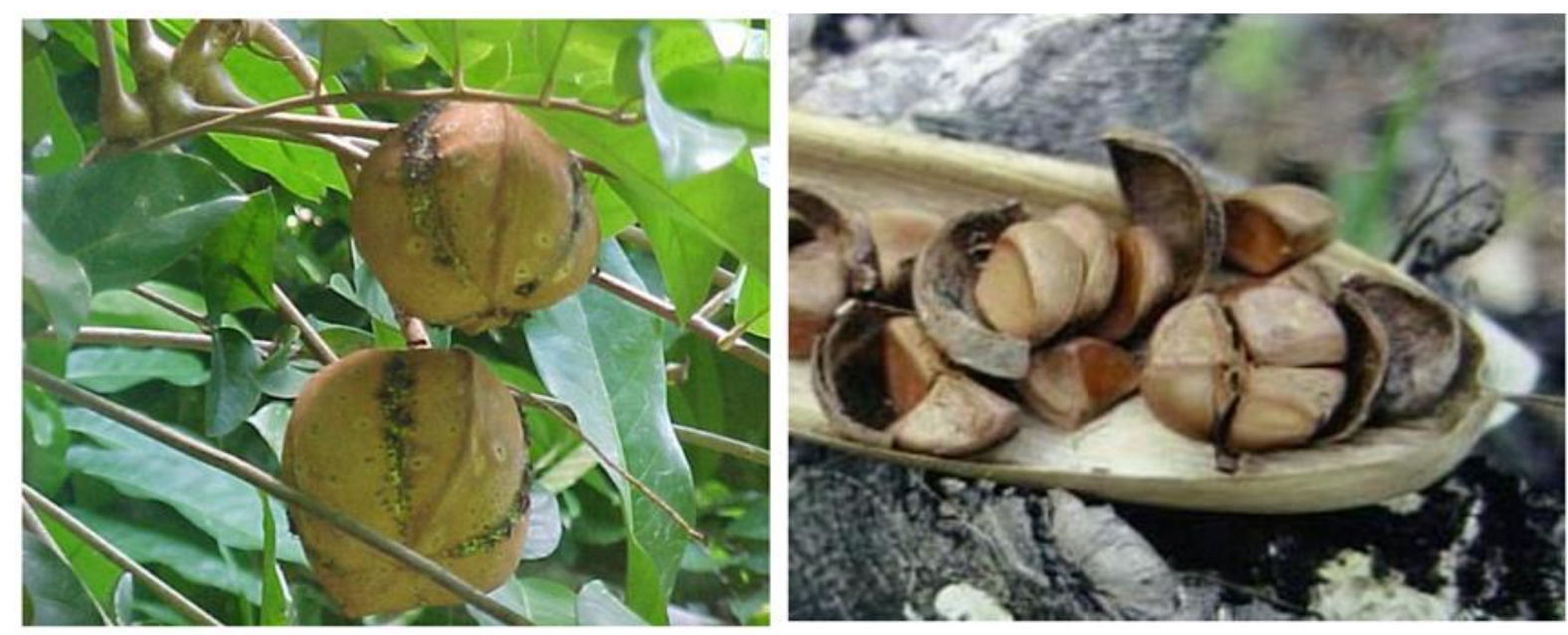

Figura 1.3 - Imagens do fruto (esquerda) e a semente (direita) da Carapa guianensis.

Tabela 1.1 - Composição química, obtida a partir da cromatografia gasosa, do óleo de Carapa guianensis.

\begin{tabular}{l|c}
\hline Ácidos graxos & Contribuição percentual \\
\hline Ácido Palmítico (C16:0) & 25,76 \\
Ácido Palmitoleico (C16:1) & 0,81 \\
Ácido Esteárico (C18:0) & 9,08 \\
Ácido Oléico (C18:1) & 51,81 \\
Ácido Linoleico (C18:2) & 8,3 \\
Ácido Araquídico (C20:4) & 1,61 \\
Ácido Mirístico (C14:0) & Traços \\
\hline
\end{tabular}

Fonte: SILVA, 2005. 
O óleo da $C$. guianensis é rico em ácidos graxos insaturados (Tabela 1.1), sendo muito procurada por indústrias cosméticas e farmacêuticas devido a suas propriedades antisséptica, anti-inflamatórias e antioxidantes, além de ser um bom repelente contra insetos (CARDOSO; ARAÚJO; SAYER, 2013; FERREIRA et al., 2010; PEREIRA; TONINI, 2012).

\subsection{2 - Polímeros à base de Óleos Vegetais: Interesse Mercadológico}

O uso de polímeros à base de matérias-primas naturais são descritos na literatura científica como uma ótima alternativa ao uso dos polímeros sintéticos, devido tanto a sua origem renovável e a suas propriedades pouco exploradas. Por Exemplo, MENEGHETTI e colaboradores descrevem o uso de polímeros sintetizados a partir de grupos de triglicerídeos para o preparo de resinas alquídicas visando aplicações na indústria de tintas. Além do mais, comercialmente falando, a produção de polímeros de óleos vegetais ricos em ácidos graxos, adiciona propriedades físicas aos polímeros em relação a sua flexibilidade, adesão e resistência a água e produtos químicos (SENIHA GÜNER; YAĞCI; TUNCER ERCIYES, 2006; VILELA, 2012), bem como a baixa toxicidade e baixo custo (TSUJIMOTO; UYAMA; KOBAYASHI, 2010). Por isso, esses polímeros apresentam um grande potencial para aplicações na indústria (ESPINOSA; MEIER, 2011).

Os polímeros extraídos das séries: diterpênico cauranos, copálico, oléico e o láurico, podem servir como agentes anti-inflamatórios, antitumoral e antioxidante. Particularmente os ácidos diterpênicos e láuricos, extraídos dos óleos de copaíba, andiroba, pupunha, buriti e babaçu, sugerem a possibilidade de adsorção dessas moléculas na superfície das nanopartículas por meio da complexação dos grupos carboxílicos aos íons $\mathrm{Fe}^{3+}$ superficiais usando uma camada estabilizante (RIGAMONTE-AZEVEDO et al., 2004). A adsorção dos polímero diterpênicos ácidos na superfície das nanopartículas poderão permitir a dispersão das mesmas 
e a aderência de ligações de proteinases, visando assim aplicações biomédicas (SANTOS et al., 2005; SARTORATTO et al., 2005, 2007).

\section{2 - NANOPARTÍCULAS MAGNÉTICAS DE ÓXIDO DE FERRO}

Nanopartículas baseadas em óxidos de ferro são fontes de vários estudos devido a sua natureza magnética e biocompatibilidade em diferentes meios. Suas aplicações alcançam diversos campos de nanotecnologia, principalmente em Ressonância Magnética por Imagem (RMI), Magneto-hipertermia (MHT), Liberação controlada de Fármacos, Separação Magnética, Microeletrônica e Aplicações Ambientais (LOPES; SOUZA JR; OLIVEIRA, 2010; TIETZE et al., 2013; YUE-JIAN et al., 2010).

Essas nanopartículas são formadas por ferritas cúbicas, apresentando como fórmula geral $\mathrm{MFe}_{2} \mathrm{O}_{4}$ onde $\mathrm{M}$ representa átomos metálicos com duas camadas de valência, dentre elas podem-se destacar a magnetita e maguemita que são representadas por $\mathrm{Fe}_{3} \mathrm{O}_{4}$ e $\gamma-\mathrm{Fe}_{2} \mathrm{O}_{3}$ respectivamente. Essas nanopartículas possuem importantes propriedades como: superparamagnetismo, alta coercividade, baixa temperatura de Curie, alta magnetização, estabilidade, baixa toxicidade, biocompatibilidade e biodegradabilidade em meios orgânicos (WU; HE; JIANG, 2008). A característica superparamagnética é um dos principais fatores de seu uso em pesquisas e é descrito através das propriedades magnéticas intrínsecas da matéria.

\subsection{1 - Propriedades Magnéticas dos Materiais}

As propriedades magnéticas dos materiais descrevem o comportamento da matéria na presença de um campo magnético externo. Essa característica, que são conhecida como momento magnético total $(\mu)$, está diretamente associada com os movimentos dos elétrons ao redor do núcleo atômico e em volta do seu próprio eixo (LIU et al., 2013; SILVEIRA, 2006). 
De acordo com FARIA e LIMA (2005), o momento magnético do orbital $\left(\mu_{o r b}\right)$ está relacionado com a nuvem eletrônica que se move ao redor do átomo e, apesar de ser descrito pela teoria quântica ainda baseia-se no modelo atômico Bohr. $\mathrm{O} \mu_{\text {orb }}$ pode ser descrito pela Equação 1.1:

$$
\mu_{\text {orb }}=-\frac{e}{2 m_{e}} \cdot L
$$

onde $\frac{e}{2 m_{e}}$ é o momento de dipolo magnético do orbital e L é o momento angular do orbital dos elétrons. Utilizando um pouco de mecânica quântica é possível quantizar o momento angular do orbital (L) de forma que o mesmo só poderá assumir determinados valores, que são descritos pela Equação 1.2:

$$
L=m_{l} \frac{h}{2 \pi}
$$

onde $h$ é a constante de Planck e $m_{l}$ é o número quântico do orbital magnético. Substituindo a Equação 1.1 na 1.2 temos:

$$
\mu_{\text {orb }}=-m_{l} \frac{e h}{4 \pi m_{e}}
$$

Quando o número quântico do orbital magnético assume valor natural para o magnetismo eletrônico o momento magnético orbital $\left(\mu_{\text {orb }}\right)$ é definido pelo magnéton de Bohr $\left(\mu_{B}\right)$, como mostra a Equação 1.4.

$$
\mu_{B}=\frac{e h}{4 \pi \cdot m_{e}}=9,27 \cdot 10^{-24} J \cdot T^{-1} .
$$


Para o momento magnético do spin $\left(\mu_{s}\right)$ que é uma propriedade fundamental da partícula e está relacionado com o movimento do elétron em torno de seu próprio eixo, temos uma relação de proporcionalidade direta com o momento angular intrínseco dos elétrons $(S)$, sendo definido pela Equação 1.5:

$$
\mu_{s}=-\frac{e}{m_{e}} . S
$$

Sendo assim o momento magnético total $(\mu)$ intrínseco do átomo nada mais é do que um conjugado das interações relacionadas com o momento dos orbitais com o momento dos spins dos elétrons de acordo com a Equação 1.6.

$$
\mu=\mu_{o r b}+\mu_{s}
$$

A partir da Equação 1.6 é possível classificar magneticamente os materiais de acordo com a resposta a presença de um campo magnético externo $\left(B_{\text {ext }}\right)(\mathrm{COEY}, 2009$; HAYT JR; BUCK, 2008).

As substâncias magnéticas podem ser classificadas como: Ferromagnéticas, Antiferromagnéticas, Ferrimagnéticas, Diamagnéticas, Paramagnéticas, e as Superparamagnéticas. A Tabela 1.2 apresenta em termos de influência do campo magnético externo a classificação os materiais magnéticos. As substâncias classificadas como ferromagnéticas são aqueles onde cada domínio magnético se alinha em paralelo e no mesmo sentido que $B_{\text {ext }}$, ou seja, o $\mu_{s}$ é muito maior que o $\mu_{\text {orb }}$ logo a magnetização interna é muito maior que a aplicada, este material tende a permanecer magnetizado mesmo após a retirada de $B_{\text {ext }}$ (Figura 1.4a). 
Tabela 1.2 - Classificação dos materiais na presença de um campo magnético externo (HAYT JR; BUCK, 2008).

\begin{tabular}{c|c|c}
\hline \multicolumn{1}{c}{ Classificação } & Momentos Magnéticos & Valores de B \\
\hline Diamagnética & $\left(\mu_{\text {orb }}+\mu_{s}\right)=0$ & $B_{\text {int }}<B_{\text {ext }}$ \\
Paramagnética & $\left(\mu_{\text {orb }}+\mu_{s}\right)=$ pequeno & $B_{\text {int }}>B_{\text {ext }}$ \\
Ferromagnética & $\left(\mu_{\text {orb }}+\mu_{s}\right) \gg 0$ & $B_{\text {int }} \gg B_{\text {ext }}$ \\
Antiferromagnética & $\left(\mu_{\text {orb }}+\mu_{s}\right)>0$ & $B_{\text {int }} \doteq B_{\text {ext }}$ \\
Ferrimagnética & $\left(\mu_{\text {orb }}+\mu_{s}\right)>0$ & $B_{\text {int }}>B_{\text {ext }}$ \\
Superparamagnética & $\left(\mu_{\text {orb }}+\mu_{s}\right)>0$ & $B_{\text {int }}>B_{\text {ext }}$ \\
\hline
\end{tabular}

As substâncias ferrimagnéticas e antiferromagnéticas possuem o mesmo comportamento. Porém, no caso da ferrimagnética nem todos os domínios se alinham com o $B_{\text {ext }}$. Como resultante, temos que o campo magnético interno $\left(B_{\text {int }}\right)$ é um pouco menor que os materiais ferromagnéticos (Figura 1.4b). Nas antiferromagnéticas, a força entre os átomos dos domínios tendem a fazer com que os momentos magnéticos atômicos busquem um alinhamento de forma antiparalela ao $B_{\text {ext }}$ o que gera um baixo campo magnético resultante (Figura 1.4c).

Para as substâncias Paramagnéticas, os domínios magnéticos tendem a se alinhar de modo aleatório, o que gera um $\mu$ total nulo, quando o material é colocado na presença de um campo magnético externo apenas uma pequena parte de seus domínios magnéticos tendem a se alinhar com o campo externo o que gera um momento magnético total quase nulo (Figura 1.4d). Ao retirar esses materiais do campo magnético externo seus domínios tendem a assumirem a orientação original. Nas substâncias diamagnéticas seus domínios magnéticos, que estão alinhados de modo aleatório, se alinham de forma antiparalela ao $B_{\text {ext }}$ de forma que o campo magnético gera um momento magnético total nulo (Figura 1.4e). A natureza das substâncias magnéticas também pode ser descrita em termos da susceptibilidade magnética atribuída ao material (FARIA; LIMA, 2005). 


\section{a) Ferromagnética}

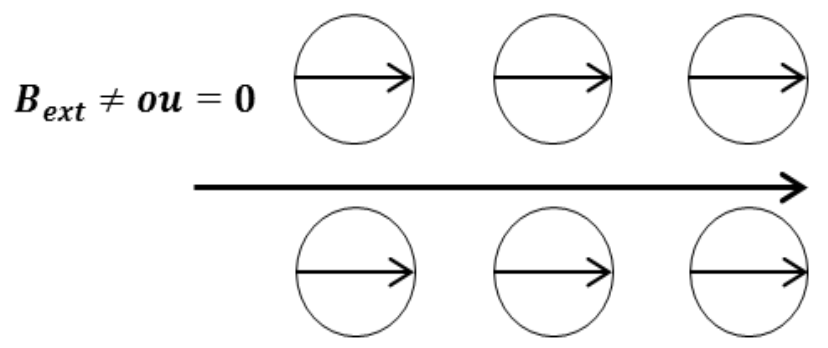

\section{b) Ferrimagnética}

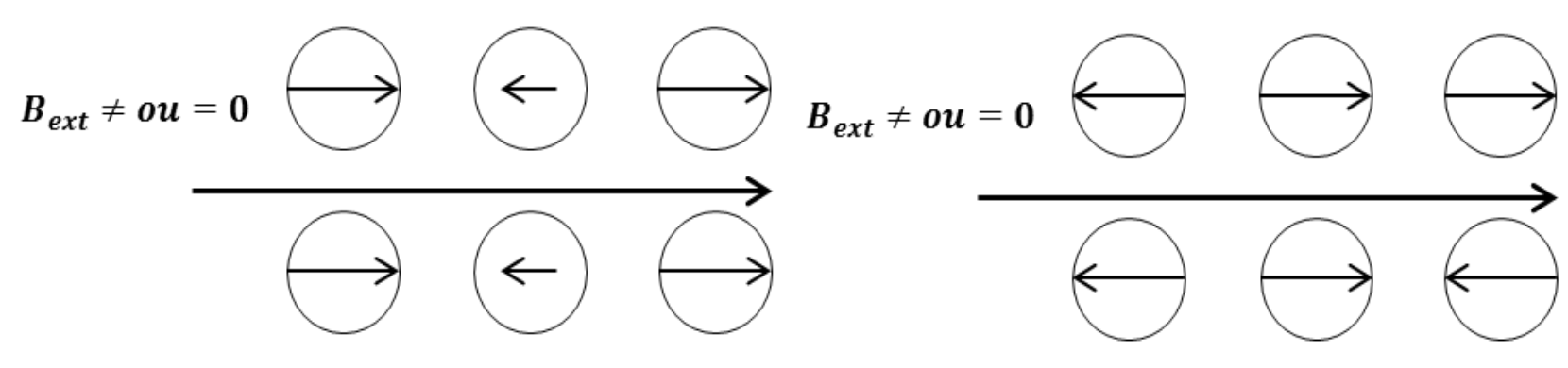

d) Paramagnética

c) Antiferromagnética

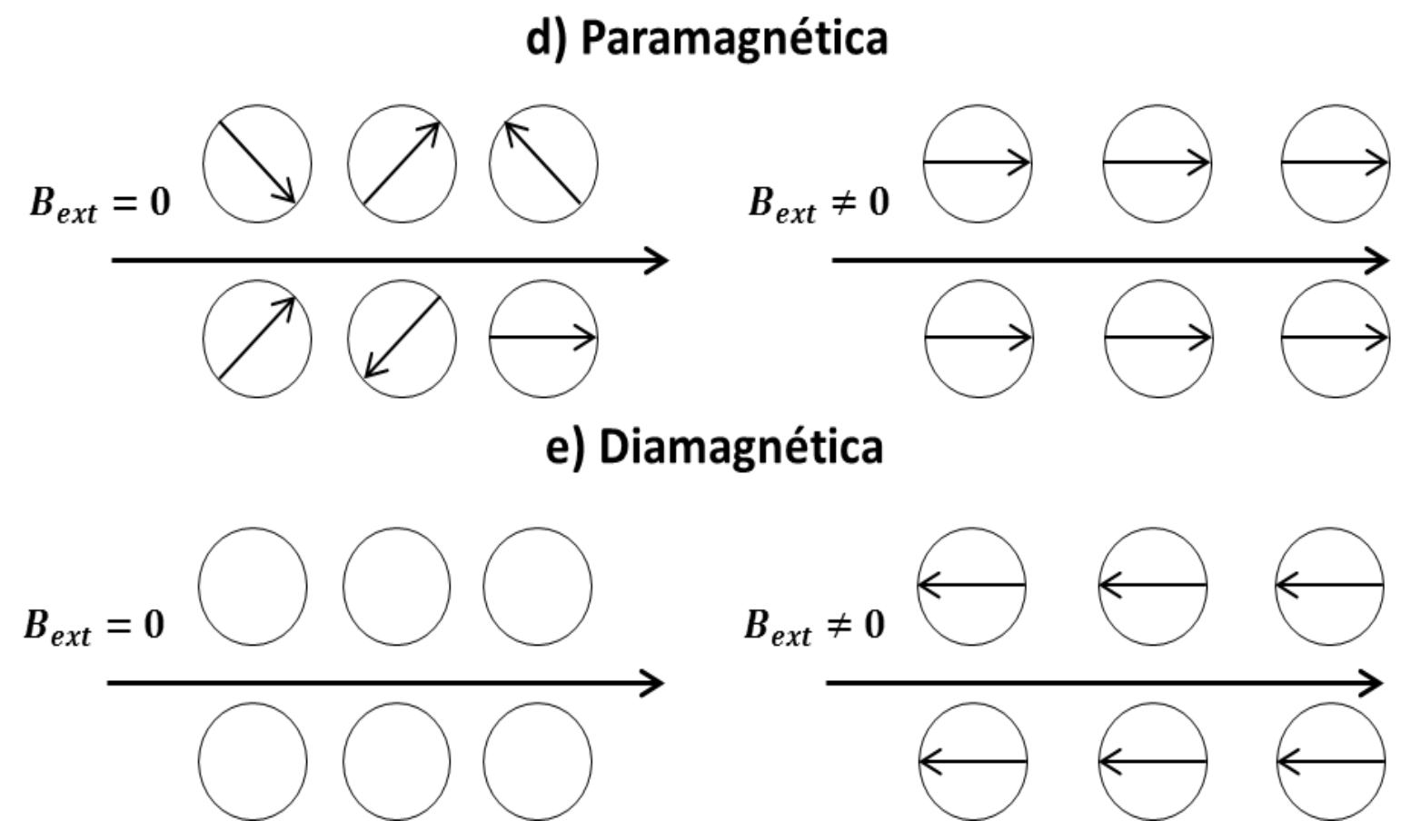

Figura 1.4 - Classificação das substâncias magnéticas de acordo com o arranjo de seus dipolos magnéticos (FARIA; LIMA, 2005). 


\subsubsection{1 - Superparamagnetismo dos Óxidos de Ferro}

Uma das principais propriedades atribuídas às nanopartículas de óxido de ferro está diretamente associada com seu tamanho. Como mostra a Figura 1.5, que relaciona o campo coercivo (Hc) de um material com o seu diâmetro médio (D). É possível observar que, ao reduzir o diâmetro de uma partícula ferromagnética abaixo de um certo diâmetro, conhecido como diâmetro crítico (Dc) é possível considerar os domínios magnéticos do composto férrico como um único monodomínio. Nesse ponto partículas antes ferromagnéticas passam a se comportar como materiais paramagnéticos, porém com um momento magnético com aproximadamente $10^{3}$ vezes maior que o magnéton de Born, a esse fenômeno dá-se o nome de superparamagnetismo (SILVEIRA, 2006). As nanopartículas baseadas em óxidos de ferro como a magnetita $\left(\mathrm{Fe}_{3} \mathrm{O}_{4}\right)$ e a maguemita $\left(\gamma-\mathrm{Fe}_{2} \mathrm{O}_{3}\right)$ possuem como principal característica propriedades superparamagnéticas. Isso explica sua aplicação em diversos estudos em $\mathrm{N} \& \mathrm{~N} \& \mathrm{Nb}$.

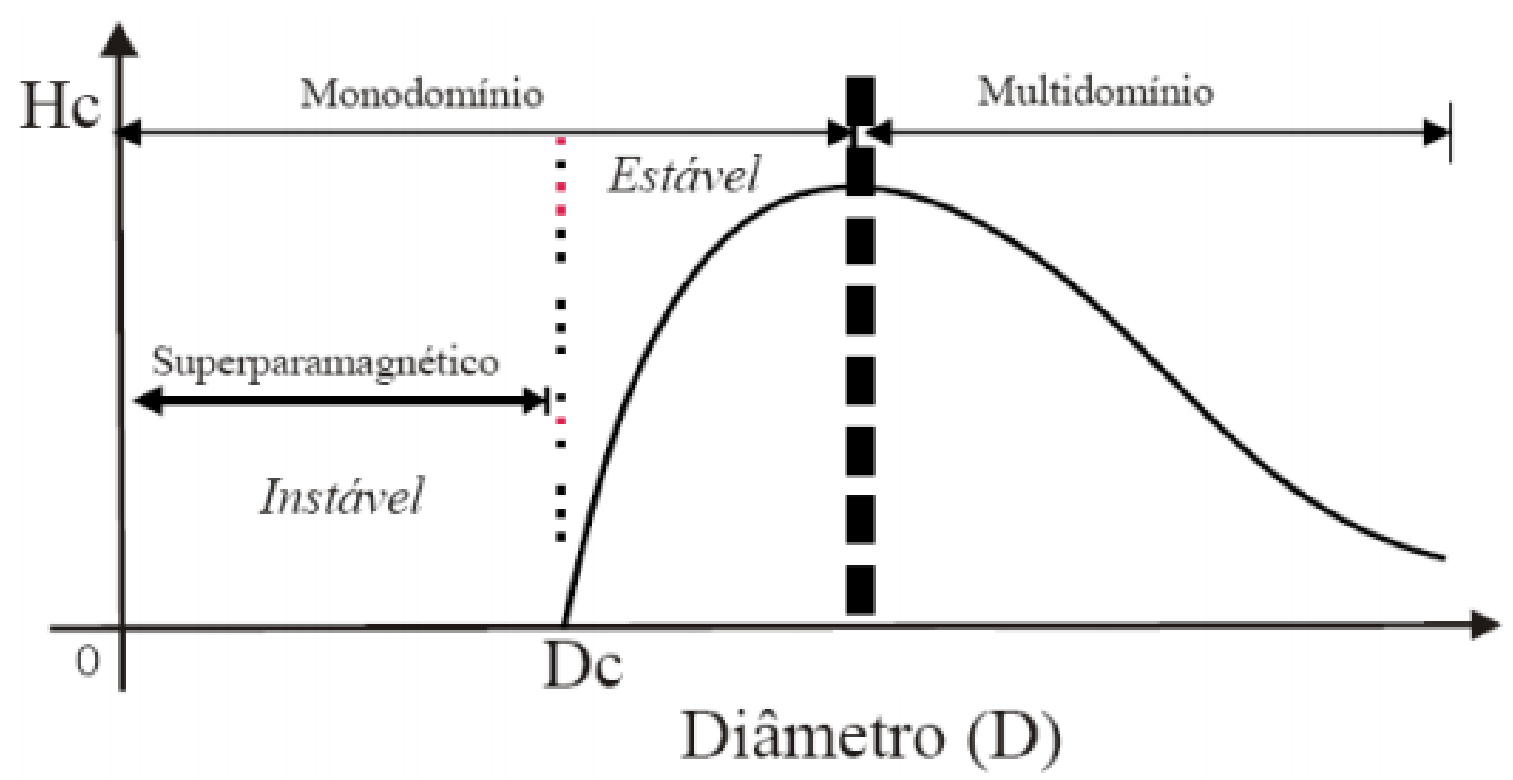

Figura 1.5 - Gráfico relacionando diâmetro dos materiais magnéticos com campo Coercivo (CULLITY,1972 adaptado). 
As nanopartículas de magnetita possuem uma alta taxa de magnetização, porém oxidam com facilidade, formando nanopartículas de maguemita que são mais estáveis, porém com uma menor taxa de magnetização (FARIA; LIMA, 2005).

\subsection{2 - Estrutura Cristalina}

A estrutura cristalina das nanopartículas baseadas em óxidos de ferro, é formada por uma rede cúbica de face centrada (CFC), onde se encontram sítios tetraédricos e octaédricos que estão dispostos de acordo com a Figura 1.6, essa estrutura é conhecida como espinélio invertido (NAMANGA et al, 2013; SILVEIRA, 2006). Estruturalmente a magnetita e maguemita são bem parecidas, porém a magnetita contém íon $\mathrm{Fe}^{2+}$ ocupando oito sítios tetraédricos e o de $\mathrm{Fe}^{3+}$ ocupando 16 sítios octaédricos, enquanto na maguemita todos os sítios são ocupados por íons $\mathrm{Fe}^{3+}$ (SILVEIRA, 2006).

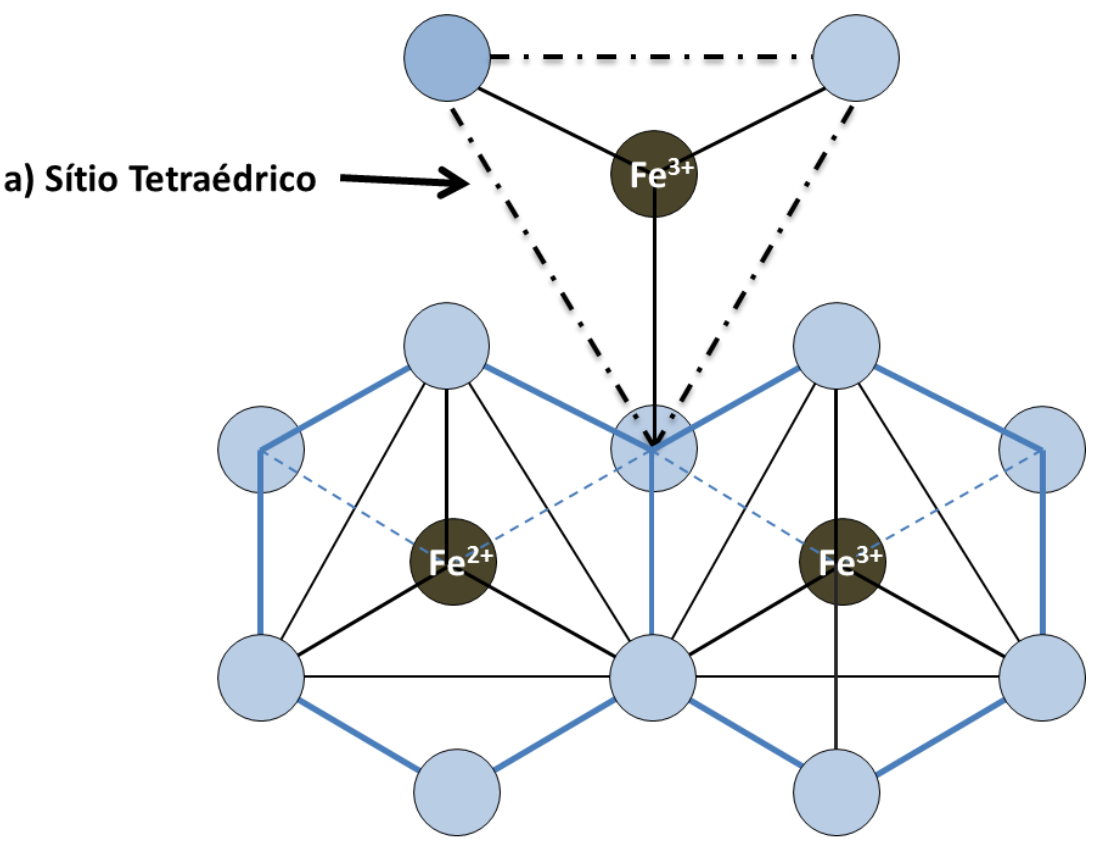

b) Sítios Ocataédricos

Figura 1.6 - Representação da estrutura cristalina das nanopartículas de magnetita $\left(\mathrm{Fe}_{3} \mathrm{O}_{4}\right)$. (a) Sítios Tetraédrico (b) Sítios Octaédricos. (NAMANGA et al, 2013) 
Suas propriedades magnéticas derivam de seu processo de síntese, sendo que é possível obter as nanopartículas por diversos métodos físico-químicos como: Microemulsão, Decomposição Térmica, Coprecipitação, Sol-gel entre outros (LAURENT et al., 2008; YUEJIAN et al., 2010). Para este estudo utilizou-se o processo de coprecipitação por hidrolise em meio alcalino, também conhecido como método Massart (CHIN; YAACOB, 2007).

\section{3 - NANOCOMPÓSITOS MAGNETO POLIMÉRICOS}

Os nanocompósitos magneto-poliméricos (NCM) são materiais híbridos, formados por um conjugado de dois ou mais materiais, onde pelo menos um está em nanoescala. O objetivo é integrar propriedades de diferentes compostos em um único material (ESTEVES; BARROSTIMMONS; TRINDADE, 2004; PYUN, 2007). Várias pesquisas atribuem aos nanocompósitos o uso de partículas, fibras ou lamelares dispersas em uma matriz polimérica, sendo que suas aplicações alcançam diversas áreas de estudo, indo da biotecnologia até a microeletrônica (PYUN, 2007; RODRIGUEZ, A F R; JACOBSON; et al., 2013).

\subsection{1 - Classificação dos Nanocompósitos Magneto-Poliméricos}

Os nanocompósitos magneto-poliméricos podem ser sintetizados e classificados de acordo com suas dimensões, podendo ser divididos como: Pó ou Suspensão, Fluídos, Filmes (mono e multicamadas) e Sólidos Tridimensionais (MAI; YU, 2006). Cada tipo de nanocompósito pode apresentar variadas características e diversas aplicações (Figura 1.8).

Os NCM na forma de pó ou suspensão (Figura 1.7a) são normalmente formados por estruturas tipo core/shell, onde temos um núcleo nanopartículado recoberto por uma camada polimérica (CHAUDHURI; PARIA, 2012). Porém, WANG e colaboradores (2009), 
destacaram o preparo de nanocompósitos do tipo core/shell, em que as nanopartículas magnéticas formam o shell que recobriu as microesferas poliméricas.

No preparo de um NCM é comum o uso de nanopartículas superparamagnéticas de magnetita e maguemita, em razão de sua característica superparamagnética e alta biocompatibilidade, em relação às outras ferritas. Já os polímeros podem ser diversos, tanto os naturais: carboidratos, lipídios e proteínas, como os artificiais: PVA, PEG, Dextran, Ácidos Policarboxilícos, Poliaminas entre outros (CHAUDHURI; PARIA, 2012).

Os NCMs em forma de pó ou suspensão podem ser utilizados para detecção, separação e até o direcionamento de materiais dentro do organismo. Outro uso muito estudado atualmente é o da Magneto-hipertermia, onde o nanocompósito magneto-polimérico ao ser colocados na presença de um campo magnético oscilante tende a aumentar a temperatura do meio onde está inserido, em consequência a esse efeito diversos estudos estão sendo feitos relacionando-o com o tratamento de células cancerígenas (CÉSAR et al., 2010; GRAVINA et al., 2002; LAURENT et al., 2008).

Nos ferrofluidos, os NCMs são constituídos por uma grande concentração de nanopartículas magnéticas que são recobertas por uma matriz polimérica em suspensão. Com isso há uma forte interação com o campo magnético externo. Esse tipo de material é muito utilizado na indústria em sistemas de resfriamento a baixa temperatura, lubrificantes e sistemas de impressão. Além do mais, o polímero utilizado para formar o ferrofluido pode possuir agentes químicos ativos, de forma a interagir mais fortemente com o ambiente em que está inserido. Esses nanomateriais podem ser utilizados como catalisadores e separadores de substâncias (CHAUDHURI; PARIA, 2012; MAI; YU, 2006). 
Em fibras magnéticas unidimensionais (Figura 1.7b), o NCM pode apresentar magnetorestrição e permeabilidade a microondas. Esse tipo de nanomaterial é utilizados na fabricação de materiais magnéticos inteligentes como: escudos magnéticos e atuadores de altatensão (BAVASTRO et al., 2014).

\section{Estrutura $\quad$ Propriedades $\quad$ Aplicações}

a)

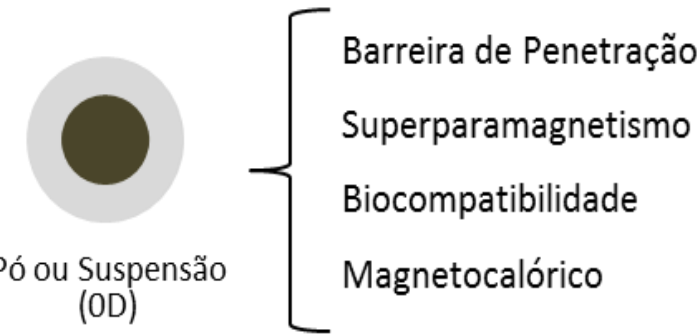

b)

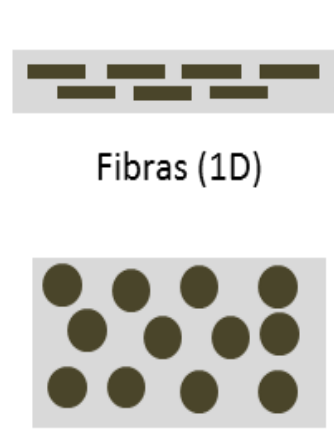

Filmes-Finos (2D)

d)

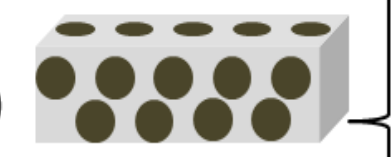

Sólidos (3D)
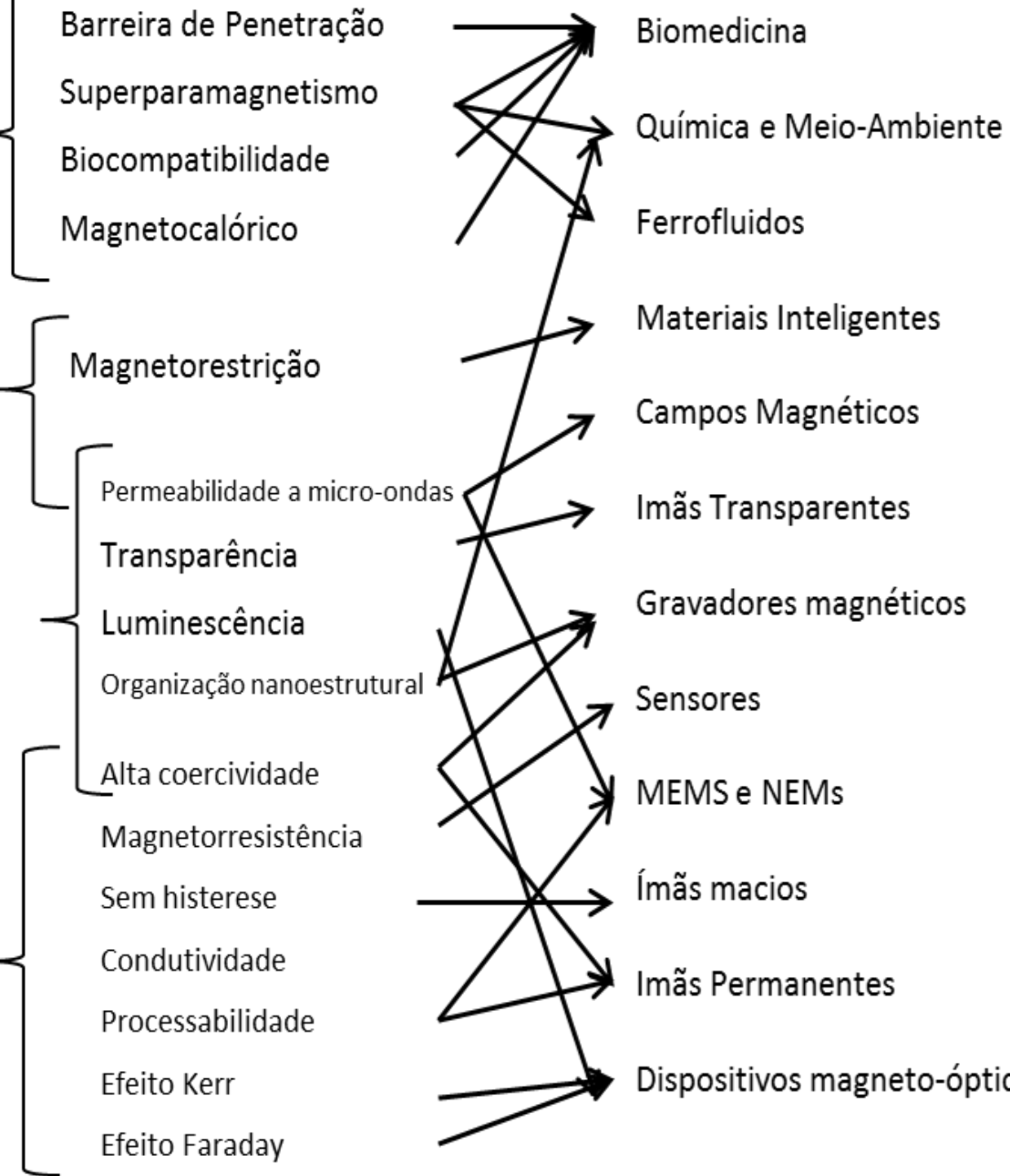

Materiais Inteligentes

Campos Magnéticos

Imãs Transparentes

Gravadores magnéticos

Sensores

MEMS e NEMS

Ímãs macios

Imãs Permanentes

Dispositivos magneto-ópticos

Figura 1.7 - Classificação dos nanocompósitos magneto-poliméricos. (a) Pó ou Suspensão. (b) Fibras (c) Filmes-finos e (d) Sólidos Tridimensionais (MAI; YU, 2006 adaptado).

Nanocompósitos magneto-poliméricos em forma de Filmes bidimensionais possuem diversas possíveis aplicações (Figura 1.7c), o tipo de aplicação está associado diretamente com as propriedades físicas atribuídas as nanopartículas como: o efeito de rotação de Faraday, a 
magnetorresistência de tunelamento (TMR), Magnetorresistência Gigante (GMR) e o arranjo de seus domínios magnéticos. Existem pesquisas na utilização de nanocompósitos no campo de gravação de dados de alta densidade, onde o mesmo é descrito como a próxima geração de gravadores magnéticos. Por exemplo, um filme magnético com $5 \mathrm{~nm}$ de espessura pode armazenar cerca de $10^{10} \mathrm{bit} / \mathrm{cm}^{2}$, sendo que, a princípio, seria possível utilizar diversas ferritas no processo de fabricação de um dispositivo para armazenamento de dados (MAI; YU, 2006; MATSUNUMA et al., 2012).

Para os nanocompósitos tridimensionais temos estruturas tipo bulk formadas por nanoestruturas (Figura 1.7d). O material polimérico pode ser usado para compactar as nanopartículas. Este sistema pode fazer com que o material formado possa substituir os laminados em seletivas aplicações no eletromagnetismo.

\subsection{2 - Tipos de Síntese de Nanocompósitos Magneto-Poliméricos}

De acordo com MAI e YU (2006), os processos de síntese influenciam diretamente na performance do NCM, sendo que os procedimentos de síntese são de vital importância na formação de um material de qualidade e característico para uma aplicação.

Para síntese dos NCM existem quatro processos básicos, onde estão envolvidas a precipitação dos percussores que formam as nanopartículas magnéticas e a policondensação de monômeros formando os polímeros. São eles:

Dispersão das nanopartículas pré-sintetizadas no monômero e uma polimerização in situ;

Dispersão dos precursores na matriz polimérica e em seguida a precipitação in situ; 
Mistura dos percursores com os monômeros seguida de reações simultâneas de precipitação e polimerização.

A precipitação das nanopartículas magnéticas e polimerização do monômero de forma separada, seguida com a dispersão das partículas na matriz polimérica;

Esses quatro processos tendem a formar um determinado tipo de NCM. A polimerização in situ, por exemplo, tende a formar estruturas core-shell, podendo ser com uma nanopartícula magnética no núcleo ou com várias, além de estruturas ordenadas e sólidos tridimensionais com alta densidade (Figura 1.8). Por exemplo, JIANG e colaboradores (2008) descrevem em seu trabalho, a síntese de um NCM, tipo core-shell, de ferritas magnéticas com Polianilina, obtidas por polimerização in situ. O material apresentou natureza ferromagnética e magnetização de saturação dependente da concentração de partículas magnéticas em seu núcleo.

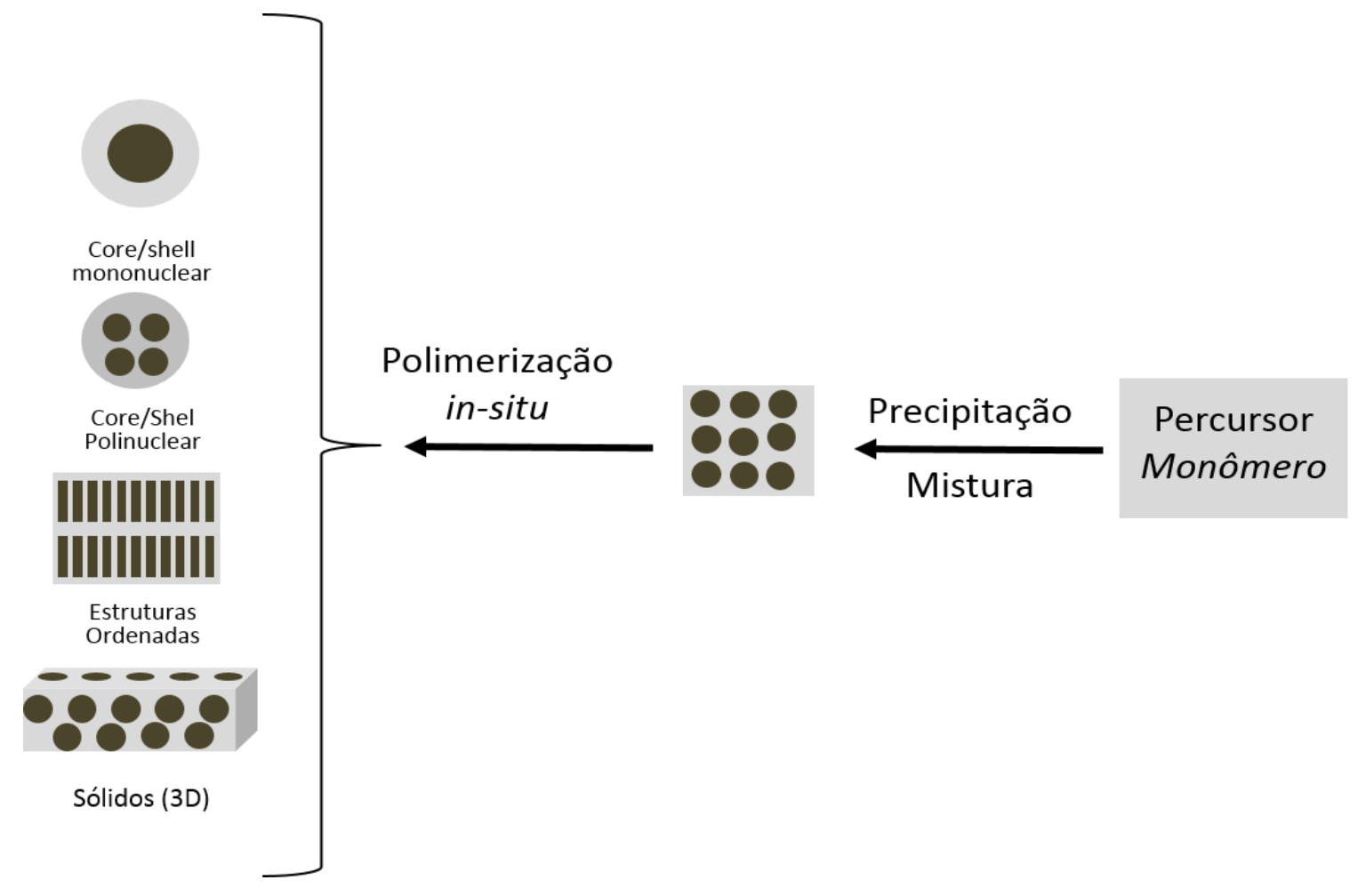

Figura 1.8 - Rota de síntese dos NCM por polimerização “in-situ” (MAI; YU, 2006 adaptado). 
A precipitação in situ produz com mais facilidade estruturas core-shell com núcleos monos ou multipartículados e NCM ordenado (Figura 1.9). Por exemplo, GREGORIOJAUREGUI e colaboradores (2012) reportam a síntese de um nanocompósito baseado em nanopartículas magnéticas de $\mathrm{Fe}_{3} \mathrm{O}_{4}$ recobertas por um biopolímero chamado de Quitosana, sintetizadas por este método. As nanopartículas apresentaram diâmetro médio entre 10-11 nm, houve agregação das nanopartículas formando um core-shell com várias partículas em núcleo e a cobertura de Quitosana obteve uma eficiência de 53,6\%.

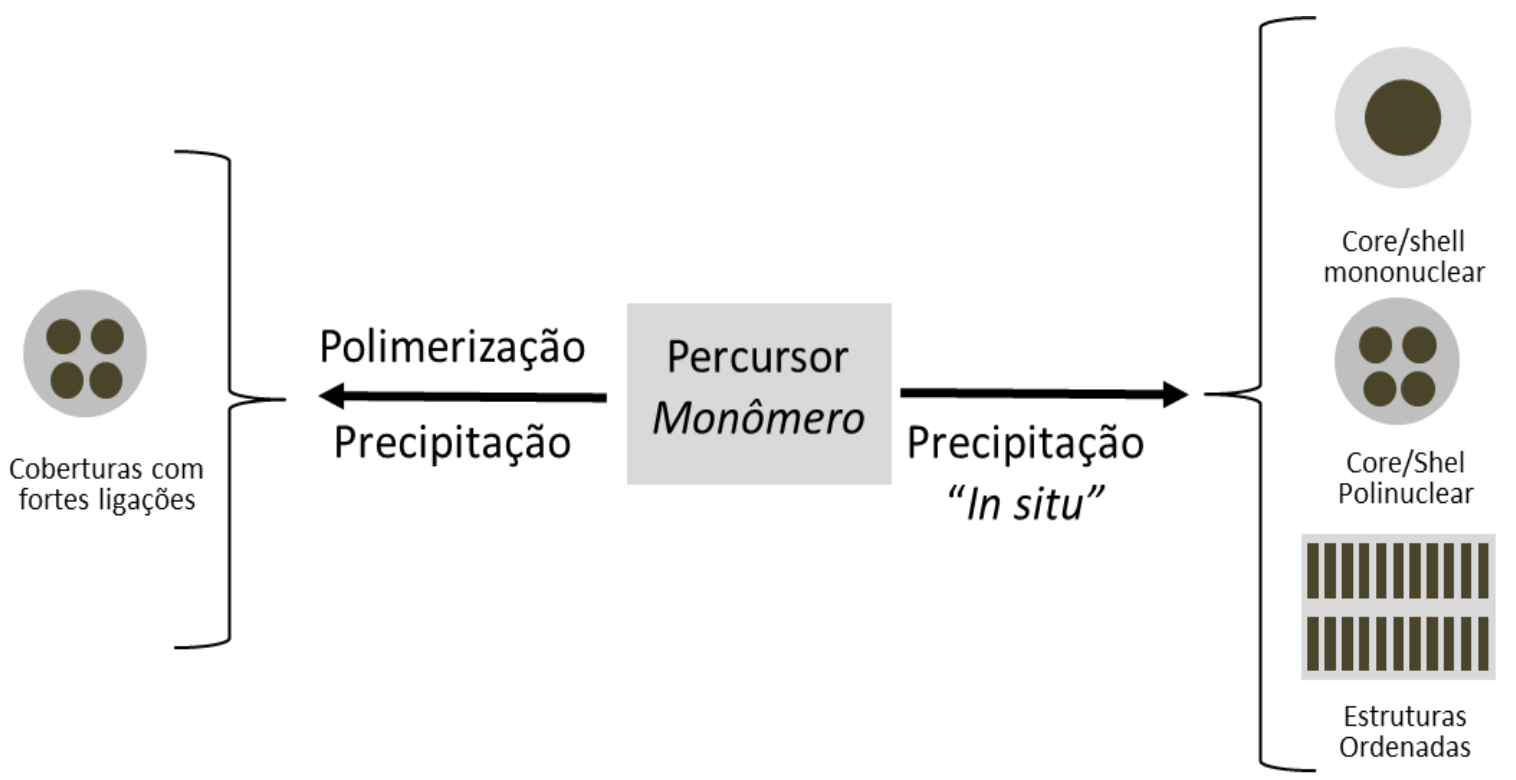

Figura 1.9 - Rotas de síntese dos NCMs por polimerização e precipitação "in situ" (direita) e precipitação "in situ” (Esquerda) (MAI; YU, 2006 adaptado).

Como mostrado na Figura 1.9 (Direita), a síntese por polimerização do monômero ocorrendo de forma simultânea a precipitação dos precursores gera nanocompósitos com maior homogeneidade e fortes ligações entre as nanopartículas e a matriz polimérica (MAI; YU, 2006). Por fim o método de dispersão das nanopartículas na matriz polimérica. Por esta rota, é possível sintetizar nanoestruturas core-shell com apenas uma nanopartícula no núcleo, assim como fibras unidimensionais, filmes bidimensionais e sólidos tridimensionais (Figura 1.10). 


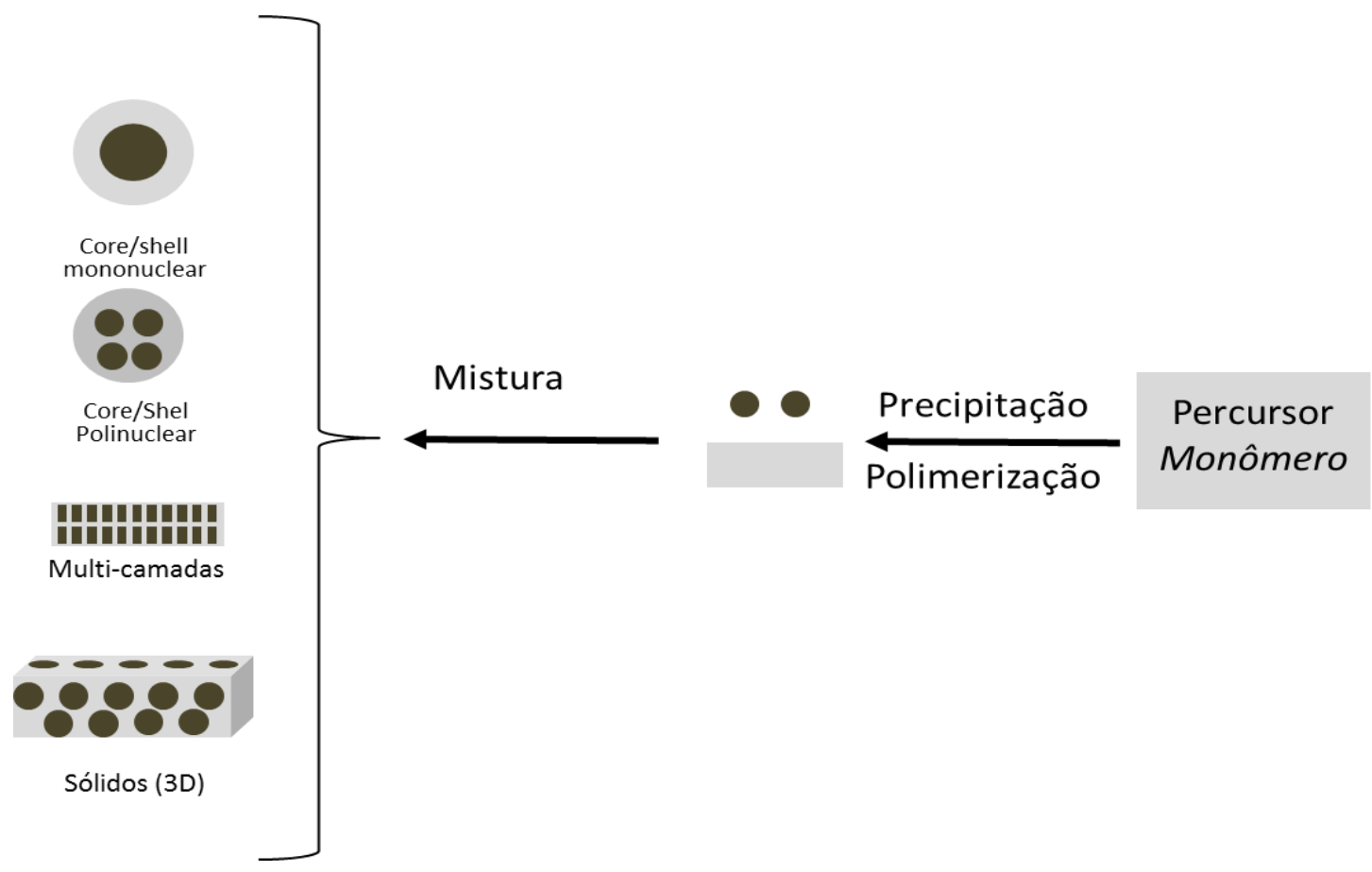

Figura 1.10 - Rota de síntese dos NCM por polimerização e precipitação seguida de uma mistura (MAI; YU, 2006 adaptado).

Neste trabalho foram sintetizados e caracterizados nanocompósitos magnetopoliméricos à base de nanopartículas magnéticas de maguemita recobertas por uma matriz polimérica, preparada a partir de monômeros extraído de óleos essenciais, encontrados na Amazônia. As técnicas utilizadas tanto na síntese quanto na caracterização das amostras utilizadas neste trabalho estão descritas no próximo capítulo. 


\section{CAPÍTULO 2 - MATERIAIS E MÉTODOS}

Neste capítulo estão descritos os processos para a síntese dos nanocompósito magnéticos híbridos à base de óleos essenciais extraídos da semente de C. guianensis, bem como as técnicas utilizadas para sua caracterização.

\section{1 - PREPARAÇÃO DO NANOCOMPÓSITO MAGNETO-POLIMÉRICO}

Os processos para síntese do nanocompósito híbrido, utilizado neste trabalho, foram divididos em três etapas: i) Polimerização do óleo "in natura”; ii) Síntese das nanopartículas magnéticas; iii) Preparação do nanocompósito híbrido.

Foram utilizados os seguintes reagentes: Cloreto Férrico $\left(\mathrm{FeCl}_{3} \cdot 6 \mathrm{H}_{2} \mathrm{O}\right)$, Cloreto Ferroso $\left(\mathrm{FeCl}_{2} \cdot 4 \mathrm{H}_{2} \mathrm{O}\right)$, Hidróxido de Amônia $\left(\mathrm{NH}_{4} \mathrm{OH}\right)$, Etilenoglicol $\left(\mathrm{C}_{2} \mathrm{H}_{6} \mathrm{O}_{2}\right)$ e Hidróxido de Potássio $(\mathrm{KOH})$, Água Deionizada $\left(\mathrm{H}_{2} \mathrm{O}\right)$ e os Óleos vegetais in natura extraídos de sementes de $C$. guianensis. 


\subsection{1 - Polimerização do Óleo “in natura”}

Para a preparação do polímero foram utilizadas amostras in natura de óleos essenciais, extraídos das sementes de $C$. guianensis. O óleo utilizado foi extraído diretamente da semente da Andiroba, conforme procedimento descrito por SILVA (2005). O óleo vegetal foi filtrado, aquecido e centrifugado, a fim de retirar água e possíveis impurezas.

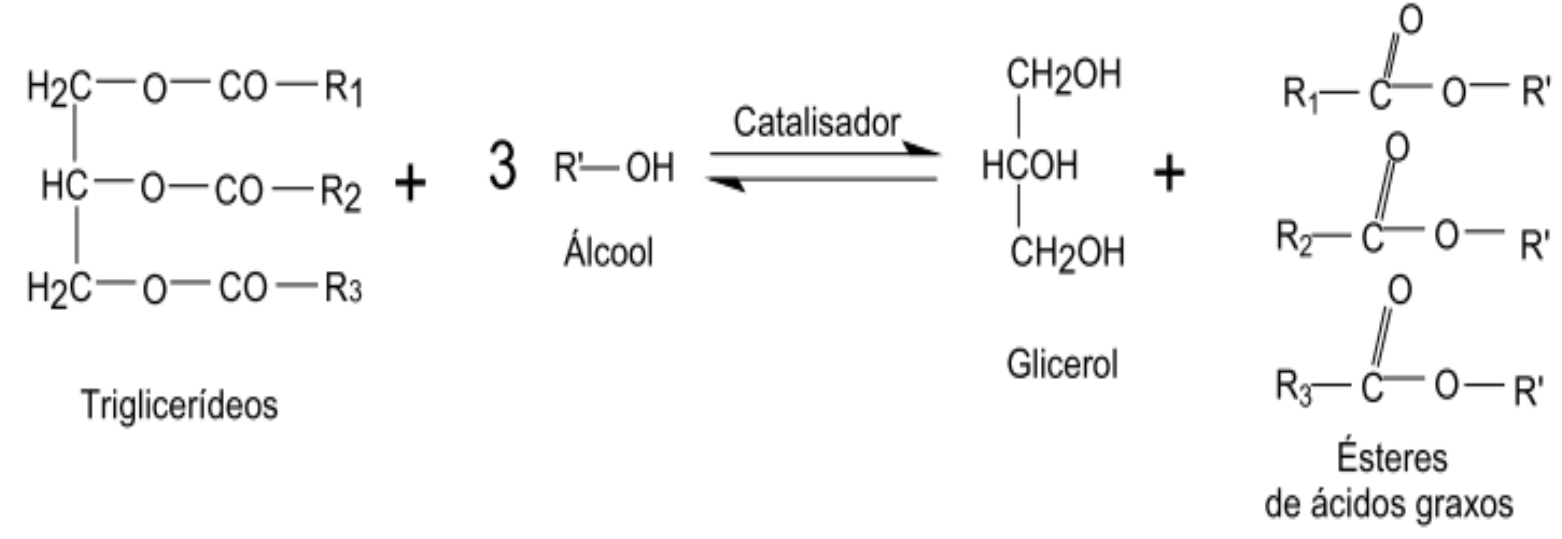

Figura 2.1 - Transesterificação dos triglicerídeos em solução alcoólica (SILVA, 2005).

O polímero foi extraído do óleo natural utilizando a técnica de policondensação (MIAO et al., 2014; SENIHA GÜNER; YAĞCI; TUNCER ERCIYES, 2006; SHARMA; KUNDU, 2008). O óleo “in natura" passou primeiramente por um processo de transesterificação, para quebrar a cadeia de triglicerídeos formando assim monômeros de ácidos graxos livres (Figura 2.1). Para isso foi preparado uma solução contendo $10 \mathrm{ml}$ de $\mathrm{KOH}$ a $6 \mathrm{~N}$ dissolvidos em $90 \mathrm{ml}$ do óleo "in natura". No preparo, o óleo foi colocado sobre agitação constante enquanto o $\mathrm{KOH}$ foi despejado lentamente, a solução foi deixada sobre agitação constante por cerca de 10 min a temperatura ambiente em seguida foi adicionado $150 \mathrm{ml}$ de $\mathrm{H}_{2} \mathrm{O}$. A solução resultante foi agitada constante e exposta a uma temperatura de $100{ }^{\circ} \mathrm{C}$ por 20 min. Por fim a amostra foi colocada em um funil de decantação por 72 horas para que as fases 
se separassem. Observou-se a formação de três fases. A fase intermediaria foi utilizada nos próximos processos.

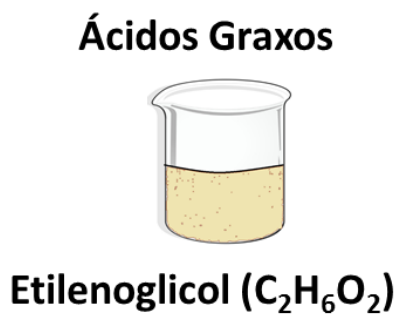

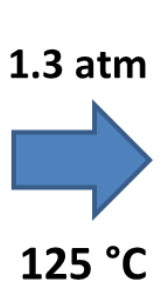

\section{Centrifugação}

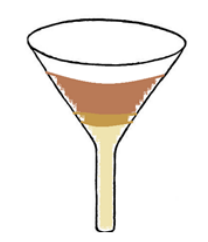

Decantagem

$72 \mathrm{~h}$
Separação

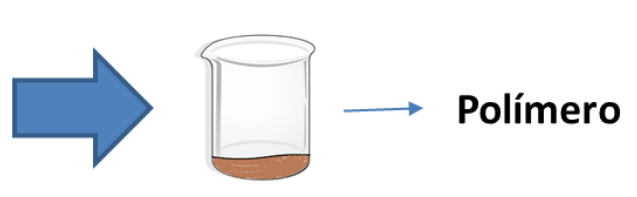

Liofilização

Figura 2.2 - Esquema de polimerização de ácidos graxos livres transesterificados a partir de triglicerídeos de óleos vegetais.

Após separação do glicerol as amostras foram então misturada, em razão 1:1, com $\mathrm{C}_{2} \mathrm{H}_{6} \mathrm{O}_{2}$ e aquecidas em autoclave a uma temperatura de $125^{\circ} \mathrm{C}$ e a uma pressão de $1,3 \mathrm{~atm}$ por três horas, visando assim forçar a reação de polimerização. Passado o tempo a amostra foi colocada novamente para descansar em um funil separador por 72 horas. Após a separação das fases, o sobrenadante foi submetido a um processo de centrifugação e liofilização (Figura 2.2). O sobrenadante obtido foi separado para ser adsorvido nas nanopartículas, funcionando assim como ativadores na superfície da nanopartícula ( RODRIGUEZ, A F R; COAQUIRA; et al., 2013; SILVA, 2005).

\subsection{2 - Síntese das Nanopartículas de Óxido de Ferro}

As nanopartículas magnéticas à base de óxido de $\mathrm{F}_{\mathrm{e}}$ foram obtidas através do método de coprecipitação por hidrólise alcalina de íons $\mathrm{Fe}^{2+}$ e $\mathrm{Fe}^{3+}$ em solução de hidróxido de Amônia $\left(\mathrm{NH}_{4} \mathrm{OH}\right)$ (Figura 2.3).

Primeiramente misturou-se em um béquer $\mathrm{FeCl}_{3} .6 \mathrm{H}_{2} \mathrm{O}$ juntamente com $\mathrm{FeCl}_{2} .4 \mathrm{H}_{2} \mathrm{O}$, na razão 1:2, adicionando posteriormente $\mathrm{H}_{2} \mathrm{O}$. Logo em seguida a amostra foi levada a um 
agitador magnético a cerca de $200 \mathrm{rpm}$ mantendo uma temperatura de $60{ }^{\circ} \mathrm{C}$ por 15 minutos. Ao adicionar o $\mathrm{NH}_{4} \mathrm{OH}$ à solução inicial, ocorreu o rompimento das ligações dos compostos ocasionando a mudança de coloração para cor escura, indicando um precipitado formado por nanopartículas de $\mathrm{Fe}_{3} \mathrm{O}_{4}$ (CHIN; YAACOB, 2007), a amostra foi deixada no agitador até atingir $74^{\circ} \mathrm{C}$ para melhor formação das redes cristalinas da magnetita. A reação química para a formação da $\mathrm{Fe}_{3} \mathrm{O}_{4}$ é descrita pela Equação 2.1.

$$
\mathrm{Fe}^{2+}+\mathrm{Fe}^{3+}+8 \mathrm{OH}^{-} \rightarrow \mathrm{Fe}_{3} \mathrm{O}_{4}+4 \mathrm{H}_{2} \mathrm{O}
$$

Ao atingir a temperatura a solução supracitada foi retirada do agitador magnético e colocada para decantação das partículas, que estão suspensas no sobrenadante.
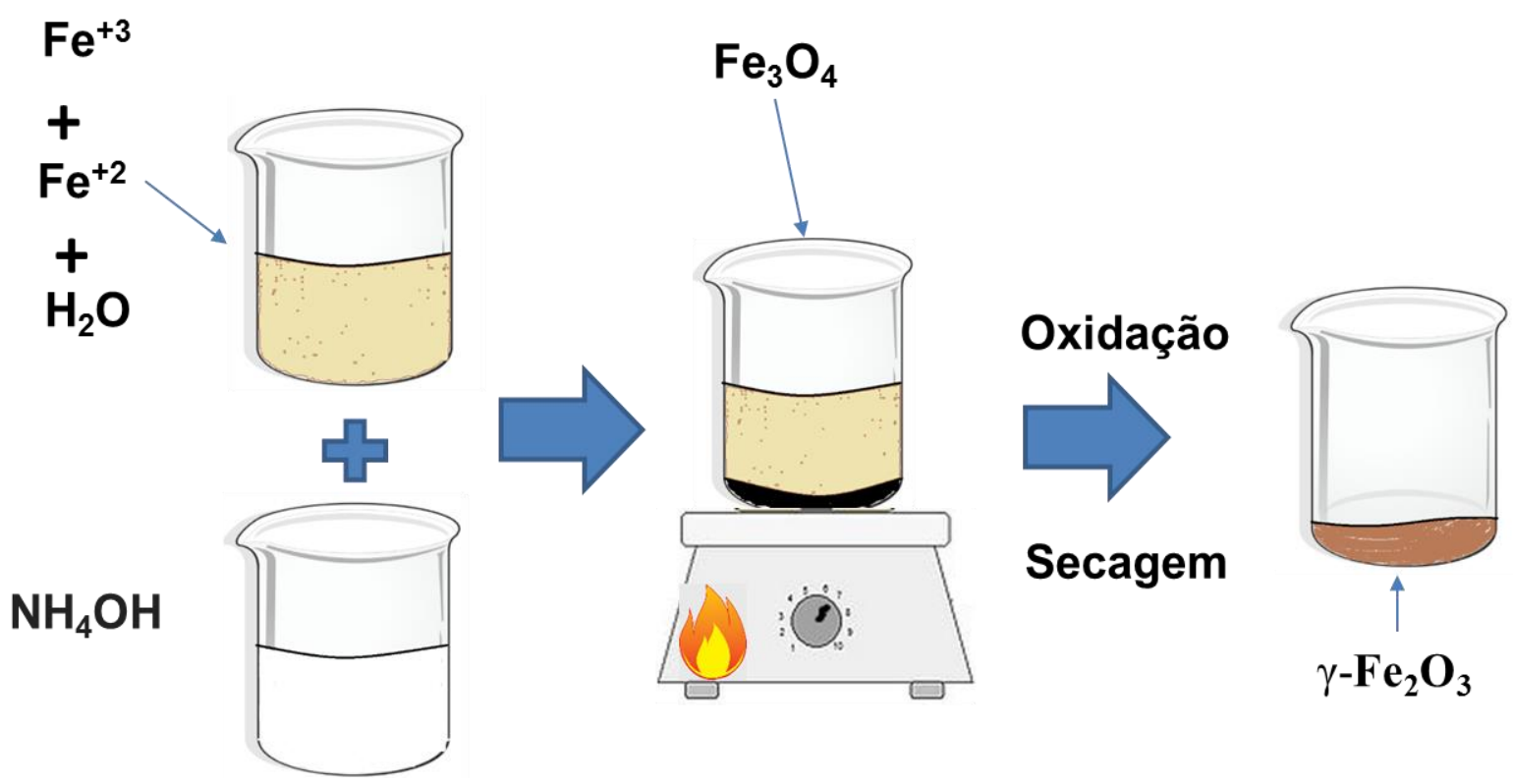

Figura 2.3 - Esquema simplificado da síntese das nanopartículas magnéticas.

Os precipitados foram então lavados com água deionizada durante um determinado tempo até que seu pH atingisse valores entre 8 e 9. As nanopartículas de $\mathrm{Fe}_{3} \mathrm{O}_{4}$ foram colocadas 
em ambiente oxidante (ar-atmosférico) formando assim nanopartículas de $\gamma-\mathrm{Fe}_{2} \mathrm{O}_{3}$, que possuem uma coloração marrom, a reação química é descrita pela Equação 2.2.

$$
\mathrm{Fe}_{3} \mathrm{O}_{4}+2 \mathrm{H}^{+} \rightarrow \gamma-\mathrm{Fe}_{2} \mathrm{O}_{3}+\mathrm{Fe}^{2+}+4 \mathrm{H}_{2} \mathrm{O}
$$

A última etapa da obtenção de nanopartículas consiste no processo de secagem, a temperatura ambiente. Com a secagem da amostra, o sólido formado foi macerado para separar as nanopartículas e peneirado, utilizando peneiras micrométricas. (LAURENT et al., 2008; SANTOS et al., 2012).

\subsection{3 - Síntese do Nanocompósito Híbrido}

O nanocompósito magneto-polimérico foi obtido pelo processo descrito por MAI e YU (2006), onde as nanopartículas de maguemita e o polímero sintetizado a partir do óleo extraído da semente de $C$. guianensis são preparados separadamente, seguido de uma mistura.

Para a preparação do nanocompósito magneto-polimérico, as nanopartículas de $\gamma$ - $\mathrm{Fe}_{2} \mathrm{O}_{3}$ foram recobertas por uma camada estabilizante de ácido oleico $\left(\mathrm{C}_{18} \mathrm{H}_{34} \mathrm{O}_{2}\right)$, em razão 1:1. Depois a solução passa por um processo de sonicação por 3 min, visando assim uma maior homogeneização da solução. Por fim a solução supracitada foi misturada com a matriz polimérica, passando novamente pelo processo de sonicação formando o nanocompósito magneto-polimérico (Figura 2.4). Pré-testes foram feitos, variando a proporção de nanopartículas magnéticas e o polímero extraído do óleo da $C$. guianensis, até adquirir uma boa estabilidade na dispersão e formação do nanocompósito. 


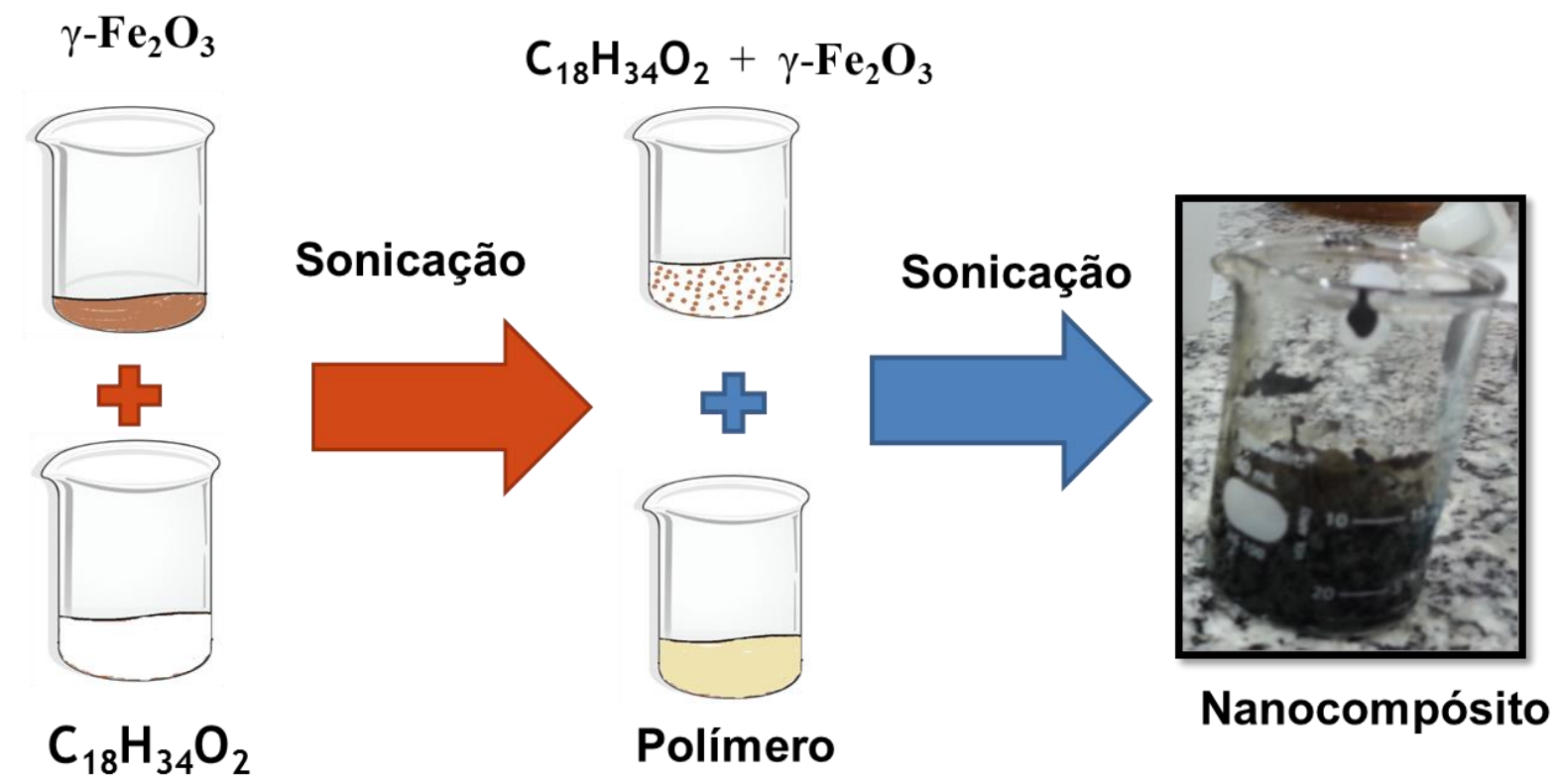

Figura 2.4 - Esquema simplificado da síntese do nanocompósito magneto-polimérico.

Tabela 2.1 - Amostras investigadas com suas respectivas nomenclaturas.

\begin{tabular}{l|c}
\multicolumn{1}{c|}{ Amostras } & Nomenclaturas \\
\hline Nanopartículas à base de em óxidos de Ferro & NPs \\
Óleo da Carapa guianensis "in natura" & OCA \\
Polímero extraído do óleo da Carapa guianensis & PCA \\
Nanocompósito magneto-polimérico à base do óleo da Carapa guianensis & NMC \\
\hline
\end{tabular}

Para este estudo, nanopartículas magnéticas recobertas por ácido oleico, foram dispersas na matriz polimérica em uma razão 1:1. Após a dispersão a amostra passa por um processo de liofilização e secagem, formando assim o NCM, pronto para caracterização. A Tabela 2.1 apresenta as amostras sintetizadas e prontas para a investigação, com suas respectivas nomenclaturas.

\section{2 - TÉCNICAS DE CARACTERIZAÇÃO}

Para a caracterização das amostras sintetizadas, foram utilizadas diversas técnicas afim de elencar informações sobre natureza óptica e estrutural do NMC. Essas técnicas são: 
Difratometria de Raios X, Microscopia Eletrônica de Transmissão, Microscopia Eletrônica de Varredura e Espectroscopias no: Uv-Visível, Infravermelho com Transformada de Fourier, Energia Dispersiva de Raios X e por Fotoacústica.

\subsection{1 - Difratometria de Raios X (DRX)}

A Difratometria de Raios X (DRX) em pó é uma das principais técnicas para caracterização de materiais cristalinos, sua vantagem está em ser uma técnica analítica, não destrutiva e que não requer um preparo elaborado das amostras. A técnica é utilizada para avaliar a cristalinidade, parâmetros da rede, índice de Miller, distância interplanar, tamanho médio dos domínios cristalinos e fase magnética.

O equipamento para medidas de DRX possui uma fonte de Raios X que varia de 0,7 até $2 \AA$ A , ao atingir uma estrutura cristalina o feixe é difratado. Essa difração dos Raios X obedece a lei que deu o Prêmio Nobel Física, em 1915, a Willian Henry Bragg e seu filho Willian Lawrence Braag (NUSSENZVEIG, 2010). A Lei de Braag fala que a amplitude máxima do raio difratado irá ocorrer quando a diferença de trajeto é um múltiplo do comprimento de onda incidente, conforme Equação 2.3 e Figura 2.5.

$$
\lambda=2 d \operatorname{sen}(\theta)
$$

onde, $d$ é o espaço entre os planos atômicos da fase cristalina e $\lambda$ é o comprimento de onda da fonte de Raios X. A partir do difratograma gerado pelo DRX os picos de difração são comparados com valores da ficha padrão (ASTM) para identificar a estrutura cristalina da nanopartícula. 


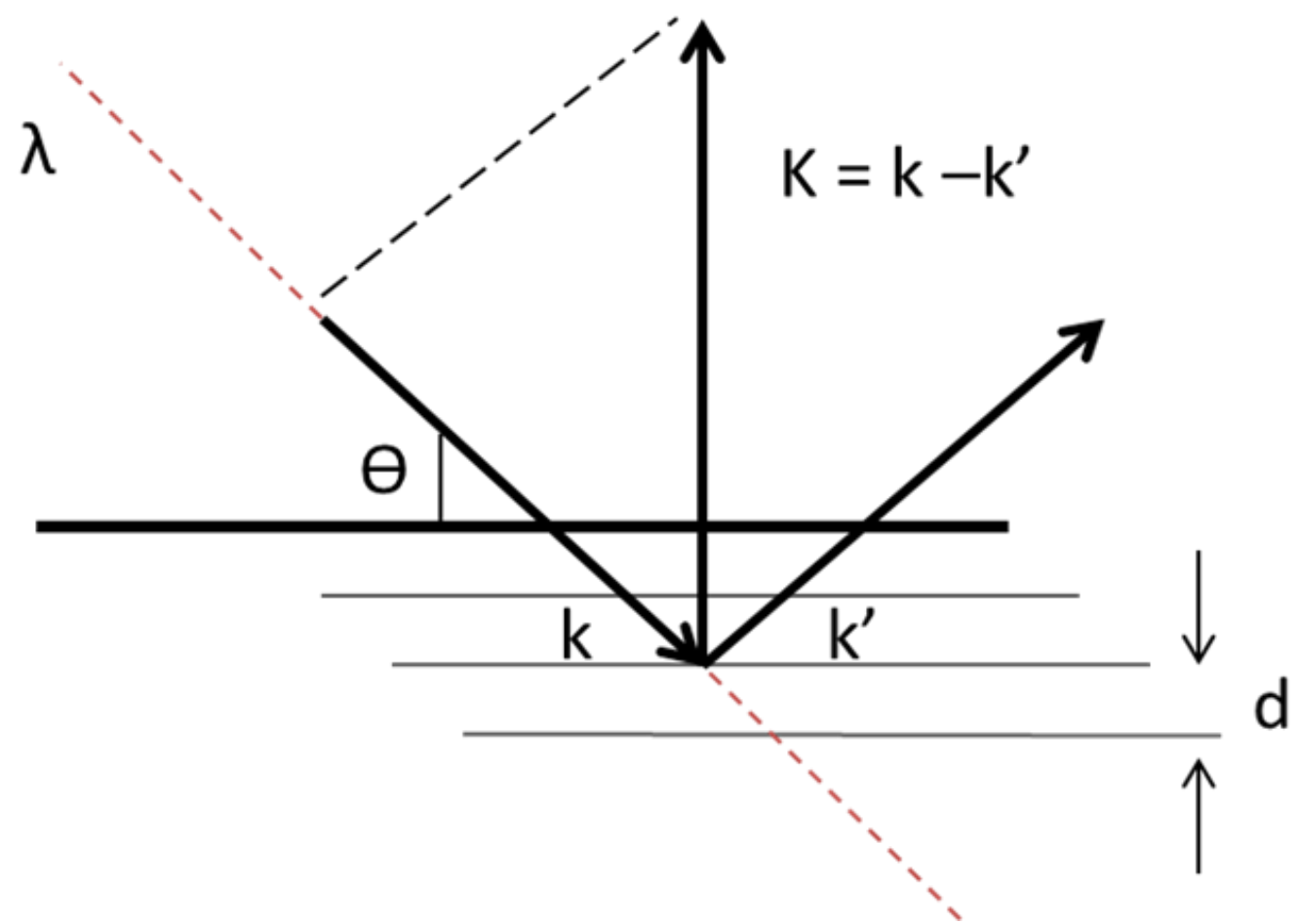

Figura 2.5 - Lei de Bragg que descreve que a amplitude máxima do raio difratado irá ocorrer quando a diferença de trajeto é um múltiplo do comprimento de onda incidente.

O DRX é utilizado para estimar o diâmetro médio $D$ das nanopartículas e para isso utiliza-se a Equação de Debye-Scherrer (Equação 2.4) que relaciona a largura da meia altura da reflexão mais intensa com o diâmetro de materiais esféricos (LAURENT et al., 2008; SARTORATTO, P.P.C. et al., 2007).

$$
D_{h k l}=\frac{K \lambda}{\beta \cos (\theta)}
$$

onde $\mathrm{D}$ é o diâmetro médio entre os domínios cristalinos, a constante $\mathrm{K}$ depende da forma da partícula (para partículas esféricas os valos se aproxima de 0,94 ), $\lambda$ é o comprimento de onda do feixe de Raios X, $\theta$ é o ângulo de difração e C é a largura na metade da altura do pico de difração corrigido através da Equação 2.5. 


$$
\beta=\sqrt{\beta_{\text {amostra }}^{2}-\beta_{\text {padrão }}{ }^{2}}
$$

Para este trabalho foi utilizado um difratômetro da marca SHIMADZU modelo DRX6000, com um range em ângulos entre 10 e 80 graus e com fonte de cobre com linha em $\mathrm{Cu} K$ 1,54 Angstrom em $40 \mathrm{KV}$ e 20mA, localizado no Instituto de Química da Universidade de Goiás - UFG. O difratograma foi obtido a temperatura ambiente, com ângulos de varredura entre 10 a 80 graus em modo contínuo com velocidade de aquisição 2 graus por minuto.

\subsection{2 - Microscopia Eletrônica de Transmissão (MET)}

A técnica de Microscopia Eletrônica de Transmissão (MET) utiliza um microscópio com estrutura parecida com o microscópio óptico, porém utiliza como fonte de iluminação um feixe proporcionado e por um canhão de elétrons, de alta-voltagem, perfeitamente focalizado na superfície das amostras por um conjunto de lentes eletroestáticas e eletromagnéticas (Figura 2.6).

Ao atingir a amostra, o feixe incidente pode ou não interagir, sendo que as interações mais importantes são os espalhamentos elásticos, onde não há transferências de energia entre o feixe de elétrons e a amostra e o espalhamento inelástico onde há transferência de energia porém o feixe transmitido não interage com amostram (Figura 2.7). Essas interações formam as tonalidades da imagem final formada (FARINA, 2010).

Para o estudo de nanoestruturas magnéticas a microscopia eletrônica de transmissão (MET) fornece informações sobre morfologia, diâmetro médio, avalia a polidispersão dos tamanhos de nanopartículas (GUO; TAN, 2009; MAMANI et al., 2013; SHAMELI et al., 2012). As amostras foram diluídas em $\mathrm{H}_{2} \mathrm{O}(1: 100$ e 1:1000) e passaram por processos de 
centrifugação e ultrassom, visando obter uma maior homogeneidade e desagregação, depois elas foram colocadas em uma tela e recobertas por uma camada polimérica (Formvar). Após o período de secagem da camada polimérica, as amostras foram levadas para análise em um MET.

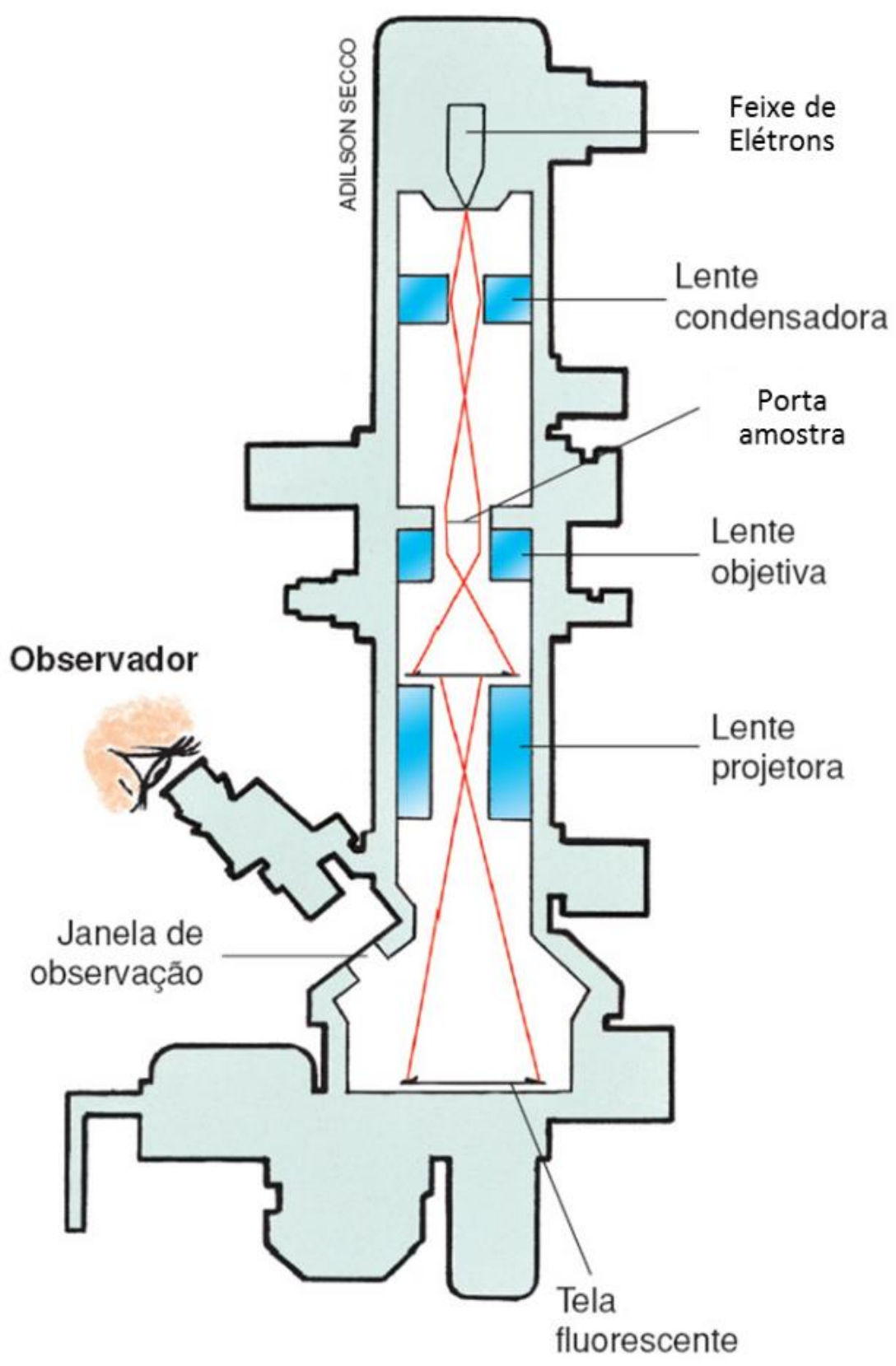

Figura 2.6 - Esquema de funcionamento de um Microscópio Eletrônico de Transmissão (FARINA, 2010). 


\section{FEIXE INCIDENTE}

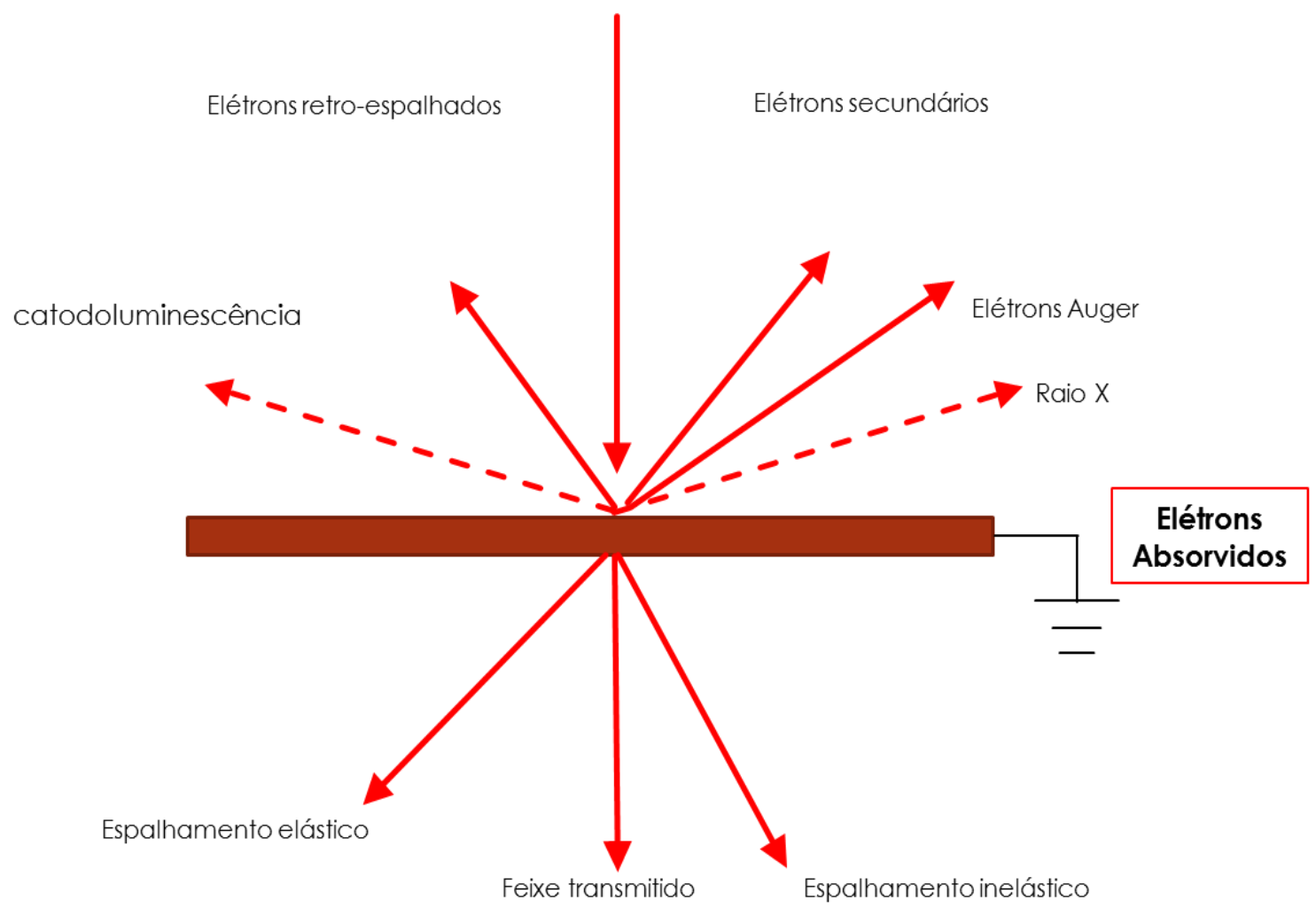

Figura 2.7 - Representação esquemática dos tipos de interação do feixe eletrônico com a amostra no microscópio de transmissão.

O diâmetro das nanopartículas e sua dispersão podem ser obtidas através da imagem produzida pelo MET. Utilizando o software específico (Image Tools) é possível fazer a contagem das nanopartículas, construindo assim um histograma, relacionando a polidispersão dos diâmetros das nanoestruturas. O perfil das amostras nanopartículadas estudadas podem ser encontrados, ajustando o histograma com uma função log-normal $P(D)$ descrita por PAYET et al., 1998 e dada pela Equação 2.6.

$$
P(D)=\frac{1}{D \sigma \sqrt{2 \pi}} e^{\frac{-\ln ^{2}\left(\frac{D}{D_{M E T}}\right)}{2 \sigma^{2}}}
$$

onde $D$ é o diâmetro da partícula, $D_{M E T}$ é o diâmetro médio obtido pelo MET e $\sigma$ é o desvio padrão do diâmetro obtido experimentalmente. 
As medidas de MET foram obtidas em um microscópio eletrônico modelo JEOL 100 CXII do Laboratório de Microscopia Eletrônica de Transmissão do Instituto de Biologia da Universidade de Brasília - UnB.

\subsection{3 - Microscopia Eletrônica de Varredura (MEV)}

A técnica de Microscopia Eletrônica de Varredura funciona de modo similar ao MET, onde um feixe de elétrons é focalizado por um conjunto de lentes e atinge a amostra. $\mathrm{O}$ sistema é preparado de forma que o feixe que incide na amostra não a ultrapasse e somente percorra sua superfície, sendo detectada por diversos sensores. Essa técnica pode gerar importantes informações a respeito da morfologia, topografia e composição elementar dos materiais investigados (FILHO, 2012).

As micrografias das nanopartículas de maguemita e do nanocompósito magnetopolimérico foram feitas no Laboratório de Microscopias Eletrônicas do Instituto de Biologia da Universidade de Brasília - UnB. As amostras foram diluídas em diferentes concentração (1:100 e 1:1000) e recobertas por uma fina camada de um material condutor, essa fina camada irá facilitar a movimentação dos elétrons na superfície da amostra.

\subsection{4 - Espectroscopias}

As espectroscopias são importantes ferramentas na determinação de grupos funcionais ligados as moléculas e átomos, por isso são muito utilizadas para caracterização de compostos orgânicos (DYER, 1965; SARAVANAN; BALACHANDRAN, 2014).

As técnicas de espectroscopias estão relacionadas com o comportamento dos átomos submetidos a um feixe de ondas eletromagnéticas, esse comportamento pode ser dividido entre 
os efeitos de emissão e absorção. Basicamente as espectroscopias estão relacionadas com a emissão e absorção causada por elétrons em diferentes camadas da eletrosfera do átomo. Esses conceitos estão relacionados com a excitação dos átomos por diferentes meios (aquecimento, energia absorvida e etc),

As técnicas de espectroscopia utilizam o mesmo princípio. A dualidade onda-partícula da luz foi divulgada em trabalhos de Einstein, Planck e Bohr e descreve que um feixe pode se comportar tanto como uma onda como uma partícula, sendo assim sua energia pode ser descrita pela Equação 2.7 (STUART, 2004).

$$
E_{f}=h v \text {, }
$$

onde $h$ é a constante de Planck e $v$ é a frequência.

Ao atingir uma molécula o feixe de luz pode ser espalhado, mudando assim sua direção, ou absorvido pela molécula o que ocasionará a excitação de seus elétrons. Para que isso ocorra a frequência desse feixe deve ser equivalente a gap da energia de transição entre o estado fundamental e o de excitação dos elétrons (Equação 2.8).

$$
v=\frac{E_{1}-E_{0}}{h} .
$$

A molécula em seu estado excitado pode apresentar determinados níveis de energia, estes níveis estão associados a distribuição da nuvem eletrônica dos átomos que formam a molécula, por isso são chamados de níveis eletrônicos de energia, com a excitação a molécula pode apresentar níveis de vibração (estiramento simétrico e assimétrico das ligações do composto) e rotacionais característicos do composto orgânico (DYER, 1965). 


\subsubsection{1 - Espectroscopia de Absorção (UV-VIS)}

A espectroscopia de absorção no Ultravioleta e Visível é utilizada na identificação de grupos funcionais de moléculas ligadas a compostos orgânicos, além de estipular a concentração desses compostos em meio solvente.

O espectro eletromagnético opera na região do ultravioleta e compreende a faixa de 200 a $400 \mathrm{~nm}$ a região do visível que está entre 400 a $800 \mathrm{~nm}$. As energias relacionadas com essas bandas do espectro estão associadas à diferença entre estados eletrônicos de muitas moléculas de uma estrutura. De posse dessa informação é possível obter o detalhamento sobre os tipos de ligações que existem na amostra que está sendo estudada (DYER, 1965). Os Espectrofotômetros no UV-VIS normalmente geram espectros de absorbância, transmitância e energia em função do comprimento de onda.

A absorção no UV-VIS depende da concentração das amostras dissolvidas em um meio e é definida pela lei de Lambert-Beer, que dá a relação entre a intensidade da luz incidida na solução, e a intensidade da luz captada pelo detector após passar pela solução (Equação 2.9).

$$
A=\log \frac{I_{0}}{I}=\varepsilon c l
$$

onde $A$ é a absorbância, $\varepsilon$ é a absorvidade molecular ou coeficiente de extinção, $c$ é $a$ concentração do material absorvedor, $l$ é a espessura da amostra no qual a luz passa. Como mostra a Figura 2.8, os espectrofotômetros são formados normalmente por: fontes de radiação, monocromador, recipientes para conter a amostra (normalmente uma cubeta de quartzo), detectores e indicadores de sinal. 


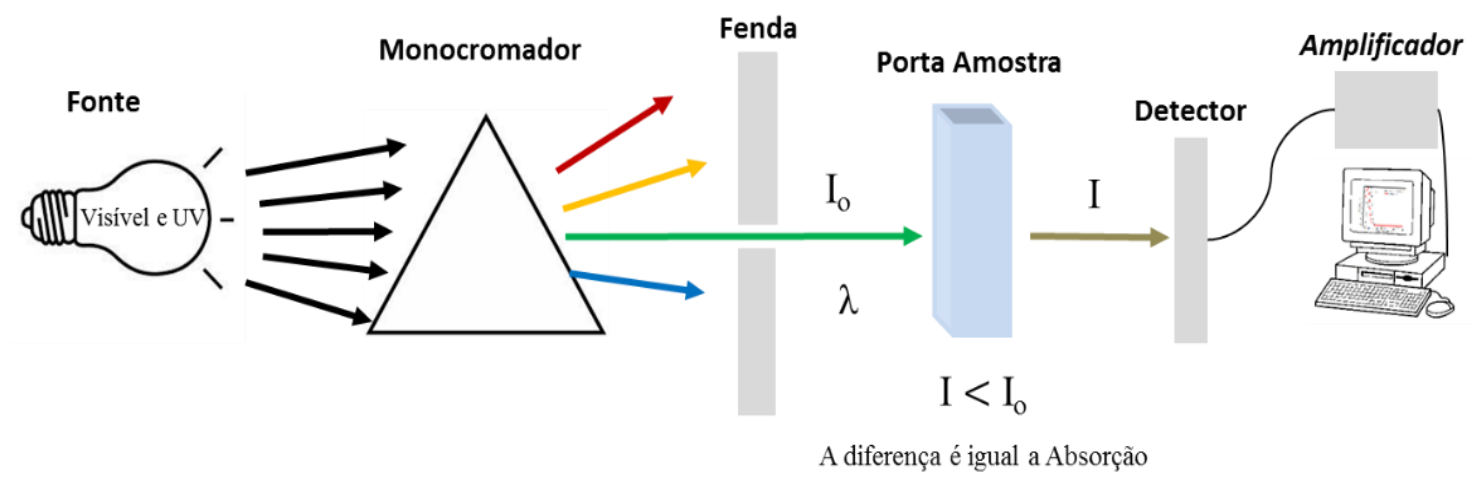

Figura 2.8- Esquema de funcionamento de Espectrômetro no UV-Vis.

Utilizando tratamento matemático adequado também é possível relacionar os picos de absorção obtidos por essa técnica com a população de elétrons excitados e seus respectivos níveis de energia. Para isso utiliza-se uma distribuição Boltzman, onde pode-se relacionar as áreas dos picos de maior intensidade com a variação dos níveis de energia dos elétrons ao serem excitados, ou seja, a Energia estado qualquer $\left(E_{n}\right)$ é proporcional a população de elétrons excitados nesse estado $\left(\mathrm{N}_{\mathrm{n}}\right)$. Desta forma, a razão entre a população de elétrons no estado de menor energia com os de maior energia pode ser representada pela Equação 2.10.

$$
\frac{N_{1}}{N_{2}}=e^{\frac{-\left(E_{1}-E_{2}\right)}{K T}}
$$

onde $K$ é a constante de Boltzman $\left(\mathrm{m}^{2} \mathrm{~kg} \mathrm{~s}^{-2} \mathrm{~K}^{-1}\right)$ e T é a temperatura (K).

Para este trabalho utilizou-se o Espectrofotômetro no UV-VIS, marca: Nova, modelo: 2102 UVPC, localizado nas dependências do Laboratório de Nanomateriais e Nanobiomagnetismo da Fundação Universidade Federal de Rondônia - UNIR. Devido à alta sensibilidade do equipamento, as amostras de nanopartículas de maguemita e do nanocompósito magneto-polimérico foram diluídas a 3\%, 5\%, e 10\% em água destilada e deionizada. 


\subsubsection{2 - Espectroscopia no Infravermelho por Transformada de Fourier (FTIR)}

A Espectroscopia no Infravermelho por transformada de Fourier é uma ótima técnica para determinar grupos funcionais existentes em compostos orgânicos. A técnica está relacionada com as frequências de vibrações entre os átomos das moléculas ao serem excitadas por um feixe luminoso nas bandas do infravermelho, que vão de 50 à $12500 \mathrm{~cm}^{-1}$ ou 800 à 200000 nm (DYER, 1965; SILVERSTEIN; WEBSTER, 2006).

Ao serem excitadas as moléculas podem apresentar até dois modos vibracionais: estiramento e flexão, além do mais, esses dois modos podem apresentar seis tipos de vibrações distintas, as vibrações de estiramento podem ser simétricas ou assimétricas, já as do tipo flexão podem apresentar modos vibracionais conhecidos como: tesoura, torção, balanço ou rotação (DYER, 1965). A intensidade das bandas, gerados no espectro, podem ser expressas em transmitância (T) ou absorbância (A). A transmitância é a razão entre a energia radiante transmitida por uma amostra e a energia radiante que nela incide. A absorbância é o logaritmo, do recíproco da transmitância (Equação 2.11).

$$
A=\log \left(\frac{1}{T}\right)
$$

Como mostra a Figura 2.9, os espectrofotômetros de infravermelho por transformada de Fourier são formados por fontes de radiação no IR, que ao passar por um interferômetro gera dois feixes luminosos que incidem sobre a amostra e captados por um detector gerando assim um interferograma. A conversão do interferograma para espectro é conseguida pelo tratamento matemático utilizando as transformadas de Fourier. 
Para este trabalho a técnica de FTIR foi utilizada na caracterização do óleo "in natura" da C. guianensis e do polímero sintetizado, afim de determinar os grupos moleculares existentes nas amostras.

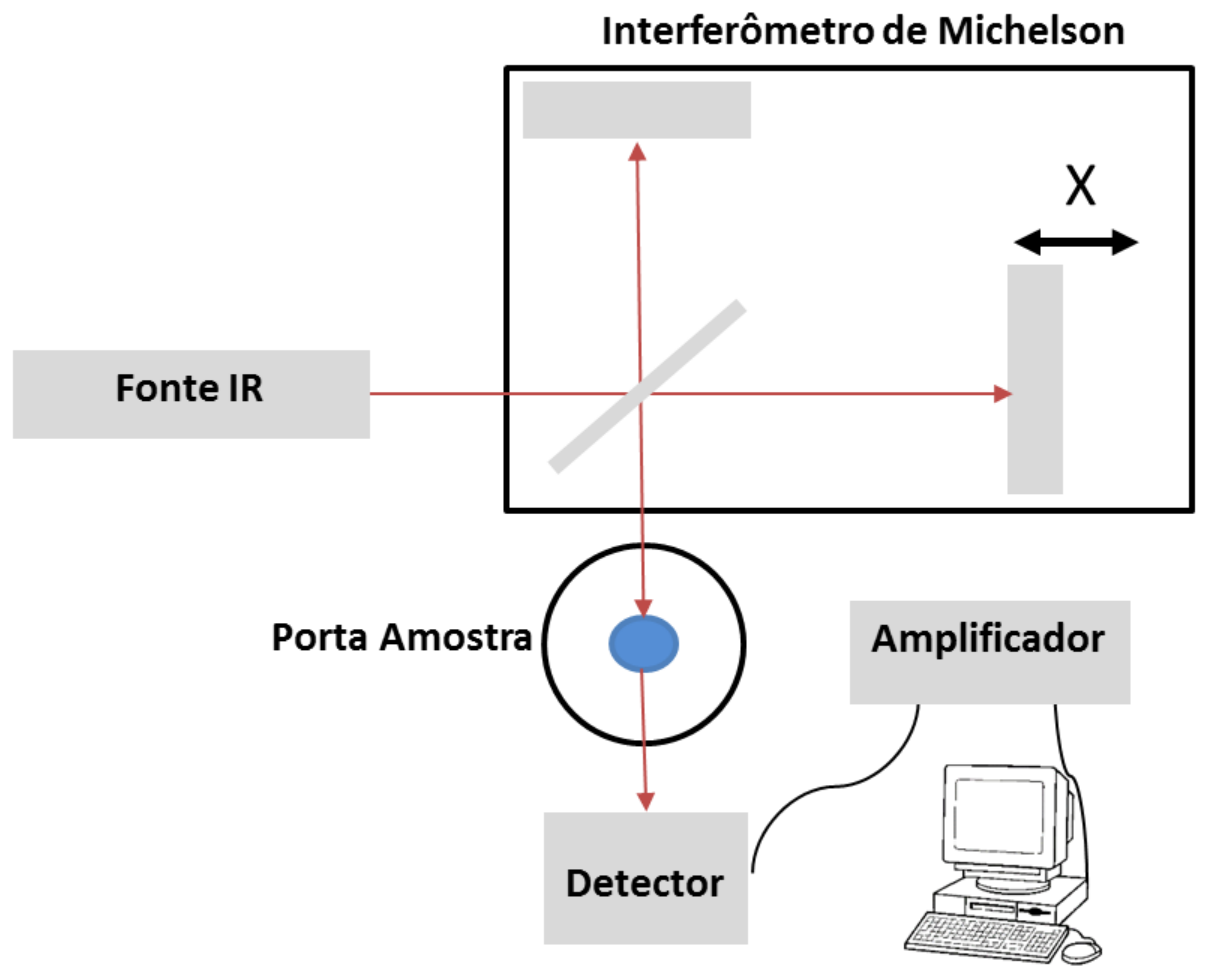

Figura 2.9 - Esquema de construção de um Espectrômetro no infravermelho por transformada de Fourier.

O Espectroscopia no Infravermelho por transformada de Fourier utilizado nesta pesquisa é da marca SHIMADZU e opera em uma banda que vai de $400 \mathrm{~cm}^{-1}$ até $4000 \mathrm{~cm}^{-1}$, ele se localiza no Laboratório de Química Analítica da Fundação Universidade Federal de Rondônia - UNIR.

\subsubsection{3 - Espectroscopia Fotoacústica (EF)}

A técnica de espectroscopia por fotoacústica se caracteriza pela obtenção de espectros de absorção óptica através de um sinal acústico. O arranjo experimental, descrito na Figura 
2.10, consiste em uma fonte de luz, um modulador de sinal ajustável (chopper), uma célula fotoacústica. A fonte de luz passa por um monocromador, depois é modulada pelo chopper e por fim incide sobre a amostra, esse processo gera um sinal fotoacústico que é captado por um sensor dentro de uma célula fotoacústica, nesta célula existe um microfone ultrassensível que é utilizado para detectar os sinais acústicos resultantes da desexcitação dos elétrons.

Ao passar por um amplificador o sinal de EF revelará importantes informações sobre a estrutura da amostra (MORAIS et al., 2003; RODRIGUEZ, A F R; JACOBSON; et al., 2013). As medidas podem ser realizadas no ultravioleta, visível e no infravermelho $10.000 \mathrm{~cm}^{-1}$ a $\left.3000 \mathrm{~cm}^{-1}\right)$.

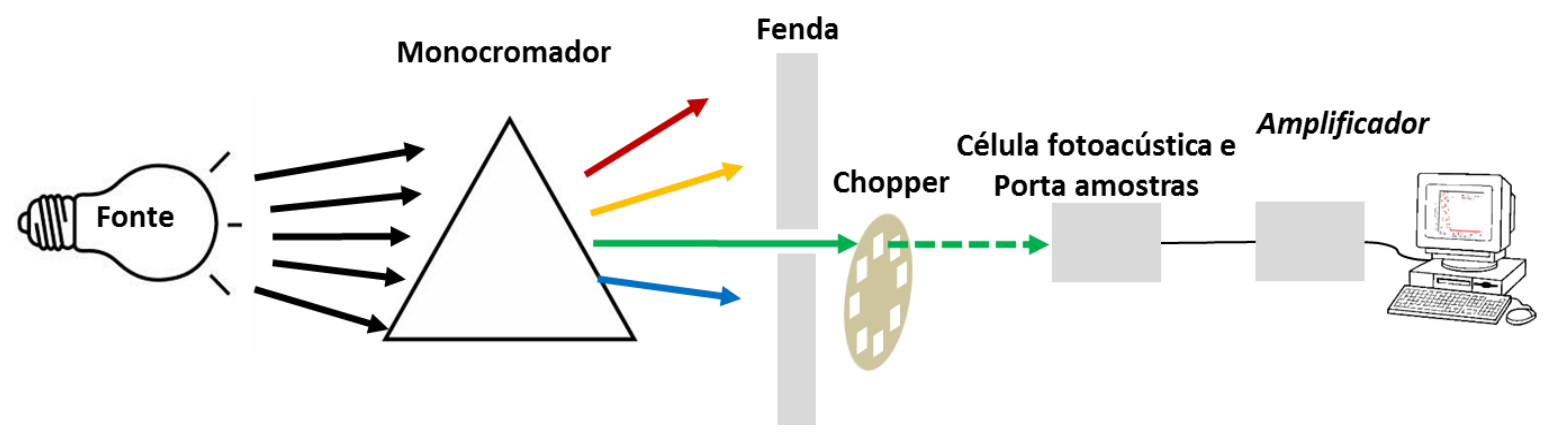

Figura 2.10 - Esquema com o arranjo experimental da técnica de espectroscopia por Fotoacústica.

Para o estudo das nanopartículas, estão associadas as bandas L, S e C. A banda L, referente a região de 800 à 500 nm está associada com a cobertura das nanopartículas, a banda $\mathrm{S}$, referente a região de $500 \mathrm{~nm}$, está associado com as propriedades moleculares nas camadas da superfície das nanopartículas e na banda C, entre 300 e 500 nm, temos informações sobre a absorção referente ao espectro luminoso nos núcleos nanopartículados (MORAIS et al., 2003). Para este estudo utilizou-se o Espectrofotômetro Fotoacústico que opera em uma banda que vai de $270 \mathrm{~nm}$ até $700 \mathrm{~nm}$ e está localizado no Instituto de Física da Universidade de Brasília UNB. 


\subsubsection{4 - Espectroscopia por Energia Dispersiva de Raios X (EDX)}

A Espectroscopia por Energia Dispersiva de Raios X é uma importante técnica para o estudo microscópico elementar dos materiais. Quando o feixe no comprimento de raios X incide sobre a amostra, os elétrons mais internos dos átomos e os íons constituintes são excitados e ejetados da eletrosfera, gerando assim uma vacância na camada eletrônica, para resolver esse problema os elétrons que estão nas camadas de maior energia são obrigados a saltar para o sitio vago, nesse processo o mesmo libera energia radiante que são captadas por um detector (Figura 2.11).

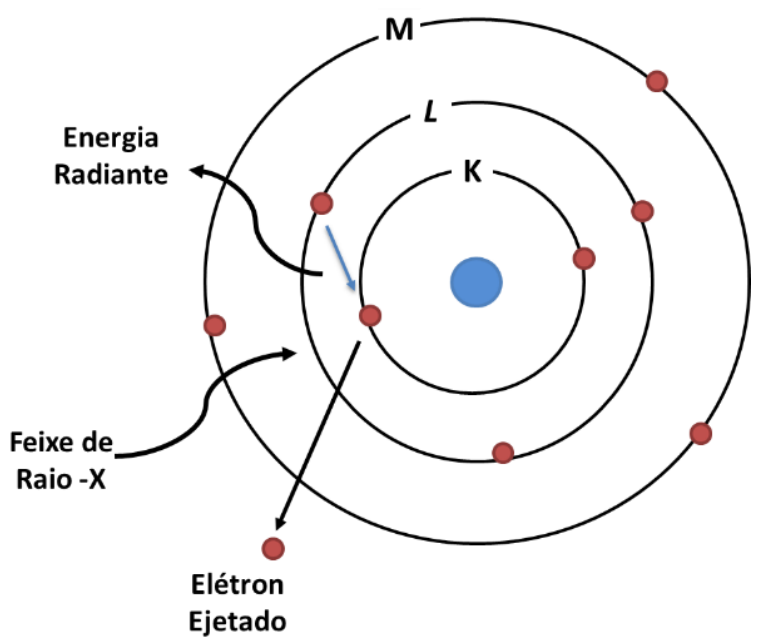

Figura 2.11 - Diagrama esquematizado do princípio da Espectroscopia por Energia Dispersiva no Raios X.

Sabendo que os elétron de um determinado átomo possuem distintos níveis de Energia é possível utilizar o EDX para determinar qual a composição elementar de uma amostra de forma qualitativa e quantitativa, desde que seu número atômico $(Z)$ seja maior que 10 (BORISENKO; OSSICINI, 2007). O EDX é utilizado, neste trabalho, para avaliar o processo de síntese do polímero e do nanocompósito.

Para esta pesquisa utilizou-se o sistema o espectrômetro de fluorescência por energia dispersiva da marca Xenemetrix's X-Calibur localizado nas dependências do Laboratório de Nanomateriais e Nanobiomagnetismo da Fundação Universidade Federal de Rondônia - UNIR. 
A Tabela 2.2 relaciona as amostras sintetizadas com as técnicas que foram utilizadas para a sua investigação.

Tabela 2.2 - Relação entre as amostras sintetizadas com as técnicas utilizadas para sua investigação.

\begin{tabular}{c|ccccccc}
\hline Amostras & DRX & MET & MEV & EDX & FTIR & UV-VIS & EF \\
\hline NPs & $\mathbf{X}$ & $\mathbf{X}$ & $\mathbf{X}$ & & & $\mathbf{X}$ & $\mathbf{X}$ \\
\hline OCA & & & & $\mathbf{X}$ & $\mathbf{X}$ & $\mathbf{X}$ & \\
\hline PCA & & & & $\mathbf{X}$ & $\mathbf{X}$ & $\mathbf{X}$ & $\mathbf{X}$ \\
\hline NMC & & $\mathbf{X}$ & $\mathbf{X}$ & $\mathbf{X}$ & & $\mathbf{X}$ & $\mathbf{X}$ \\
\hline
\end{tabular}

Com o embasamento necessário para essa pesquisa todo elencado, o próximo capítulo trata exclusivamente dos resultados obtidos e as discussões sobre a síntese e caracterização das amostras, previamente descritas neste capítulo. 


\section{CAPÍTULO 3 - RESULTADOS E DisCUSSÕES}

Neste capítulo serão apresentados os resultados obtidos neste trabalho. O capítulo 3 está dividido em dois subtópicos: caracterização da nanopartículas de $\gamma-\mathrm{Fe}_{2} \mathrm{O}_{3}$ e do nanocompósito magneto-polimérico à base de no óleo extraído da semente da $C$. guianensis. $\quad$ Para a caracterização primária, foram analisadas as propriedades das $\gamma-\mathrm{Fe}_{2} \mathrm{O}_{3}$ como: estrutura, cristalinidade, tamanho e morfologia. N Na caracterização dos nanocompósitos magnetopolimérico, as técnicas, já descritas anteriormente, foram utilizadas para: determinar grupos funcionais relacionados as ligações eletrônicas, verificar formações poliméricas e avaliar a interações entre o polímero e as nanopartículas.

\section{1 - CARACTERIZAÇÃO DAS NANOPARTÍCULAS DE $\gamma-\mathrm{Fe}_{2} \mathrm{O}_{3}$}

Para a caracterização das nanopartículas de $\gamma-\mathrm{Fe}_{2} \mathrm{O}_{3}$, utiliza-se as técnicas de Difratometria de Raios X, Microscopia Eletrônica de Transmissão e Microscopia Eletrônica de Varredura. 


\subsection{1 - Medidas de Difratometria de Raios X}

O difratograma das NPs apresentou picos referentes a estrutura cristalina, que é descrita como do tipo espinélio (NAMANGA et al, 2013; SANTOS et al, 2012; SARTORATO et al, 2006), das nanopartículas de magnetita ou maguemita (Figura 3.1).

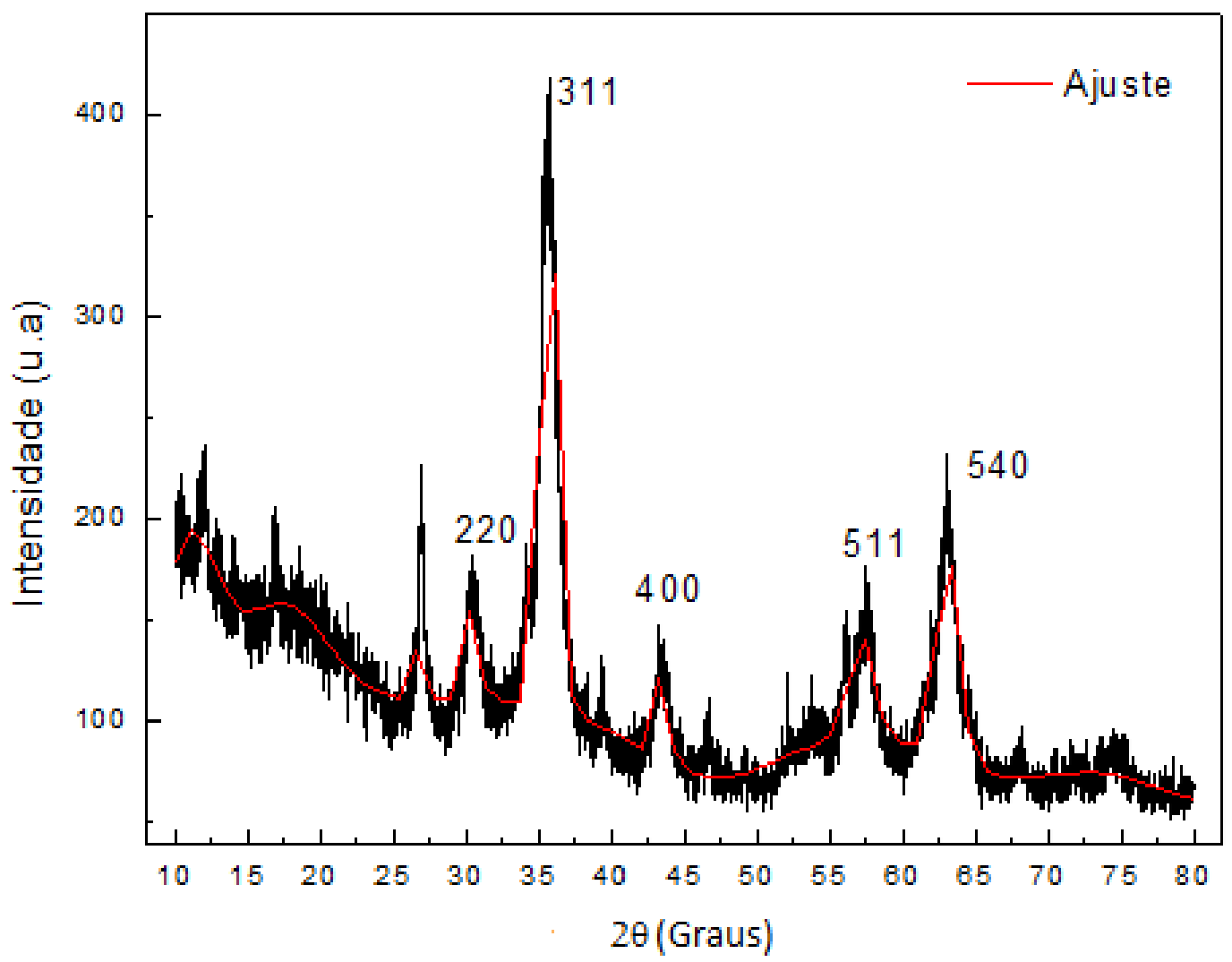

Figura 3.1 - Difratometria de Raios $\mathrm{X}$ das nanopartículas de $\gamma-\mathrm{Fe}_{2} \mathrm{O}_{3}$ sintetizadas.

Tabela 3.1 - Comparativo dos picos experimentais obtidos pela Difração de Raio-X, das nanopartículas de $\gamma-\mathrm{Fe}_{2} \mathrm{O}_{3}$ sintetizadas, com os picos tabelados pela ASTM.

Experimental

\begin{tabular}{c|c|c|c|c}
\hline hkl & Intensidade (u.a) & $\mathbf{2 \theta}$ & Intensidade (u.a) & $\mathbf{2 \theta}$ \\
220 & 22 & 30.415 & 30 & 30.122 \\
311 & 100 & 35.683 & 100 & 35.455 \\
400 & 17 & 43.423 & 20 & 43.099 \\
\hline
\end{tabular}

Os picos de reflexão relativos a coordenadas de redes bravais: 220, 311 e 400 mostram registrados pela American Society for Testing and Materials - ASTM (Tabela 3.1). Através da 
Equação de Debye-Scherrer (Equação 2.4) foi possível calcular o diâmetro médio entre os domínios cristalinos e com isso estimar o diâmetro médio das nanopartículas de $\gamma-\mathrm{Fe}_{2} \mathrm{O}_{3}$. Para este trabalho as nanopartículas apresentaram um diâmetro médio estimado em torno de $(6,9 \pm$ $0,1) \mathrm{nm}$.

Segundo LAURENT et al, (2008), o diâmetro médio das nanopartículas de magnetita ou maguemita, sintetizadas utilizando o método de coprecipitação, apresentam valores que variam entre 4,6 e 16,6 nm. Essa variação pode estar relacionada diretamente com a modulação de diversos parâmetros (temperatura, velocidade de agitação, proporção de reagentes e tempo de reação) existentes no processo de síntese.

\subsection{2 - Medidas de Microscopia Eletrônica de Transmissão}

Como foi possível observar na Figura 3.2, as nanopartículas sintetizadas apresentaram aglomeração, mesmo assim foi possível realizar uma contagem, utilizando software Image Tools, tratando os dados e obtendo um histograma (Figura 3.3). Para se fazer o ajuste do histograma utilizou-se a função log-normal modificada (Equação 2.6) determinando assim a polidispersão e o diâmetro médio das nanopartículas sintetizadas. O diâmetro médio das nanopartículas de maguemita ficou em torno de $(6,4 \pm 0,1) \mathrm{nm}$ com uma polidispersão de $(0,23$ $\pm 0,01) \mathrm{nm}$.

Ao compararmos as medidas feitas por Difratometria de Raios X com a Microscopia Eletrônica de Transmissão é possível observar que a estimativa do diâmetro médio das nanopartículas feitas por DRX apresentaram valores maiores que a estimativa feita por MET. O mesmo pode ser observado no estudo desenvolvido por SANTOS e colaboradores (2012), onde nanopartículas de $\gamma-\mathrm{Fe}_{2} \mathrm{O}_{3}$ sintetizadas através o método Massart, obtiveram diâmetros médio menores para o MET em relação ao DRX, esse fenômeno pode estar relacionado a influência de partículas maiores nas medidas do espaço interplanar dos domínios cristalinos. 


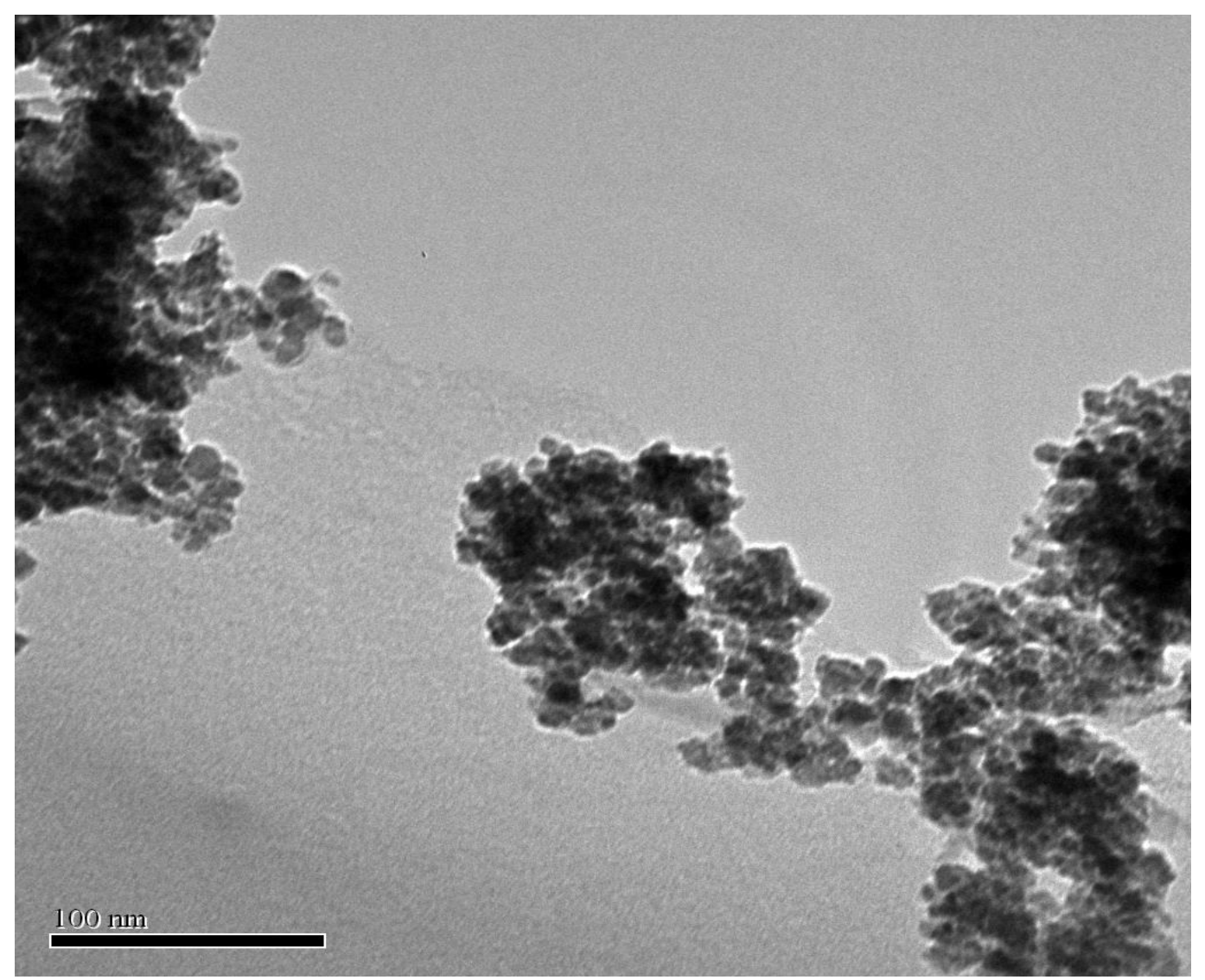

Figura 3.2 - Microscopia Eletrônica de Transmissão das nanopartículas de $\gamma-\mathrm{Fe}_{2} \mathrm{O}_{3}$ sintetizadas.

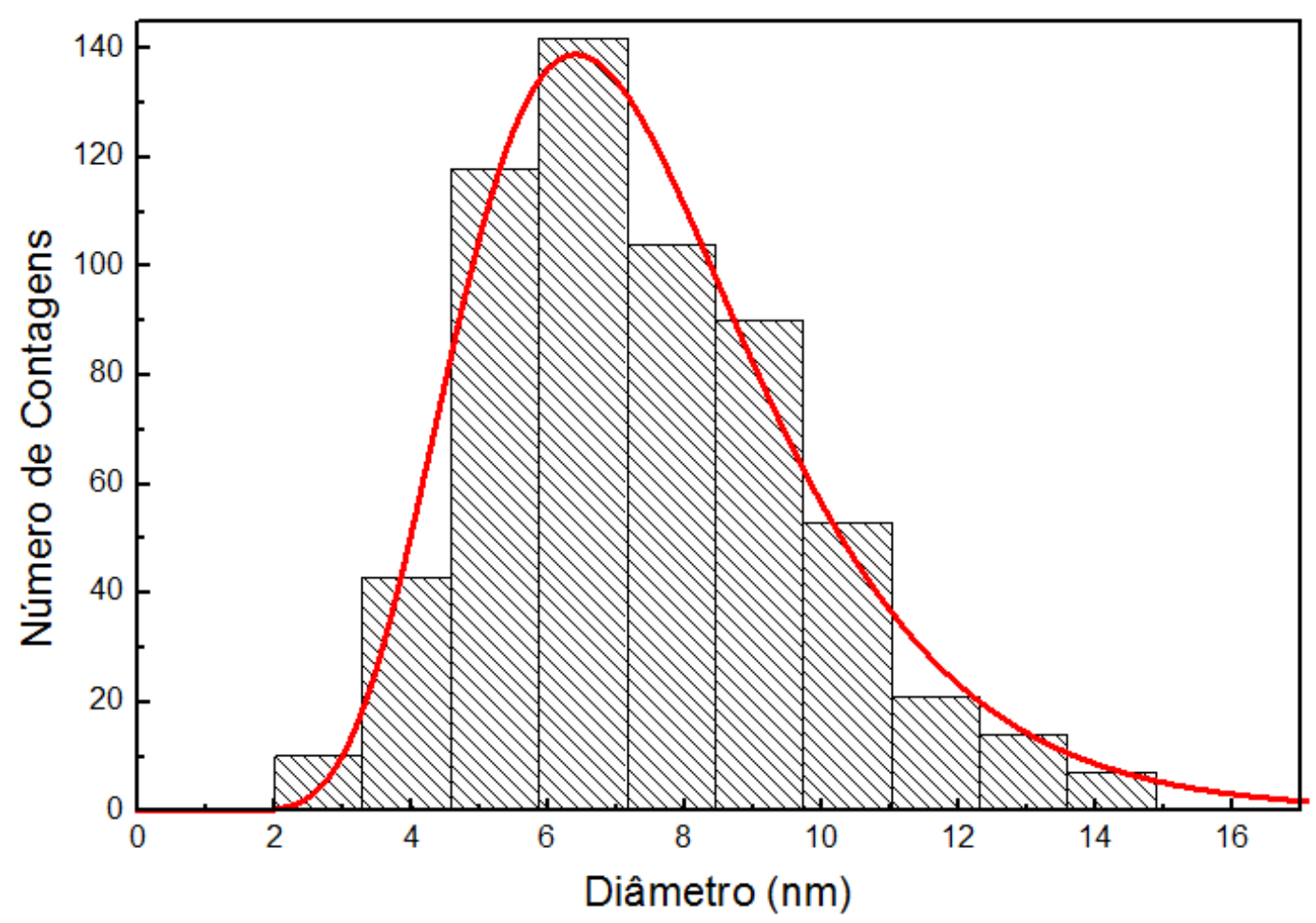

Figura 3.3 - Histograma da contagem das nanopartículas de $\gamma-\mathrm{Fe}_{2} \mathrm{O}_{3}$ sintetizadas obtidos pela Microscopia Eletrônica de Transmissão. 


\subsection{3 - Medidas de Microscopia Eletrônica de Varredura}

$\mathrm{Na}$ Figuras 3.4 temos a micrografia das amostras de $\gamma-\mathrm{Fe}_{2} \mathrm{O}_{3}$ feitas pela técnica de Microscopia Eletrônica de Varredura. As imagens indicaram que houve aglomeração das nanopartículas, possivelmente devido a uma interação magnética entre elas, ao aproximar a imagem (Figura 3.5) foi possível observar que o material sintetizado possui uma estrutura uniforme com formato aproximadamente esférico.

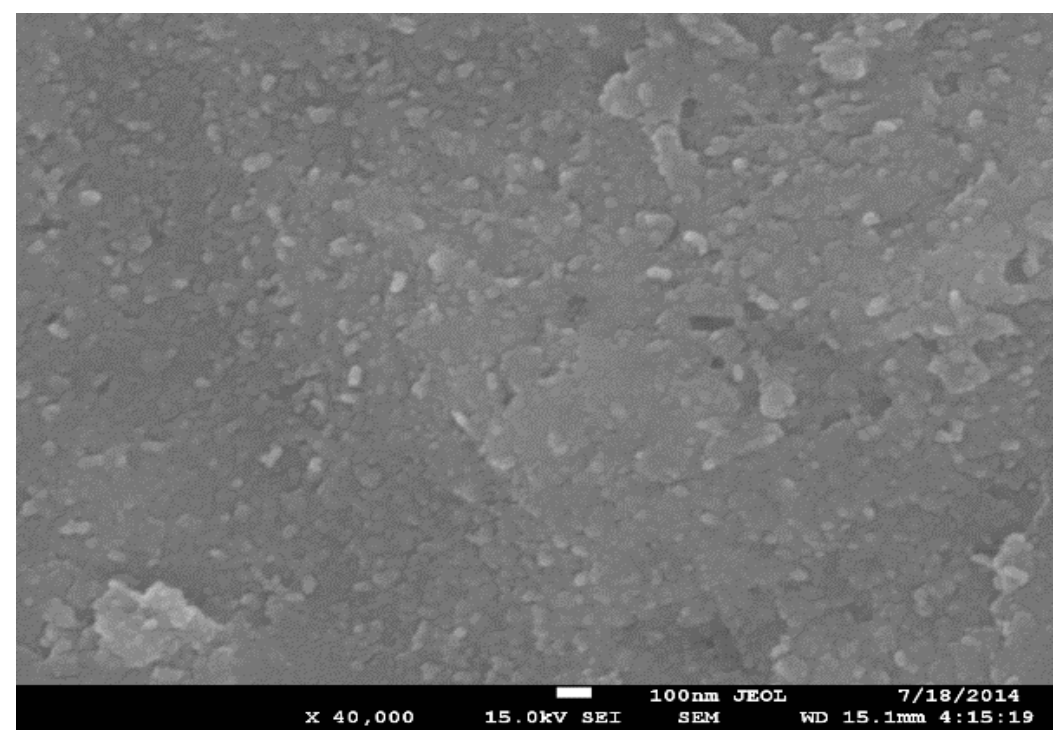

Figura 3.4 - Micrografia de Microscopia Eletrônica de Varredura das nanopartículas de $\gamma-\mathrm{Fe}_{2} \mathrm{O}_{3}$ sintetizadas, com um aumento 40.000x.

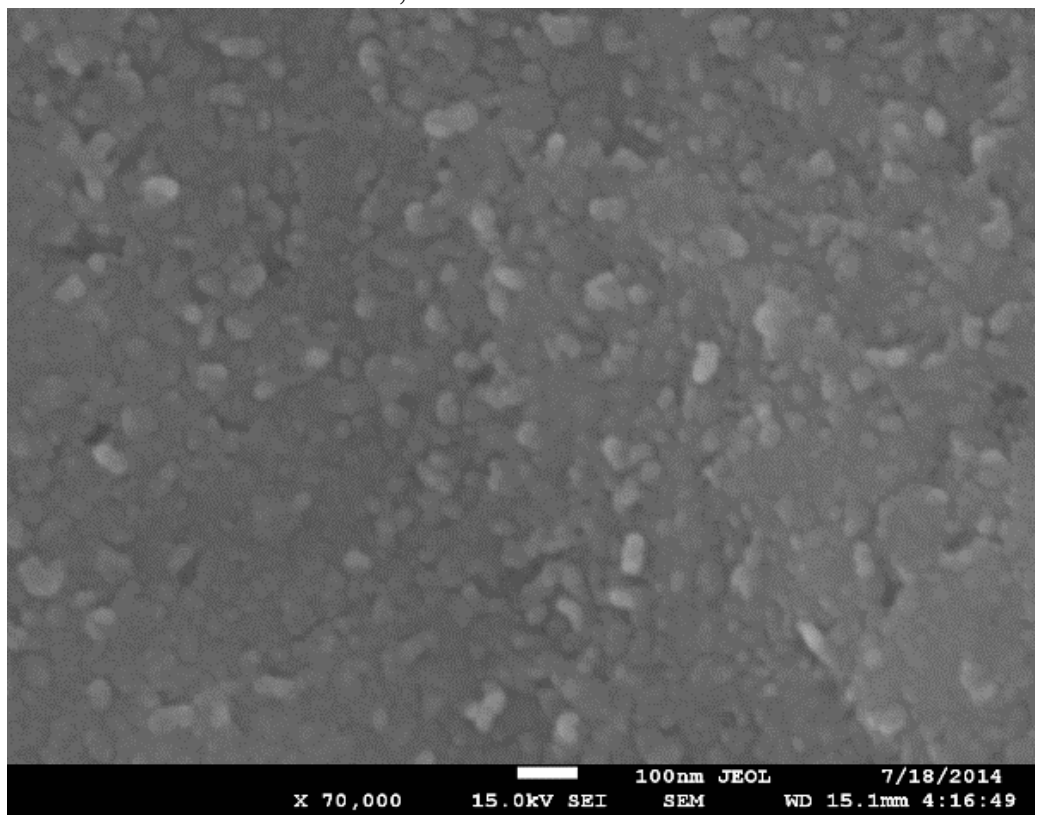

Figura 3.5 - Micrografia de Microscopia Eletrônica de Varredura das nanopartículas de $\gamma$ - $\mathrm{Fe}_{2} \mathrm{O}_{3}$ sintetizadas, com um aumento 70.000x. 


\section{2 - NANOCOMPÓSITO DE ÓLEO DE CARAPA GUIANENSIS}

Para a caracterização do nanocompósito magneto-polimérico híbrido à base dos polímeros extraídos do óleo natural, utilizam-se as técnicas de FTIR, UV-VIS, EDX, EF, MET e MEV. Com isso foi possível descrever algumas características do óleo de C. guianensis (OCA), da matriz polimérica (PCA) e avaliar a formação do nanocompósito magnetopolimérico sintetizado (NMC).

\subsection{1 - Medidas de Espectroscopia no Infravermelho por Transformada de Fourier}

Na Figura 3.6, temos o FTIR comparativo entre o óleo natural extraído da semente de C. guianensis (OCA) e a matriz polimérica extraída (PCA). Tanto o óleo natural, quanto o polímero sintetizado a partir do óleo apresentaram picos com forte intensidade, em $2918 \mathrm{~cm}^{-1} \mathrm{e}$ $2851 \mathrm{~cm}^{-1}$, que são característicos das vibrações de estiramento simétrico e assimétrico das ligações C-H. No OCA foi possível observar em $1754 \mathrm{~cm}^{-1}$ ligações $\mathrm{C}=\mathrm{O}$ relacionados a ácidos carboxílicos, ligações de ésteres C-O em $1212 \mathrm{~cm}^{-1}$ e $1167 \mathrm{~cm}^{-1}$ e em $1095 \mathrm{~cm}^{-1}$ temos a banda $O-C$-C. No PCA, o FTIR mostrou a supressão da banda $\mathrm{C}=\mathrm{O}$ em $1754 \mathrm{~cm}^{-1}$ com o aparecimento da banda O-H, em $3309 \mathrm{~cm}^{-1} \mathrm{e} 1643 \mathrm{~cm}^{-1}$. Em torno de $870 \mathrm{~cm}^{-1}$ e $1034 \mathrm{~cm}^{-1}$ o PCA apresentou bandas de vibrações assimétricas da ligação C-O dos ésteres etílicos e em $1070 \mathrm{~cm}^{-1}$ bandas de vibração características das ligações C-O de ésteres alifáticos (SILVERSTEIN; WEBSTER, 2006).

O espectro do óleo natural de C. guianensis apresenta picos característicos de óleos ricos em ácidos graxos, o surgimento das ligações C-O no PCA indicam a quebra das ligações O-H e $\mathrm{C}=\mathrm{O}$ dos ácidos que formam o óleo, ocasionado pelo reação utilizando o álcool etilenoglicol $\left(\mathrm{C}_{2} \mathrm{H}_{6} \mathrm{O}_{2}\right)$. 


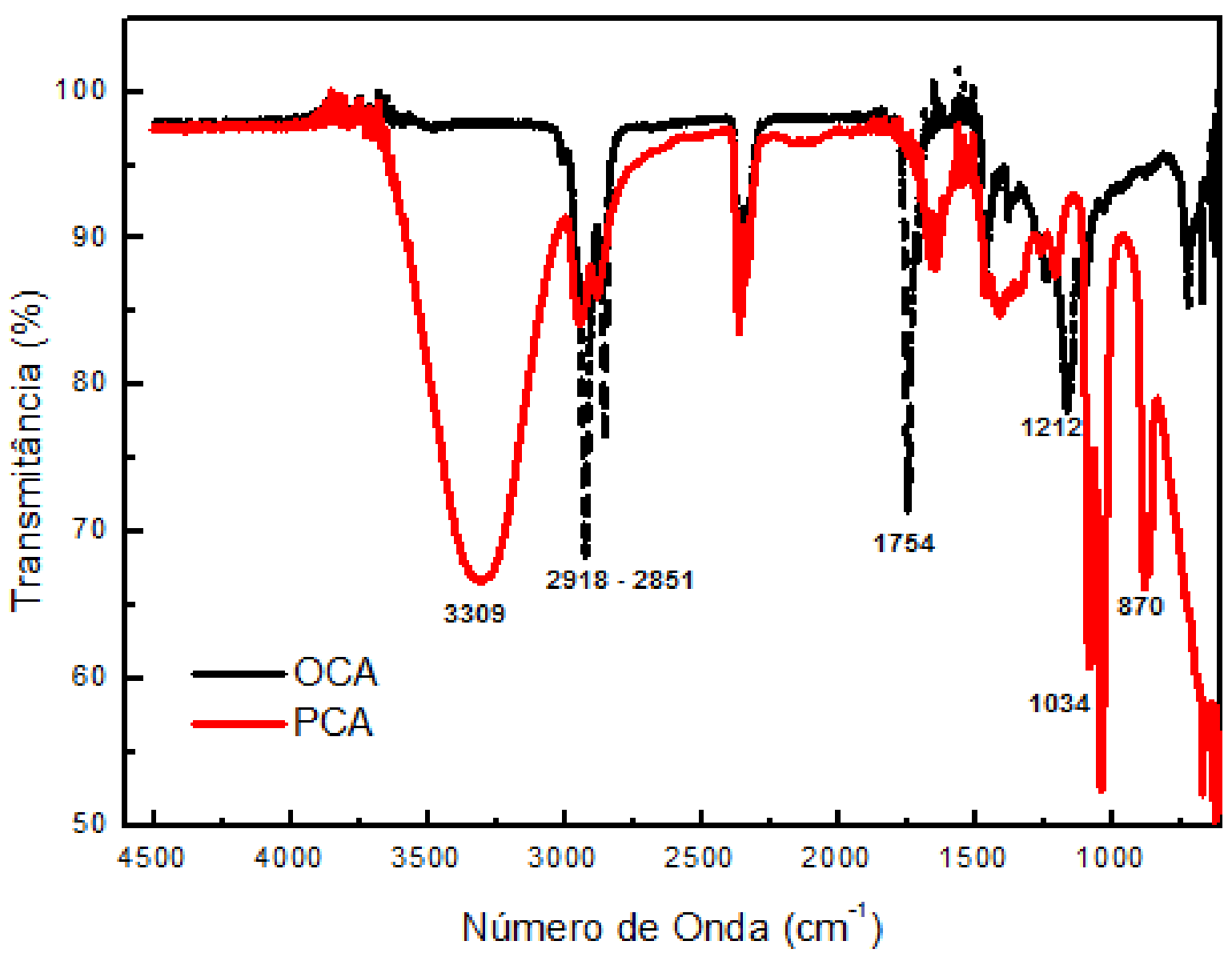

Figura 3.6 - Espectro FTIR, que relaciona a transmitância em função do Número de Onda, do polímero (PCA) e do óleo extraído da semente da Carapa guianensis (OCA).

O surgimento de ésteres na estrutura molecular do polímero extraído da semente da planta $C$. guianensis pode indicar que houve a polimerização do óleo natural (ROUMANET et al., 2013). Além do mais, segundo FRANCHETTI e MARCONATTO (2006) o aparecimento de bandas de vibrações características de ésteres alifáticos pode sugerir que o polímero formado é do tipo poliéster e que o mesmo pode possuir características biodegradáveis.

\subsection{2 - Medidas de Espectroscopia no UV- VIS}

Na Figura 3.7, observa-se o espectro de absorção eletrônica do óleo natural extraído da semente da C. guianensis (OCA) e do polímero sintetizado a partir o óleo natural (PCA). O OCA apresentou um pico de interação eletrônica em 317 nm com ombro em 246 nm e o PCA apresentou um pico de absorção em $236 \mathrm{~nm}$. Como as transições eletrônicas dos átomos que 
formam as moléculas são especificas (DYER, 1965) é possível indicar que o PCA se difere, estruturalmente falando, de seu predecessor (OCA).

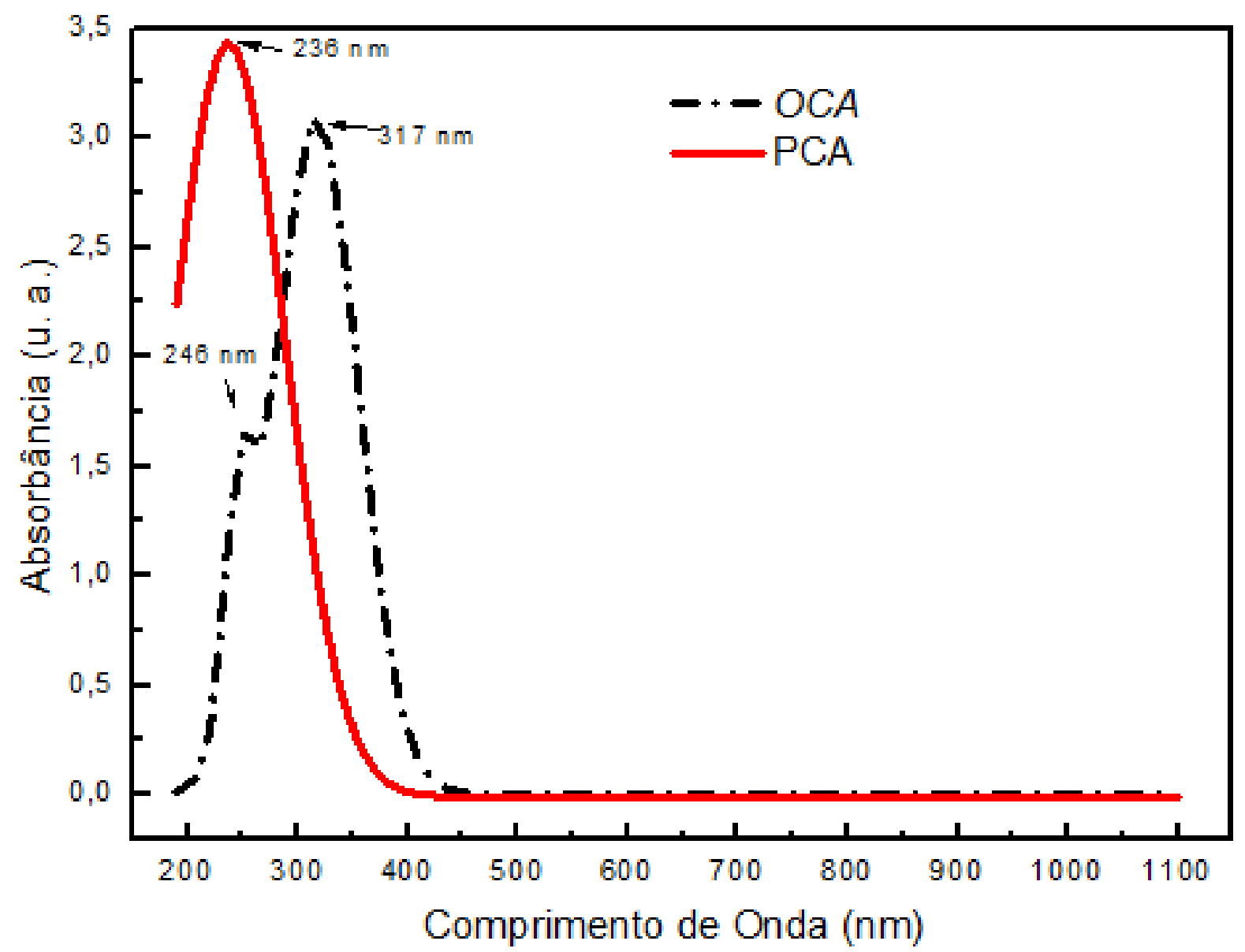

Figura 3.7 - Espectro de Absorção no UV-VIS que relaciona os picos de Absorbância (u.a) em função do Comprimento de Onda (nm), do polímero (PCA) e do óleo extraído da semente da Carapa guianensis (OCA).

A Figura 3.8 apresenta os espectros das nanopartículas de $\gamma-\mathrm{Fe}_{2} \mathrm{O}_{3}$ diluídas à $3 \%$ e $5 \%$ e o nanocompósito magneto-polimérico (NMC) à 3\%, 5\% e 10\% (conforme descrito na metodologia). Os espectros das nanopartículas com 5\% e 3\% apresentam picos $330 \mathrm{~nm}, 377$ nm e $448 \mathrm{~nm}$ com diferentes intensidades, indicando a relação direta entre o pico e absorção e a concentração de nanopartículas. O nanocompósito a 3 \% não apresenta sinal comparável com nanopartículas, já a $5 \%$ o NMC demonstra picos nas mesmas posições, além disso, surge um pico de interações em $276 \mathrm{~nm}$, provavelmente decorrente da interação ocasionadas pelo PCA. 
Para concentrações acima de $10 \%$ ocorre a saturação do sinal. As medidas indicam que o nanocompósito sintetizado apresenta uma alta concentração de nanopartículas em sua composição. Um estudo complementar é realizado utilizando os dados obtidos utilizando a técnica de UV-VIS, onde é possível estimar a população de elétrons excitados.

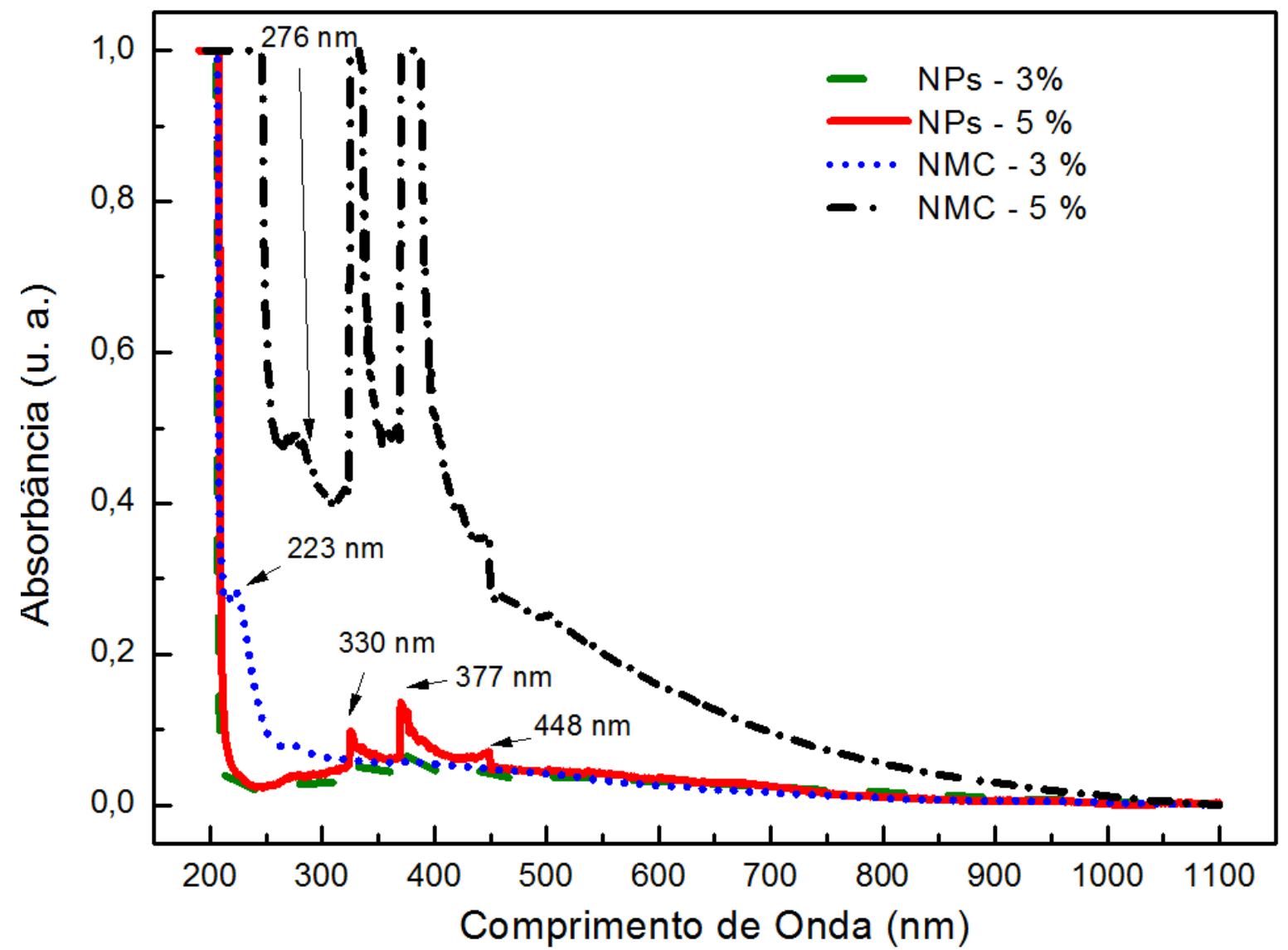

Figura 3.8 - Espectro de Absorção no UV-VIS das nanopartículas (NPs) e do nanocompósito magneto-polimérico (NMC) à base do óleo de Carapa guianensis.

A Figura 3.9 apresenta um gráfico com a população nos Nível Eletrônicos em função da Energia de Excitação, os dados foram obtidos a partir dos espectros, apresentados na Figura 3.8, das nanopartículas de maguemita (NPs) e o nanocompósito (NMC) diluídos a 5\% e tratados utilizando a distribuição de Boltzman (Equação 2.10). Com essas informações foi possível obter dois níveis eletrônicos distintos 0,45 eV e 0,60 eV. Considerando esses níveis característicos da estrutura cristalina das nanopartículas de ferro em seu estado fundamental $(0,45 \mathrm{eV})$ e excitado $(0,60 \mathrm{eV})$. Foi possível constatar que, no primeiro nível eletrônico temos o mesmo 
quantitativo de elétrons excitados tanto para o NMC quanto para o NPs, porém, quando os elétrons da estrutura cristalina da nanoestrutura de ferro saltam do estado fundamental para o estado excitado notou-se um aumento significativo na população elétrons excitados do nanocompósito (NMC) em relação as nanopartículas magnéticas de maguemita (NPs). Esses dados podem apontar que o nanocompósito magneto-polimérico possui uma alta concentração de nanopartículas magnéticas de maguemita.

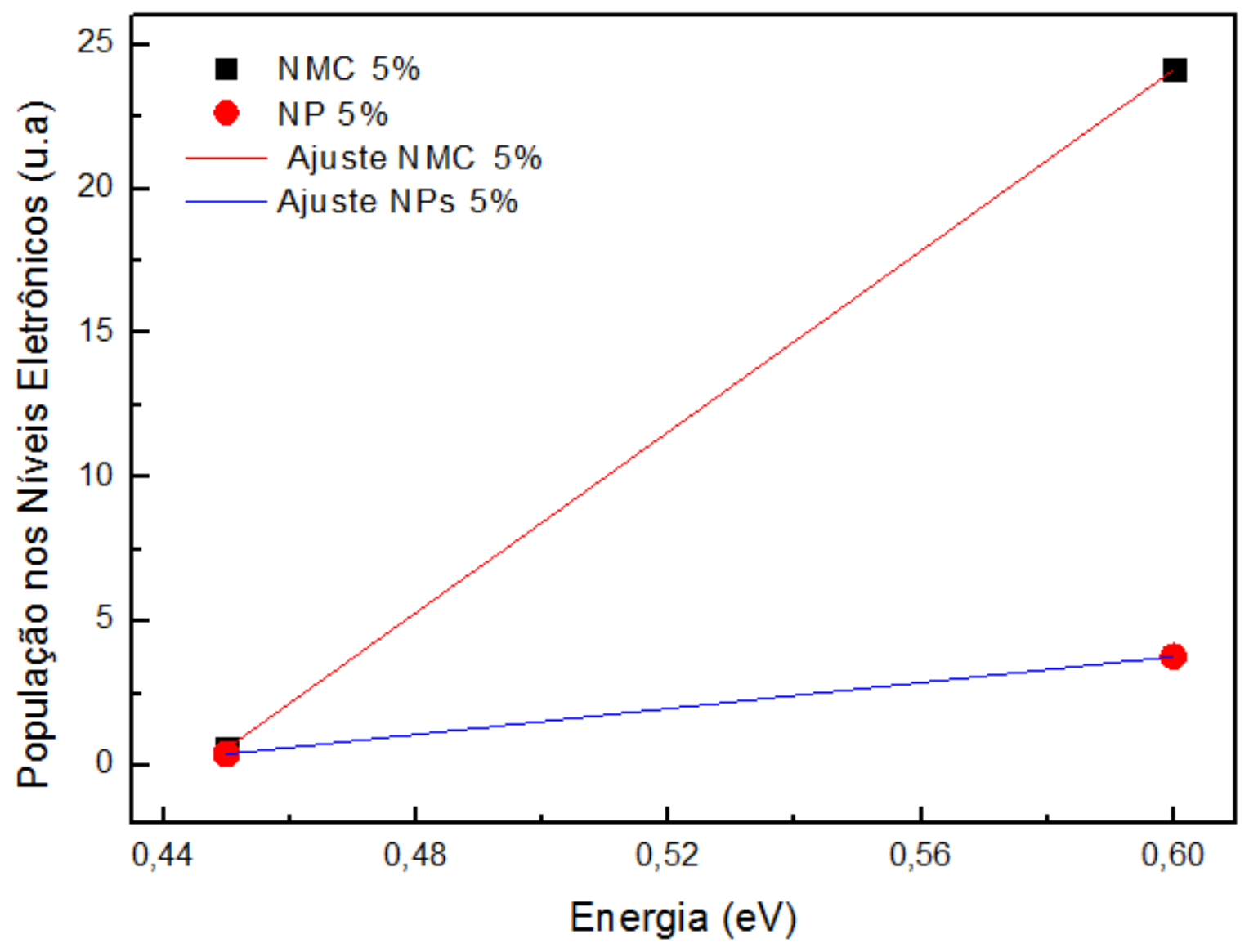

Figura 3.9 - Gráfico apresentando a população nos Níveis Eletrônicos em função da Energia para as nanopartículas (NPs) e do nanocompósito magneto-polimérico (NMC) à base do óleo de Carapa guianensis diluídos a 5\%.

A Figura 3.10 apresenta os espectros de Energia no UV-VIS das nanopartículas de $\gamma$ $\mathrm{Fe}_{2} \mathrm{O}_{3}$ diluídas (3\% e 5\%) e o nanocompósito magneto-polimérico (NMC) (3\%, 5\% e 10\%). Os espectros das nanopartículas com 5\% e 3\% apresentam interações entre $253 \mathrm{~nm}$ e $324 \mathrm{~nm}, 450$ nm e 600 nm e na região entre 940 e 1068 nm, os picos estão associados aos grupo OH e Fe-O- 
H. O PCA e o OCA apresentam interações bem definidas nas regiões entre $330 \mathrm{~nm}$ e $600 \mathrm{~nm}$, 923 nm e 1000 nm e na região que compreende entre 1000 nm e 1068 nm. Essas interações estão associadas com os grupos funcionais $\mathrm{OH}, \mathrm{C}=\mathrm{O}$ e $\mathrm{C}-\mathrm{H}$. Ao compararmos os espectros do óleo natural de $C$. guianensis com o polímero sintetizado é possível observar uma mudança no comportamento do espectro em aproximadamente $965 \mathrm{~nm}$ que está relacionado com o grupo funcional $\mathrm{C}=\mathrm{O}$, essa diminuição no pico de excitação pode ser associado a supressão das ligações de carbonilas durante a polimerização, fato esse observado na Figura 3.6. Também é possível observar o surgimento de picos de interação em 358 nm e 434 nm, comparando com o gráfico de FTIR esses picos podem estar associados ao surgimento dos grupos funcionais C-O durante a polimerização. O espectro de Energia do NMC, diluído a 3\%, apresentou picos energéticos tanto do PCA, quanto das NPs, o que sugere interações das estruturas moleculares $\mathrm{Fe}-\mathrm{O}, \mathrm{C}=\mathrm{O}, \mathrm{C}-\mathrm{O}$ e $\mathrm{O}-\mathrm{H}$.

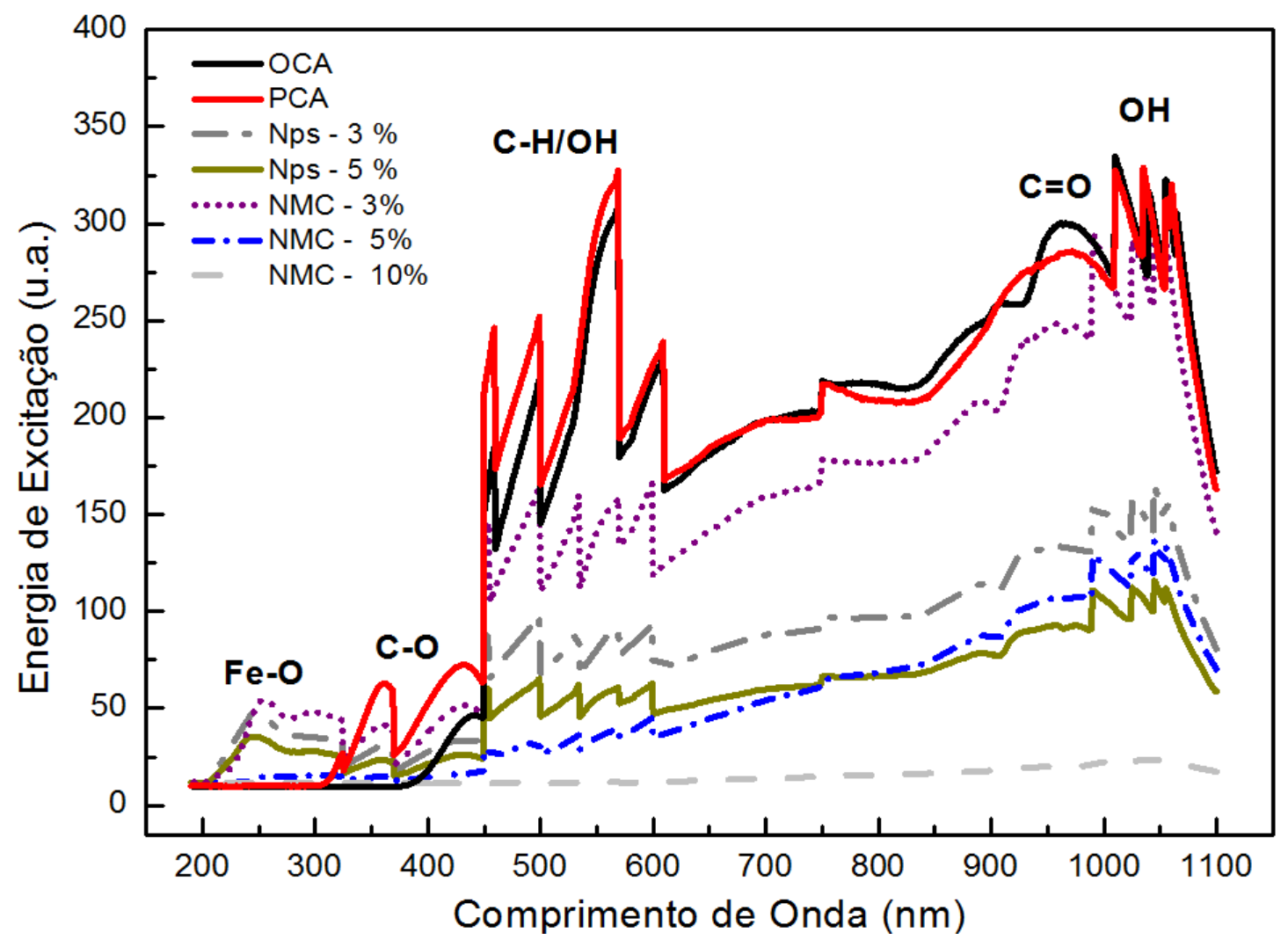

Figura 3.10 - Espectro de Energia no UV-VIS, do óleo de Carapa guianensis, do polímero sintetizado (OCA), das nanopartículas (NPs) e do nanocompósito magneto-polimérico (NMC). 
As medidas de FTIR e UV-VIS apresentaram indícios de que o polímero sintetizado a partir do óleo "in natura" de C. guianensis apresenta uma estrutura próxima à dos ácidos graxos insaturados que estão presentes no óleo "in natura”. A partir dessas analise, foi possível apontar o tipo de polímero sintetizado.

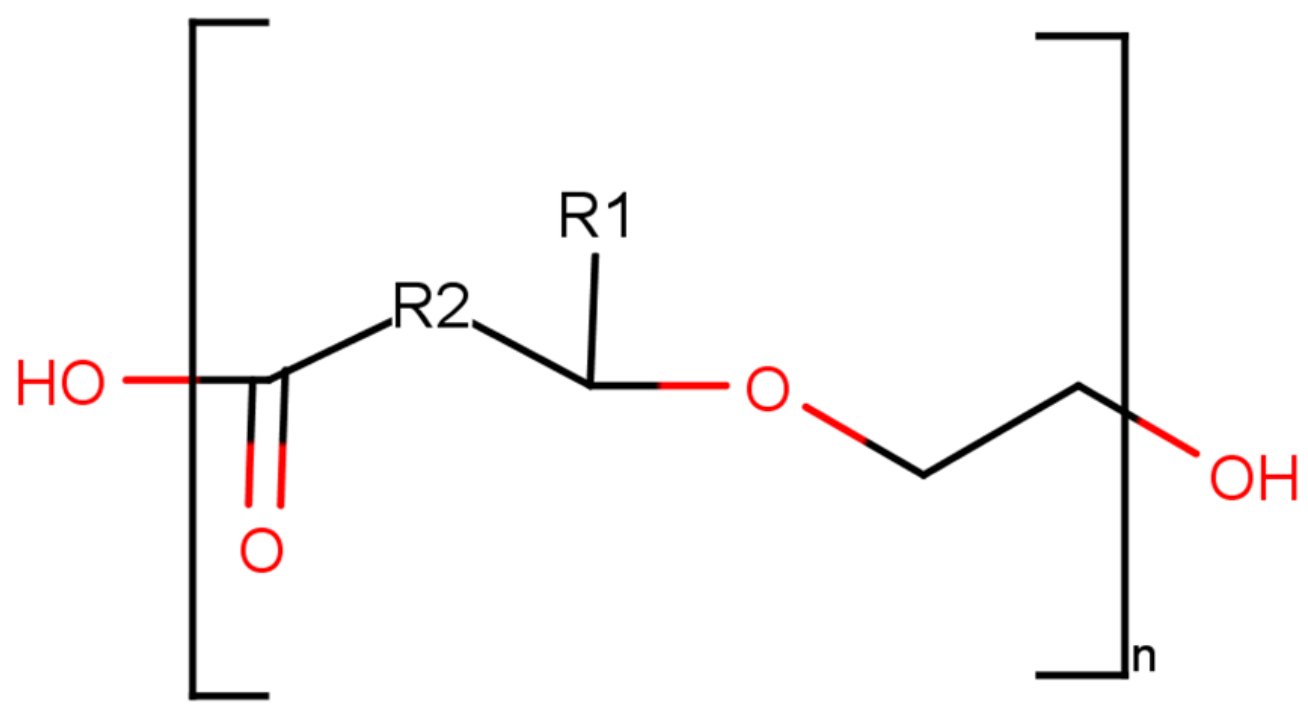

Figura 3.11 - Ilustração da estrutura molecular do polímero sintetizado a partir o óleo "in natura" da Carapa guianensis.

Na Figura 3.11 temos a estrutura da matriz polimérica sintetizada, onde R1 e R2 são as cadeias de carboxílicas características dos ácidos graxos de longa cadeia, ligadas a molécula do álcool Etilenoglicol utilizado na síntese, os dados indicam que o polímero formado é do tipo poliéster. Estruturas poliméricas similares foram descritas por MIAO et al, 2014.

\subsection{3 - Medidas de Espectroscopia por Energia Dispersiva de Raios X}

As medidas de EDX (Figura 3.12) mostram a composição elementar do OCA, PCA e o NMC, onde é possível observar que no óleo aparecem compostos como rutênio $(\mathrm{Ru})$, Ouro (Au) e cobre $(\mathrm{Cu})$. No polímero observou-se as mesmas características do óleo, porém com o surgimento de um pico relacionado com o Potássio $(\mathrm{K})$, resultante de sua síntese. O 
nanocompósito apresentou altas concentrações de Ferro $(\mathrm{Fe})$ em sua composição, porém é possível notar picos relacionados com sua matriz polimérica.

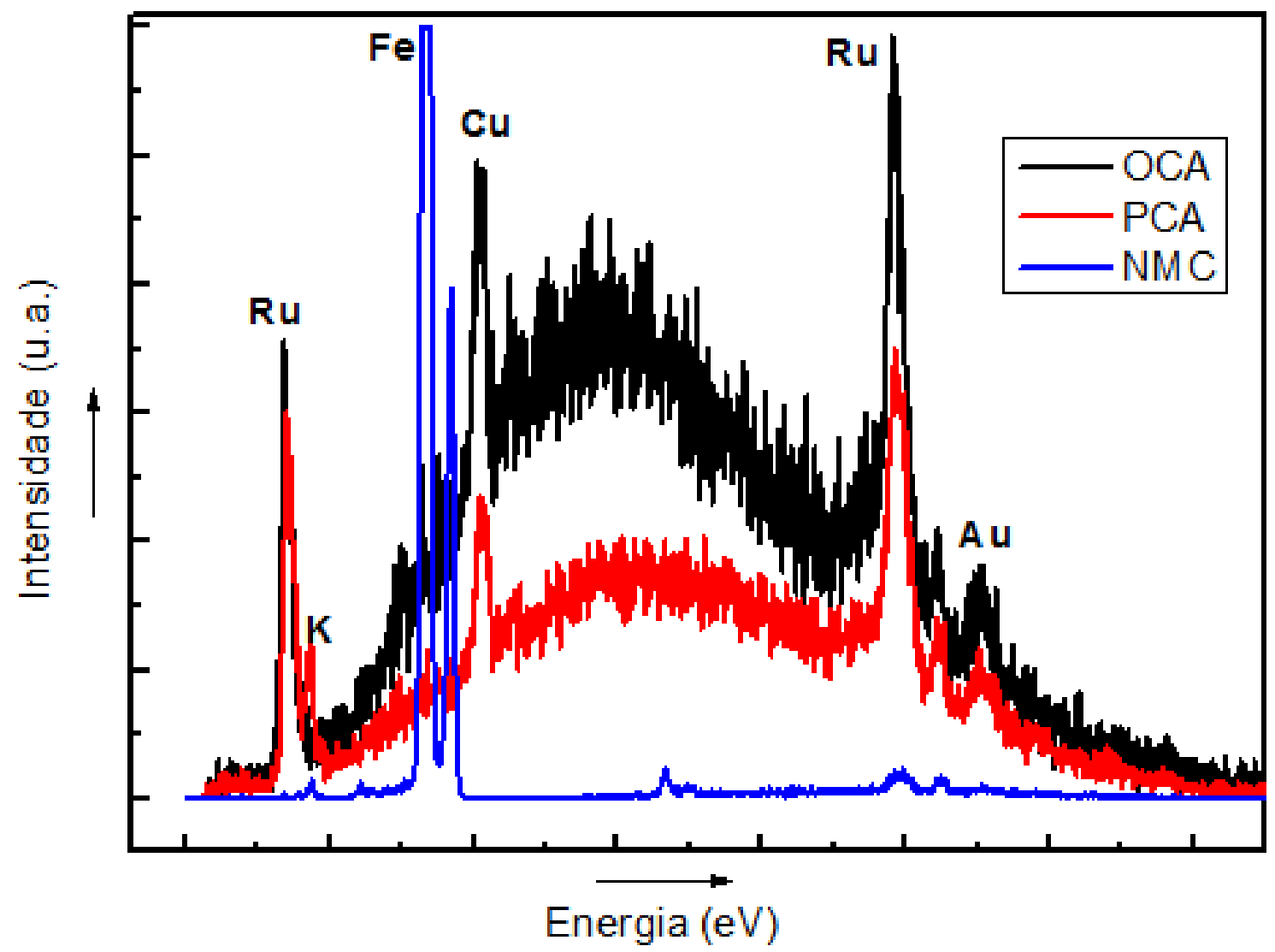

Figura 3.12 - Espectro EDX do polímero (PCA), do óleo de Carapa guianensis (OCA) e do nanocompósito magneto-polimérico (NMC),

\subsection{4 - Medidas de Espectroscopia Fotoacústica}

Utilizando a técnica de EF, foram caracterizadas as nanopartículas de maguemita, o polímero do óleo "in natura" da $C$. guianensis e o nanocompósito magneto-polimérico sintetizado. Como observado na Figura 3.12 não houve interações em torno Banda L e Banda $\mathrm{S}$ para todas as amostras, em torno da banda C é possível observa-se que as amostras de NPs apresentam um forte sinal em torno de $265 \mathrm{~nm}$, já o PCA apresenta fortes picos de interação em 265 nm, 291 nm e 306 nm (Figura 3.14). O nanocompósito magneto-polimérico apresentou vários picos de interação, dentre eles os característicos de ambas as amostras predecessoras. 


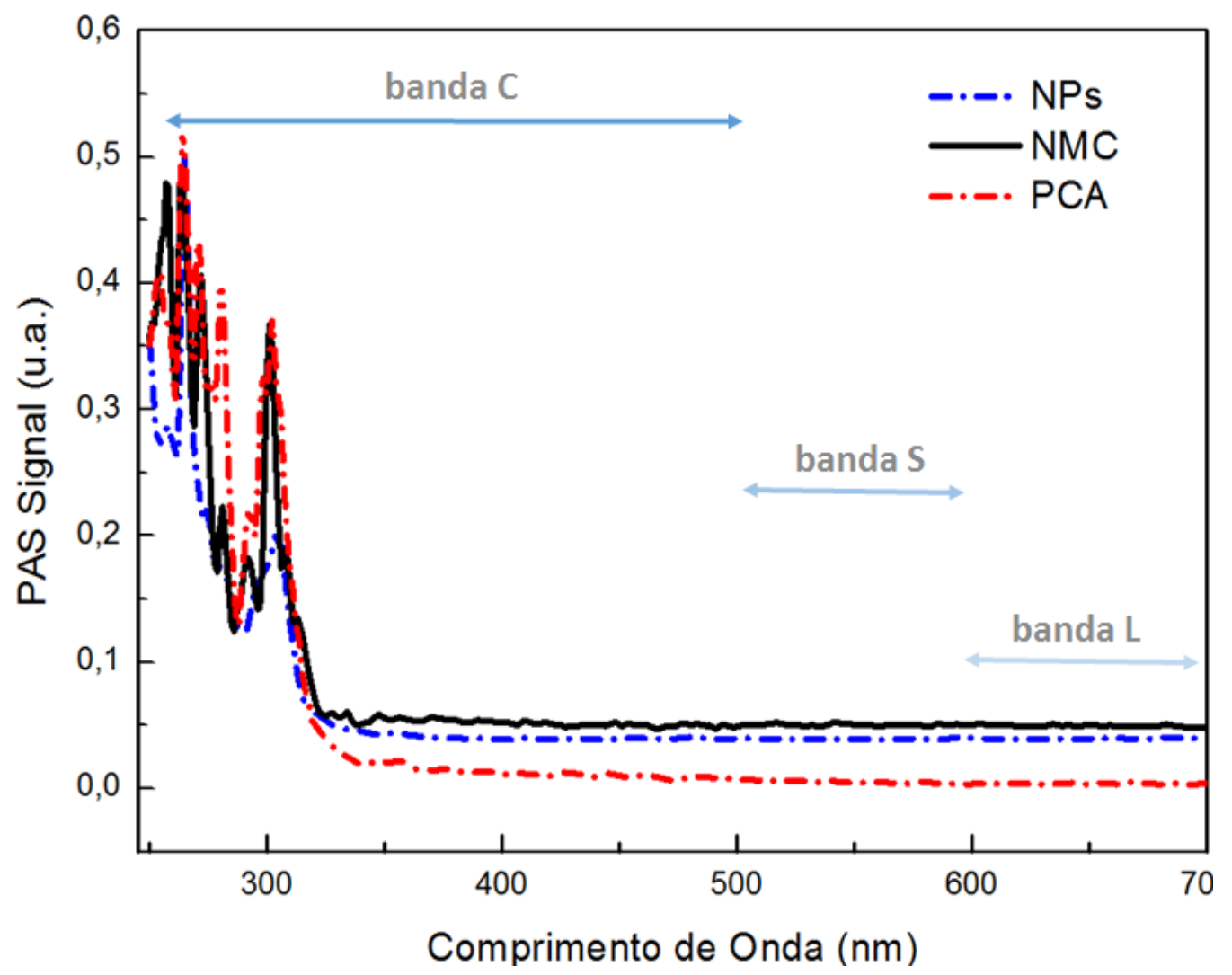

Figura 3.13. Espectro de Fotoacústica do polímero (PCA), das nanopartículas de $\gamma$ - $\mathrm{Fe}_{2} \mathrm{O}_{3}$ (NPs)e do nanocompósito magneto-polimérico à base do óleo de Carapa guianensis (NMC).

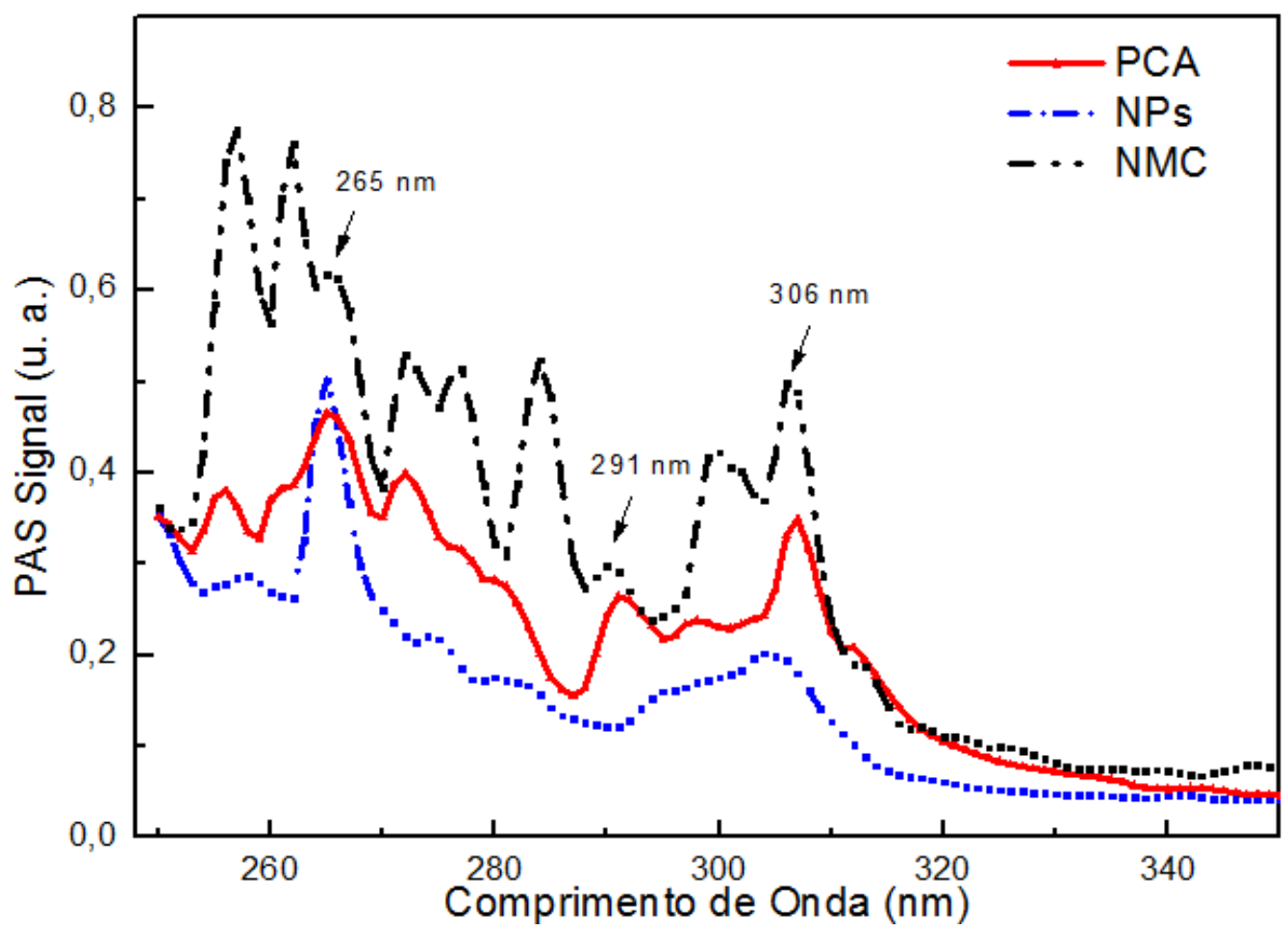

Figura 3.14. Espectro de Fotoacústica ampliado do polímero (PCA), das nanopartículas de $\gamma-\mathrm{Fe}_{2} \mathrm{O}_{3}$ (NPs) e do nanocompósito magneto-polimérico à base do óleo de Carapa guianensis (NMC). 
Sabendo que a banda $\mathrm{C}$ trata de interações nos núcleos nanopartículados (MORAIS et $a l, 2003)$ é possível sugerir que: o NMC possui os mesmos picos vibracionais característicos das amostras de NPs e PCA, esse fato pode indicar que o composto possui características híbridas, além do mais, novas vibrações foram observadas nanocompósito magneto-polimérico, possivelmente resultantes de algum tipo de interação entre as nanopartículas magnéticas de maguemita e o polímero extraído do óleo natural de C. guianensis.

\subsection{5 - Medidas de Microscopia Eletrônica de Transmissão (MET)}

Na Figura 3.15 podemos observar a micrografia das amostras do nanocompósito magneto-polimérico, obtida por Microscopia Eletrônica de Transmissão. Com uma magnificação que amplia a imagem em 80.000x é possível visualizar um grande aglomerado granulado (imagem à direita) com um comprimento médio de cerca de 200 nm, ao aumentarmos a magnitude da imagem para cerca de 300.000x (imagem à esquerda) observa-se que dentro desse granulado encontram-se as nanopartículas de $\gamma-\mathrm{Fe}_{2} \mathrm{O}_{3}$.
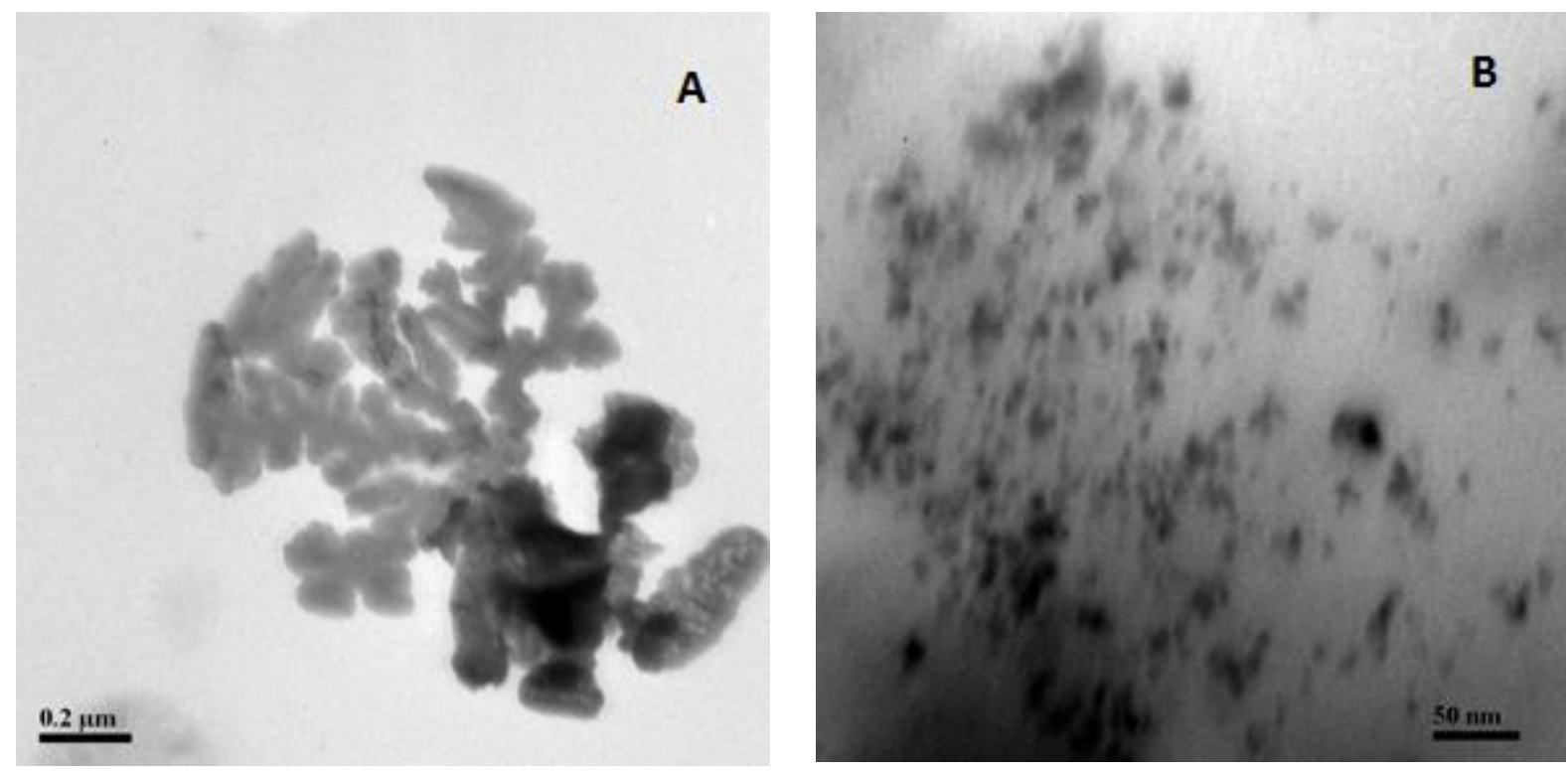

Figura 3.15 - Microscopia Eletrônica de Transmissão do nanocompósito magneto-polimérico à base do óleo extraído da semente da Carapa guianensis. (A) aumento de x80.000 vezes e (B) aumento de x300.000 vezes. 
Os dados mostram que houve a cobertura das nanopartículas pela matriz polimérica, como indicado nas medidas de espectroscopia por fotoacústica, além do mais, o nanocompósito híbrido formado é do tipo core/shell com um sistema polinuclear.

\subsection{6 - Medidas de Microscopia Eletrônica de Varredura}

Com a imagem obtida por Microscopia Eletrônica de Varredura com uma magnificação de 45.000x do NMC (Figura 3.16) foi possível observar uma grande estrutura, muito diferente das imagens obtidas das nanopartículas magnéticas (Figura 3.4 e Figura 3.5), provavelmente a superfície da camada polimérica que envolve as nanopartículas de maguemita.

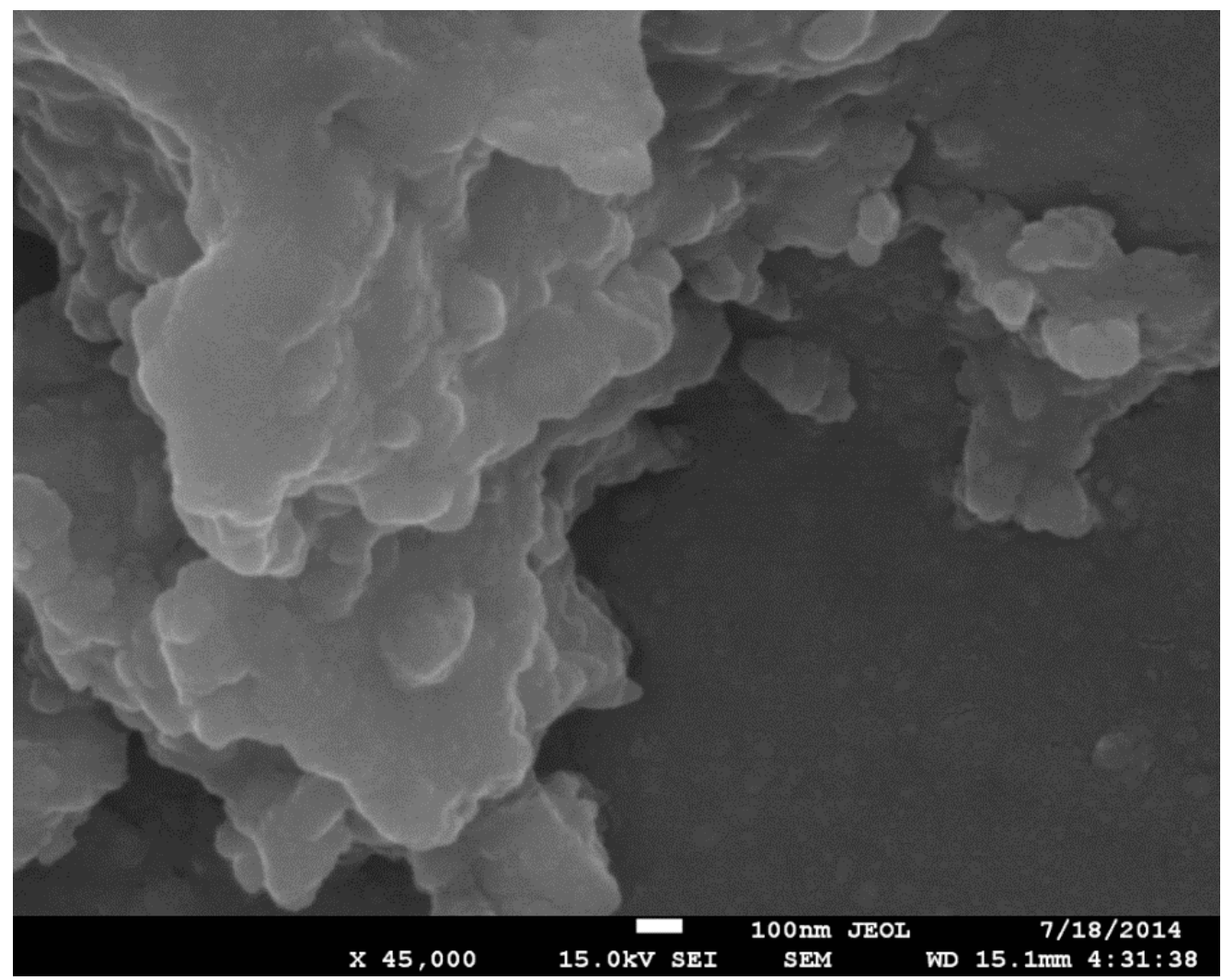

Figura 3.16 - Microscopia Eletrônica de Varredura do nanocompósito magneto-polimérico à base do óleo extraído da semente da Carapa guianensis, com um aumento de 45.000x.

Com os dados apresentados neste capítulo, foi possível elencar algumas informações relacionadas ao processo de síntese e algumas características dos materiais estudados, informações essas que estão resumidas no próximo capítulo, que trata das considerações finais deste trabalho. 


\section{CAPÍTULO 4 - CONSIDERAÇÕES FINAIS}

Neste trabalho foram produzidos novos nanomateriais híbridos a partir de nanopartículas magnéticas de maguemita recobertas por uma matriz Polimérica baseada em monômeros de origem vegetal. Para obter o nanocompósito, foram sintetizados polímeros do óleo vegetal de C. guianensis, utilizando o método de policondensação. Já, as nanopartículas magnéticas, foram sintetizadas pelo método de coprecipitação.

O diâmetro médio das nanopartículas foram determinados por DRX, MET. O DRX e o MET mostraram o diâmetro médio das nanopartículas, ficando em torno de 6,9 \pm 0,1 nm e 6,4 $\pm 0,1 \mathrm{~nm}$, respectivamente. O diâmetro médio medido pela técnica de MET ficou cerca de $10 \%$ menor que o medido pela técnica de DRX. Com as micrografias utilizando a técnica MEV, foi possível observar o formato aproximadamente esférico das nanopartículas.

Para o estudo do nanocompósito magneto-polimérico à base do óleo extraído da semente da C. guianensis, temos que: 
O FTIR mostrou a presença de ésteres poliméricos indicando a polimerização do óleo “in natura".

O UV-VIS comprovou que o polímero formado difere em parte do óleo que o precedeu. O NMC apresenta um grande concentração de nanopartículas em sua estrutura.

O EDX mostrou a composição química das amostras, no óleo bruto de C. guianensis observa-se a presença de compostos químicos como: Rutênio $(\mathrm{Ru})$, Ouro $(\mathrm{Au})$ e Cobre $(\mathrm{Cu})$, a mesma composição elementar é observada no PCA e no NMC.

Os resultados do EF indicam a interação entre a cobertura e a superfície da partícula. Já que o NMC apresenta vibrações características tanto do polímero quanto da nanopartícula.

As imagens feitas por MET do NMC mostram uma grande estrutura granular, onde é possível observar a presença de várias partículas dentro de seu núcleo, indicando a formação de nanocompósitos híbridos polinucleares.

As medidas de MEV mostraram a superfície do NMC formado. A superfície apresenta uma estrutura porosa e irregular, diferente da microscopia das NPs, o que indica que as nanopartículas foram recobertas pelo PCA.

Neste trabalho, foram desenvolvidos protocolos para a preparação de um nanocompósito magneto-polimérico à base do óleo de $C$. guianensis. O material é formado por um núcleo com várias nanopartículas magnéticas de maguemita. Sua cobertura, a matriz polimérica sintetizada a partir de produto natural apresentou boa estabilidade, capacidade de interação com outros materiais e composição elementar próxima do óleo natural.

Considera-se que os resultados deste trabalho contribuíram com as pesquisas na área de Nanociência, Nanotecnologia e Nanobiotecnologia, dando subsídios para a síntese e 
caracterização de complexos nanoestruturados utilizando compostos de origem natural como o óleo vegetal de $C$. guianensis utilizado neste estudo. 


\section{PERSPECTIVAS FUTURAS}

Como perspectivas futuras serão feitos;

$\checkmark$ Investigações que comprovem a natureza magnética das nanopartículas e do nanocompósito utilizados neste trabalho.

$\checkmark$ Metodologias que adaptem o método de síntese do polímero, de forma a separar os diferentes tipos de polímeros obtidos.

$\checkmark$ Novas análises e medidas, variando concentrações, tempo de exposição tipos de síntese.

$\checkmark$ Estudos de viabilidades para aplicações biológicas. 


\section{REFERÊNCIAS BIBLIOGRÁFICAS}

ALAM, M.; AKRAM, D.; SHAMIN, E. Vegetable oil based eco-friendly coating materials: A review article. Arabian Journal of Chemistry, v. 7, n. 4, p. 1-11 , 2014.

BAVASTRO, D.; CANOVA, A.; GIACCONE, L.; MANCA M. Numerical and experimental development of multilayer magnetic shields. Electric Power Systems Research v. 116, p. 374-380, 2014.

BELGACEM, M. N.; GANDINI, A. (Orgs.). Monomers, Polymers and Composites from Renewable Resources. [S.1.]: Elsevier Ltd, p. 552, 2008.

BORISENKO, V. E; OSSICINI, S. What is What in the Nanoworld: A Handbook on Nanoscience and Nanotechnology. 2a. ed. [S.1.]: Wiley-VCH Verlag GmbH \& Co. KGaA, p. 522. 2007.

CAO, G. NANOSTRUCTURES AND NANOMATERIALS: Synthesis, Properties, and Applications. 1. ed. [S.1.]: Imperial College Press, p. 433, 2004.

CARDOSO, P. B.; ARAÚJO, P. H. H.; SAYER, C. Encapsulation of Jojoba and Andiroba Oils by Miniemulsion Polymerization. Effect on Molar Mass Distribution. Macromolecular Symposia v. 324, n. 1, p. 114-123, 2013.

CÉSAR, A.; OLIVEIRA, T. R.; MAMANI, J. B.; MÁRIA, S.; MALHEIROS, F.; PAVON, F.; SIBOV, T. T.; JUNIOR, E. A.; GAMARRA, L. F. Magnetohyperthermia for treatment of gliomas : experimental and clinical studies Magnetohipertermia para o tratamento de gliomas : estudos experimentais e clínicos. Einstein, v. 8, n. 3, p. 361-367 , 2010.

CHAUDHURI, R. G.; PARIA, S. Core/Shell Nanoparticles : Classes, Properties, Synthesis Mechanisms, Characterization, and Applications. Chemical reviews v. 112, p. 23732433, 2012.

CHIN, A. B.; YAACOB, I. I. Synthesis and characterization of magnetic iron oxide nanoparticles via w/o microemulsion and Massart's procedure. Journal of Materials Processing Technology, v. 191, n. 1-3, p. 235-237, 2007. 
COEY, J. M. D. Magnetism and Magnetic Materials. Cambridge University Press, 2. ed., p. $617,2009$.

CULLITY, B. D. Introduction to Magnetic Materials. Addison - Wesley Publishing Company, [S.d.]. p. 1972.

DYER, J. R. Applications of absorption spectroscopy of organic compounds. Englewood Cliffs: Prentice-Hall, p. 147, 1965.

EROKHIN, V.; RAM, M. K.; YAVUZ, O. (Orgs.). The New Frontiers of Organic and Composite Nanotechnology. 1. ed. Elsevier, p. 490, 2008.

ESTEVES, A. C. C.; BARROS-TIMMONS, A.; TRINDADE, T. Nanocompósitos de Matriz Polimérica: Estratégias de Síntese de Materiais Híbridos. v. 27, n. 5, p. 798-806 , 2004.

ESPINOSA, L. M, MEIER, M. A. R., Plant oils: The perfect renewable resource for polymer science?!. European Polymer Journal v. 47, n. 5, p. 837-852, 2011.

FARIA, R. N.; LIMA, L. F. C. P. Introdução ao Magnetismo dos Materiais. 1. ed. São Paulo: Livraria da Física, p. 195, 2005.

FARINA, M.. Uma Introdução À Microscopia Eletrônica de Transmissão 14 - Col. Cbpf Tópico de Física. 1. ed. Livraria da Física, p. 161, 2010.

FERREIRA, M. R, SANTIAGO, R. R., SOUZA, T. P., EGITO, E. S., OLIVEIRA, E. E., SOARES L. A. Development and evaluation of emulsions from Carapa guianensis (Andiroba) oil. AAPS PharmSciTech v. 11, n. 3, p. 1383-90, 2010.

FILHO, N. E. S. Aplicação da Espectroscopia Fotoacústica ao estudo de materiais não cristalinos dopados: modelo para obtenção de tempo de relaxação em vidros e estudo in vitro da cinética de liberação de hormônio de blenda biodegradável. Universidade Estadual de Maringá, 2012.

GRAVINA, P.P., SANTOS, J.S., FIGUEIREDO, L. C., NETO, K. S., SILVA, M. F., BUSKE, N., GANSAU, C., MORAIS, P. C. Biocompatible magnetic fluids: a comparative birefringence investigation. Journal of Magnetism and Magnetic Materials, v. 252, p. 393-395, 2002.

GREGORIO-JAUREGUI, K. M., PINEDA, M. G., RIVERA-SALINAS, J. E., HURTADO, G., SAADE, H., MARTINEZ, J. L., ILYINA, A., LÓPEZ R. G. One-Step Method for Preparation of Magnetic Nanoparticles Coated with Chitosan. Journal of Nanomaterials v. 2012, p. $8,2012$.

GUO, Z., TAN, L. Fundamentals and Applications of Nanomaterials. 1. ed., Artech House, p. 249, 2009.

HAYT JR, William H.; BUCK, John A. Eletromagnetismo. 7. ed., Mcgraw-hill Interamericana, p. 339, 2008.

JIANG, J., LI, L., ZHU, M. Polyaniline/magnetic ferrite nanocomposites obtained by in situ polymerization. Reactive and Functional Polymers v. 68, n. 1, p. 57-62, 2008.

LAURENT, S., DELPHINE, F., MARC, P., ROCH, A., ROBIC C., ELST, L. V., MULLER, R. N. Magnetic iron oxide nanoparticles: synthesis, stabilization, vectorization, physicochemical characterizations, and biological applications. Chemical reviews v. 108, n. 6, p. 2064-110, 2008.

LIU, X., ZHONG, Z., TANG, Y., LIANG, B. Review on the Synthesis and Applications of Fe 
${ }_{3} \mathrm{O}_{4}$ Nanomaterials. v. 2013, p. 7, 2013.

LOPES, M. C., SOUZA JR, F. G., OLIVEIRA, Espumados Magnetizáveis Úteis em Processos de Recuperação Ambiental. Polímeros. v. 20, n. 2, p. 359-365, 2010.

MACKAY, P. S., KREMERS, G., KOBUKAI, S., COBB, J. G., KULEY, A., ROSENTHAL, S., KOKTYSH, D. S., GORE, J. C., PHAM, W. Multimodal imaging of dendritic cells using a novel hybrid magneto-optical nanoprobe. Nanomedicine: nanotechnology, biology, and medicine v. 7, n. 4, p. 489-496, 2011.

MAI, Y., YU, Z. (Orgs.). Polymer Nanocomposites. Woodhead Publishing Limited, p. 613, 2006.

MAMANI, J. B., COSTA-FILHO, A. J., CORNEJO, D. R., VIEIRA, E. D., GAMARRA, L. F. Characterization of magnetite nanoparticles coated with lauric acid. Materials Characterization v. 81, p. 28-36, 2013.

MARDARE, D., CORNEI, N., LUCA, D., DOBROMIR, M., IRIMICIUC, S. A., PUNGA, L., PUI, A., ADOMNITEI, C. Synthesis and hydrophilic properties of Mo doped $\mathrm{TiO}_{2}$ thin films. Journal of Applied Physics v. 115, n. 21, p. 213501, 2014.

MATSUNUMA, S., INOUE, T., WATANABE, T., DOI, T., MASHIKO, Y., GOMI, S., HIRATA, K., NAKAGAWA, S. Playback performance of perpendicular magnetic recording tape media for over-50-TB cartridge by facing targets sputtering method. Journal of Magnetism and Magnetic Materials v. 324, n. 3, p. 260-263, 2012.

MIAO, S., WANG, P., ZHIGUO, S., ZHANG, S. Vegetable-oil-based polymers as future polymeric biomaterials. Acta biomaterialia v. 10, n. 4, p. 1692-1704, 2014.

MORAIS, P. C., OliVEIRA, A. C., TRONCONI, A. L., GOETZE, T., BUSKE, N. Photoacoustic spectroscopy: A promising technique to investigate magnetic fluids. IEEE Transactions on Magnetics v. 39, n. 5, p. 2654-2656, 2003.

NAMANGA, J., FOBA, J., NDINTEH, D. T., YUFANYI, D. M., KRAUSE, W. M. Synthesis and Magnetic Properties of a Superparamagnetic Nanocomposite "Pectin-Magnetite Nanocomposite". Journal of Nanomaterials v. 2013, p. 1-8, 2013.

NUSSENZVEIG, H. M. Curso de Física Básica, São Paulo: Edgard Blücher LTDA, 2010, 427 p.

OSHTRAKH, M. I., RODRIGUEZ, A. F. R., SEMIONKIN, V. A., SANTOS, J. G., MILDER, O. B., SILVEIRA, L. B., MORMOLEJO, E. M., USHAKOV, M. V., SOUZA-PARISE, M., MORAIS, P. C. Magnetic fluid: Comparative study of nanosized $\mathrm{Fe}_{3} \mathrm{O}_{4}$ and $\mathrm{Fe}_{3} \mathrm{O}_{4}$ suspended in Copaiba oil using Mössbauer spectroscopy with a high velocity resolution. Journal of Physics: Conference Series v. 217, p. 012018, 2010.

PAYET, B., VICENT, D., DELAUNAY, L., NOYEL, G. Influence of particle size distribution on the initial susceptibility of magnetic fluids in the Brown relaxation range. Journal of Magnetism and Magnetic Materials v. 186, n. 1-2, p. 168-174, 1998.

PEREIRA, M. R. N., TONINI, H. FENOLOGIA DA ANDIROBA (Carapa guianensis, Aubl., MELIACEAE) NO SUL DO ESTADO DE RORAIMA. Ciência Florestal v. 22, n. 1, p. 47-58, 2012.

PYUN, J. Nanocomposite Materials from Functional Polymers and Magnetic Colloids. Polymer Reviews v. 47, n. 2, p. 231-263, 2007.

RAMALHO, H. F., SUAREZ, P. A. Z., A Química dos Óleos e Gorduras e seus Processos de 
Extração e Refino A Química dos Óleos e Gorduras e seus Processos de Extração e Refino. Revista Virtual de Química v. 5, n. 1, p. 2-15, 2013.

REDA, S. Y., CARNEIRO, P. I. B. Óleos e gorduras: aplicações e implicações. Revista Analytica p. 60-67, 2007.

RIGAMONTE-AZEVEDO, O. C., WADT, P. G. S., WADT, L. H. O., VEIGA JR, V. F., PINTO, A. C., REGIANI, A. M. Variabilidade química e física do óleo-resina de copaifera spp. no sudoeste da amazônia brasileira. Revista brasileira de Oleaginosas e Fibrosas v. 8, n. 2-3, p. 851-861, 2004.

RODRIGUEZ, A F R, JACOBSON, T K B., MORAES, J. S. F., FARIA, F. S. E. D. V., CUNHA, R. M., SANTOS, J. G., OLIVEIRA, A. C., AZEVEDO, R. B., MORALES, M. A., MORAIS, P. C. Spectrochimica Acta Part A: Molecular and Biomolecular Spectroscopy Photoacoustic spectroscopy study Blepharocalyx salicifolius ( Kunt ) O . Berg. v. 100, p. 75-77, 2013.

RODRIGUEZ, A F R; COAQUIRA, J. A. H., MORALES, M. A., FARIA, F. S. E. D. V., CUNHA, R. M., SANTOS, J. G., SILVEIRA, L. B., CANDELA, D. R. S., BAGGIOSAITOVITCH, E. M., RABELO, D., AZEVEDO, R. B., MORAIS, P. C. Synthesis, characterization and magnetic properties of polymer- $\mathrm{Fe}_{3} \mathrm{O}_{4}$ nanocomposite. Spectrochimica acta. Part A, Molecular and Biomolecular spectroscopy v. 100, p. 101103, 2013.

ROUMANET, P., LAFLECHE, F., JARROUX, N., RAOUL, Y., CLAUDE, S., GUÉGAN, P. Novel aliphatic polyesters from an oleic acid based monomer. Synthesis, epoxidation, cross-linking and biodegradation. European Polymer Journal v. 49, n. 4, p. 813-822, 2013.

SANTOS J. G., SILVEIRA, L. B., A. C., OLIVEIRA, AND MORAIS, P. C. Use of the photoacoustic spectroscopy in the investigation of biocompatible magnetic fluids. J. Phys. IV France, 125, 27-30, 2005.

SANTOS, J. G., SILVEIRA, L. B., FEGUEREDO, P. H., ARAÚJO, B. F., PETERNELE, W. S., RODRIGUEZ, A. F., VILELA, E. C., GARG, V. K., OLIVEIRA, A. C., AZEVEDO, R. B., MORAIS, P. C. New Magnetic Fluid Developed with Natural Organic Compounds Biocompatible. Journal of Nanoscience and Nanotechnology v. 12, n. 6, p. 4757-4761, 2012.

SARAVANAN, S; BALACHANDRAN, V. Quantum mechanical study and spectroscopic (FT-IR, FT-Raman, UV-Visible) study, potential energy surface scan, Fukui function analysis and HOMO-LUMO analysis of 3-tert-butyl-4-methoxyphenol by DFT methods. Spectrochimica acta. Part A, Molecular and Biomolecular spectroscopy v. 130, p. 60420, 2014.

SARTORATTO, P. P. C., NETO, A. V. S., LIMA, E. C. D., RODRIGUES DE SÁ, A. L. C., MORAIS, P. C. Preparation and electrical properties of oil-based magnetic fluids. Journal of Applied Physics v. 97, n. 10, p. 10Q917, 2005.

SARTORATTO, P. P. C., CAIADO, R., PEDROZA, R. C., SILVA, S. W., MORAIS, P. C. The thermal stability of maghemite-silica nanocomposites: An investigation using X-ray diffraction and Raman spectroscopy. Journal of Alloys and Compounds v. 434-435, p. 650-654, 2007.

SENIHA GÜNER, F., YAĞCI, Y., TUNCER ERCIYES, A. Polymers from triglyceride oils. 
Progress in Polymer Science v. 31, n. 7, p. 633-670, 2006.

SHAMELI, K., AHMAD, M. B., JAZAYERI, S. D., SEDAGHAT, S., SHABANZADEH, P., JAHANGIRIAN, H. Synthesis and characterization of polyethylene glycol mediated silver nanoparticles by the green method. International journal of molecular sciences $\mathrm{v}$. 13, n. 6, p. 6639-50, jan. 2012.

SHARMA, V., KUNDU, P.P. Condensation polymers from natural oils. Progress in Polymer Science v. 33, n. 12, p. 1199-1215, 2008.

SILVA, Cleber Luís Maia Da. Obtenção de ésteres etílicos a partir da transesterificação do óleo de andiroba com etanol. UNICAMP, 2005.

SILVEIRA, Luciene Batista da. Estudos de Propriedades Magnéticas de Fluidos e Nanocompósitos Magnéticos Biocompatíveis. Universidade de Brasília, 2006.

SILVERSTEIN, R. M.; WEBSTER, F. X. Identificação Espectrométrica de Compostos Orgânicos. 7. ed. Rio de Janeiro,: LTC, 2006. p. 508.

STUART, B. Infrared Spectroscopy: Fundamentals and Applications. [S.1.]: John Wiley \& Sons, Ltd, 2004. p. 203. 0470854278.

TIETZE, R., LYER, S., DURR, S., STRUFFERT, T. ENGELHORN, T., SCHWARZ, M., ECKERT, E., GOEN, T., VASYLYEV, S., PEUKERT, W., WIEKHORST, F., TRAHMS, L., DORFLER, A., ALEXIOU, C. Efficient drug-delivery using magnetic nanoparticles--biodistribution and therapeutic effects in tumour bearing rabbits. Nanomedicine : nanotechnology, biology, and medicine v. 9, n. 7, p. 961-71, 2013.

TSUJIMOTO, T., UYAMA, H., KOBAYASHI, S. Synthesis of high-performance green nanocomposites from renewable natural oils. Polymer Degradation and Stability v. 95, n. 8, p. 1399-1405, 2010.

VILELA, Carla Andreia Cunha. Síntese de Novos Materiais Poliméricos Derivados de Óleos Vegetais. Universidade De Aveiro, 2012.

WANG, C., ZHANG, C., LI, Y., CHEN, Y., TONG, Z. Facile fabrication of nanocomposite microspheres with polymer cores and magnetic shells by Pickering suspension polymerization. Reactive and Functional Polymers v. 69, n. 10, p. 750-754, 2009.

WU, W.; HE, Q.; JIANG, C.. Magnetic iron oxide nanoparticles: synthesis and surface functionalization strategies. Nanoscale research letters v. 3, n. 11, p. 397-415, 2008.

YUE-JIAN, C., JUAN, T., FEI, X., JIA-BI, Z., NING, G., YI-HUA, Z., YE, D., LIANG, G. Synthesis, self-assembly, and characterization of PEG-coated iron oxide nanoparticles as potential MRI contrast agent. Drug development and industrial pharmacy v. 36, n. 10, p. 1235-1244, 2010. 